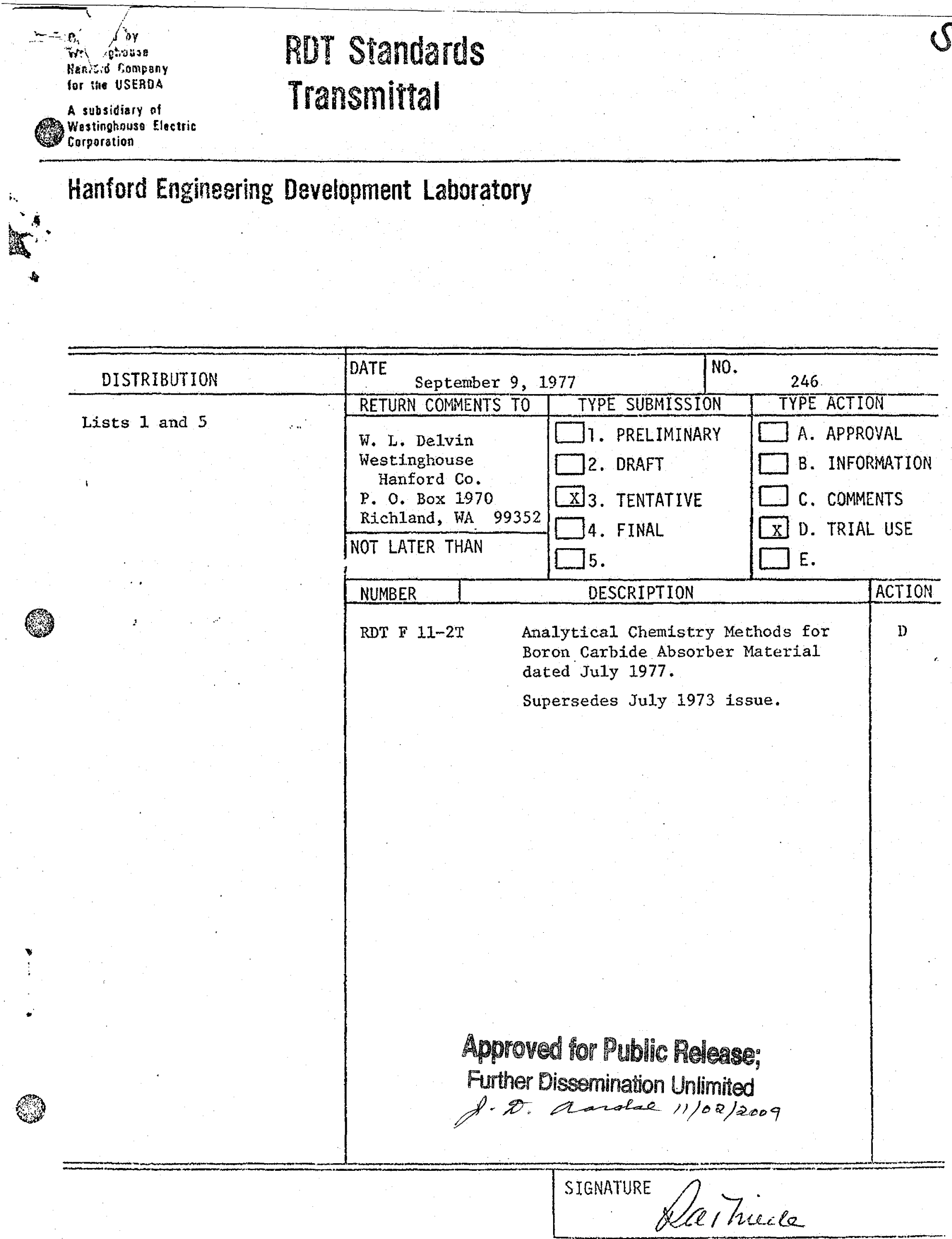


$t^{2}$

\section{ANALYTICAL CHEMISTRY METHODS FOR BORON CARBIDE ABSORBER MATERIAL.}

\section{JULY 1977}

Any further distribution by any holder of this document or of the data therein to third parties representing foreign interests, foreign governments, foreign companies, and foreign subsidiaries or foreign divisions of U.S. companies should be coordinated with the Director, Division of Feactor Development and Demonstration, U.S. Energy Research and Development Administration.

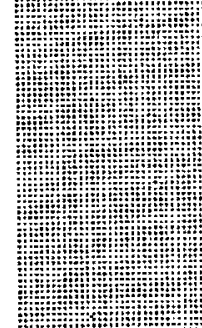
DIVISION OF REACTOR DEYELOPMENT AND DEMONSTRATION 


\section{FOREWORD}

This standard supersedes the JuIy 1973 issue RDT F 11-2T and incorporates changes that were approved for publication in this revision. These changes are identlfied by the following marginal notations:
C Change approved $7-26-77$
D Deletion approved 7-26-77
N Addition approved 7-26-77

Editorlal changes that were made during preparation of this revision are not identified. 


\section{RDT STANDARD}

U.S. ENERGY RESEARCH AND DEVELOPMENT ADMINISTRATION DIVISION OF REACTOR DEVELOPMENT AND DEMONSTRATION
RDT $\quad F 11-2 T$

DATE July 1977

PAGE OF OF $t$

\section{TABLE OF CONTENTS}

ANALYTICAL CHEMTSTRY METHODS FOR BORON CARBIDE ABSORBER MATERIAE

1. SCOPE

2. APPLICABLE DOCUMENTS

3. GENERAL REQUIREMENTS

4. TOTAL CARBON

5. TOTAL BORON

6. BORON ISOTOPIC COMPOSITION

7. SOLUBLE CARBON

8. SOLUBLE BORON

9. FLUORIDE

10. CHLORIDE

53

11. GENERAL METALIIC IMPURTTIES BY A PHOTOGRAPHIC METHOD

61

12. GENERAL METALLIC IMPURITIES BY A DIRECT READER METHOD

71

13. GAS CONTENT

75

14. WATER

85

15. NITROGEN BY SPECTROPHO'TOMETRY

16. NITROGEN BY GAS CHROMATOGRAPHY

91

99

17. OXYGEN 
RDT STANDARD

U.S. ENERGY RESEARCH AND DEVELOPMENT ADMINISTRATION DIVISION OF REACTOR RESEARCH AND DEVELOPMENT
RDT F 11-2T

DATE July 1977

PAGE
1 OF 114

\section{SCOPE}

This standard provides analytical chemistry methods for the analysis of boron carbide powder and pellets.

\section{APPLICABLE DOCUMENTS}

The following documents are a part of this standard to the extent specified herein. The issue of a document in effect on the date of the invitation to bid, including any amendments or other published changes also in effect, shall apply unless otherwise specified. Where this standard appears to conflict with the requirements of a reference document, such conflict shall be brought to the attention of the purchaser for resolution.

\subsection{RDT Standard.}

RDT 2-8T Qualification and Control of Analytical Chemistry Laboratories for Control Rod Absorber Material Analysis

\subsection{Amerlcan Society for Testing and Materials (ASTM) Publications.}

ASTM E 116 . Recommended Practices for Photographic Photometry in Spectrochemical Analysis

ASTM E 130 Designation of Shapes and Sizes of Graphite Electrodes.

2.3 The Matheson Co. Publication.

Matheson Gas Data Book, 4th Edition.

\section{GENERAL REQUIREMENTS}

3.1 Analytical Methods. The analytical methods in this standard describe acceptable equipment and procedures for use by trained analysts. Other methods approved by the purchaser may be used. Identification of brand names and model numbers are for information; equivalent equipment may be used instead. Special safety hazard precautions are noted where appropriate. The analytical methods are presented in the following typical form.

3.1.1 Application. The material to be analyzed and its form are given. Recommended sample size, range of the method, or limits of the analysis are noted.

\subsubsection{Sumary. A brief summary of the method is presented.}


3.1.3 Interferences. Impurities or materials that can contribute to incorrect results are noted. Methods for avoiding the interferences may be given.

3.1.4 Apparatus. Specific apparatus and equipment needed for the method are listed. Equipment normally found in a chemical 1aboratory is usually not Iisted.

3.1.5 Reagents and Standards. Specific reagents and standards are given. Unless otherwise spectfied, analytical grade reagents sha11 be used. Special storage or handling requirements are noted. method are given.

3.1.6 Calibration. Requirements for the calibration of the

3.1.7 Analysis. Steps for performing the analysis are given. Precautions, recommendations and references are noted.

3.1.8 Calculations. A procedure is given, including appropriate equations, to calculate the result.

3.1.9 Precision. The relative standard deviation* or the standard deviation attainable by the method is stated. The proficiency of the analyst and the condition and adequacy of the equipment wil1 determine the degree of precision obtained within a particulax laboratory.

3.2 Laboratory Qualification. Analytical laboratories performing analyses in accordance with this standard shall conform to the requirements of RDT i 2-8.

3.3 Tolerances. Unless otherwise specified, al1 values for measurements stated in the methods (volume, weight, time, temperature, etc.) are nominal values. The actual meastrements used, however, sha11 be within $\pm 5 \%$ of the stated value. For example, "add $20 \mathrm{ml}$ " means that a volume between 19 and $21 \mathrm{ml}$ shall-be added. Required tolerances are specified in one of the two following ways:

1. Tolerance limits are given with the value. For example, $15 \pm 0.1 \mathrm{ml}, 1 \mathrm{~h} \pm 10 \mathrm{~min}$, or "take a $50 \mathrm{mg}$ sample weighed to the nearest $0.1 \mathrm{mg}$."

2. When one or more significant figures are given to the right of the decimal point, the tolerance limit is \pm 5 in the next digit located beyond the last one stated. For example, $5.0 \mathrm{ml}$ means $5.0 \pm 0.05 \mathrm{ml}$.

*The standard deviation ( $s$ ) expressed as a percentage of the average $(\bar{x})$ of the quantity measured; or expressed as an equation, relative standard deviation $=(s / \bar{x})(100)$. 


\section{TOTAL CARBON}

4.1 Application. This method is app1icable to the determination of total carbon in samples of boron carbide powder and pellets. The recommended amount of boron carbide for each analysis ts 150 to $200 \mathrm{mg}$.

4.2 Summary. The sample mixed with a flux material is burned in oxygen at a temperature not lower than $1400^{\circ} \mathrm{C}$. The carbon dioxide product is passed through a gas treatment train to ensure that any carbon monoxide formed is converted to carbon dioxide and to remove dust, sulfur dioxide, and moisture. The carbon dioxide is absorbed in Ascarite. and weighed.

4.3 Interferences. At the specification limits usually established for nuclear-grade boron carbide, interferences are insignificant.

\subsection{Apparatus.}

1. Analytical balance capable of weighing to at least $0.1 \mathrm{mg}$.

2. Crucible, zircon ceramic, LECO (Laboratory Equipment Corp.) No. 528-035 or equivalent.

3. Crucible covers, porous, ceramic, LECO No. 528-042 or equivalent.

4. Diamond (Plattner) mortar (or equivalent) or boron carbide mortar.

5. Combustion system.

The letters in parentheses refer to the components shown in Fig. 1.

a. Induction furnace (A), LECO No. $521-000$ or equivalent.

CAUTION: Contact with the high frequency induction coil will produce severe electrical shock and may cause burns.

b. Combustion tube (B), fused silica, LECO No. 550-122 or equivalent.

c. Dust trap (C), LECO No. 501-010 or equivalent.

d. Catalyst furnace (D), LECO No. 507-000 or equivalent.

e. Drying tubes, Kimble No. 46010 or equivalent.

The first tube $\left(E_{1}\right)$ is filled with magnesium perchlorate and the second tube $\left(E_{2}\right)$ is filled with Drierite. 


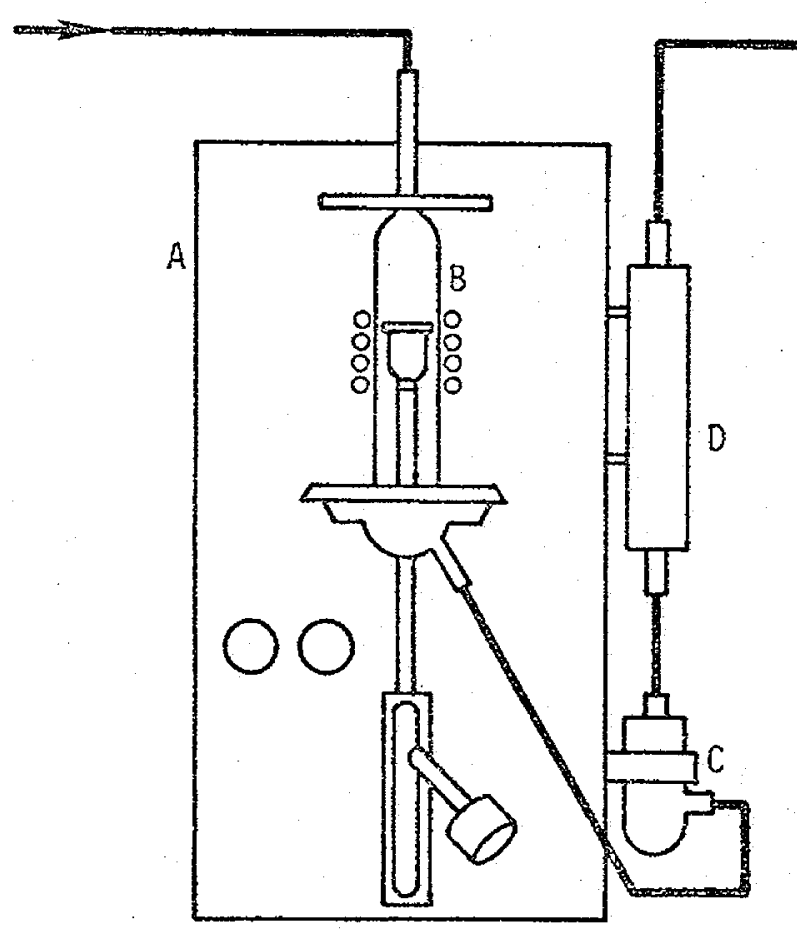

A. INDUCTION FURNACE

B. COMBUSTION TUBE

C. DUST TRAP

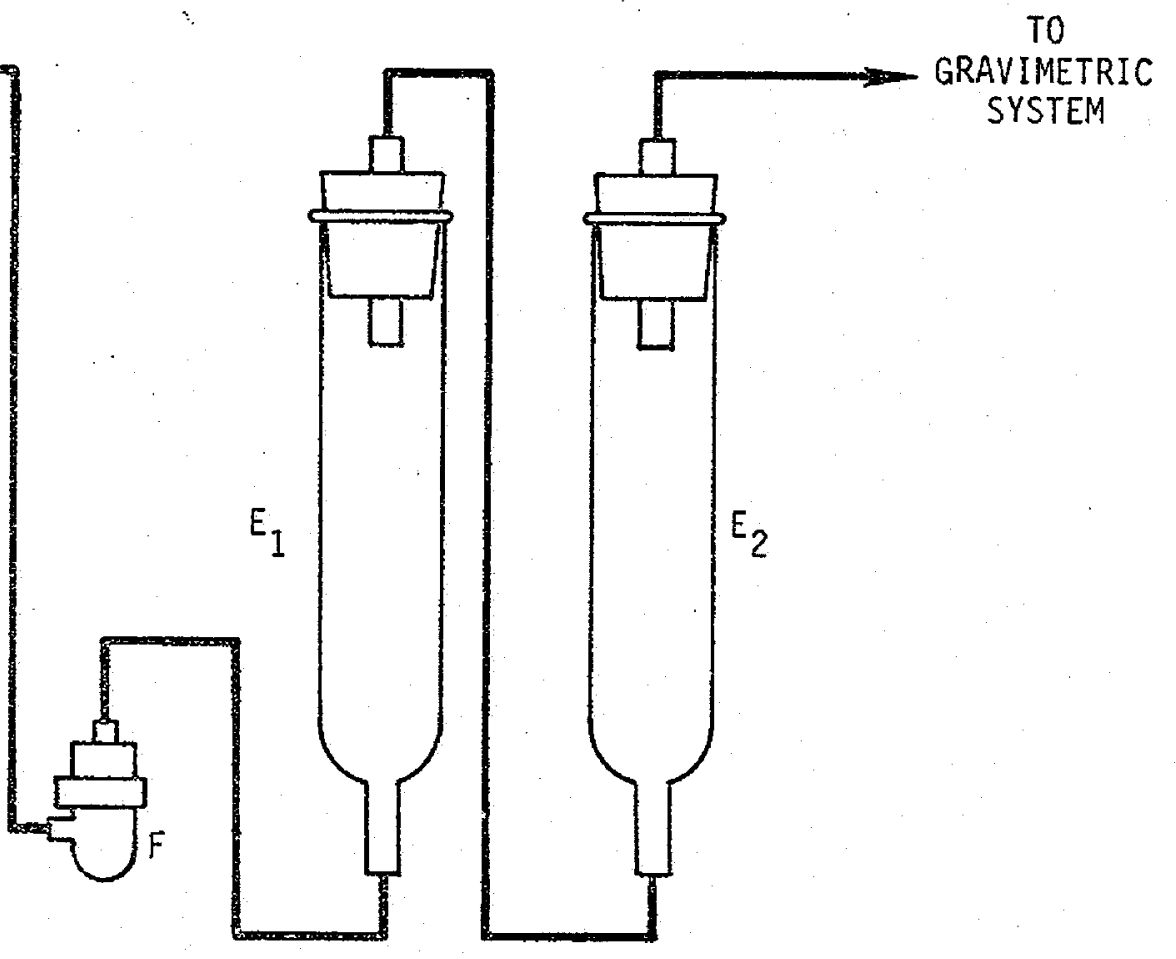

D. CATALYST FURNACE

$E_{1}$. MAGNESIUM PERCHLORATE TUBE

$E_{2}$. DRIERITE TUBE

F. SULFUR TRAP

Fig. 1. Combustion System. 
These tubes prevent water released from the sample from entering the absorption bulb.

f. Sulfur trap (F), LEC No. 503-033 or equivalent.

6. Gravimetric system.

The letters in parentheses refer to the components shown in Fig. 2 .

a. Nesbitt absorption bulb (A), Kimble No. 16010 or equivalent, modified with $12 / 5$ socket joints on both the entrance and exit port.

The bulb is filled as shown in Fig. 2 .

b. Drying tube (B), Kimble No. 46010 or equivalent.

This tube is illed with magnesium perchlorate, Drierite, and Ascarite to prevent any back diffusion of water and carbon dioxide into the absorption bulb.

c. Flowmeter (C), Manostat No. $1044 \mathrm{~B}$ or equivalent.

The total system has two flowmeters, one located before the furnace (Fig. 3) and one after the absorption bulb (Fig. 2). This arrangement helps to detect leaks in the system.

7. Oxygen purification system.

The letters in parentheses refer to the components shown in Fig. 3 .

a. Gas regulator (A) for oxygen.

b. Drying tubes, Kimble No. 46010 or equivalent.

The three tubes are filled as follows: The first $\left(B_{1}\right)$ with magnesium perchlorate to dry the oxygen; the second $\left(B_{2}\right)$ with Drierite to Indicate when trap $B_{1}$ is spent; the third tube $\left(B_{3}\right)$ with Ascarite to remove carbon dioxide.

c. Gas flow regulating valve (c), Matheson No. 32 or equivalent.

d. Flowmeter (D), Manostat No. 10443 or equivalent.

8. Sieve, No. 100 mesh (U. S. Standard Sieve Series), 3 in.

$(76 \mathrm{~mm})$ diameter, brass or stainless steel. 


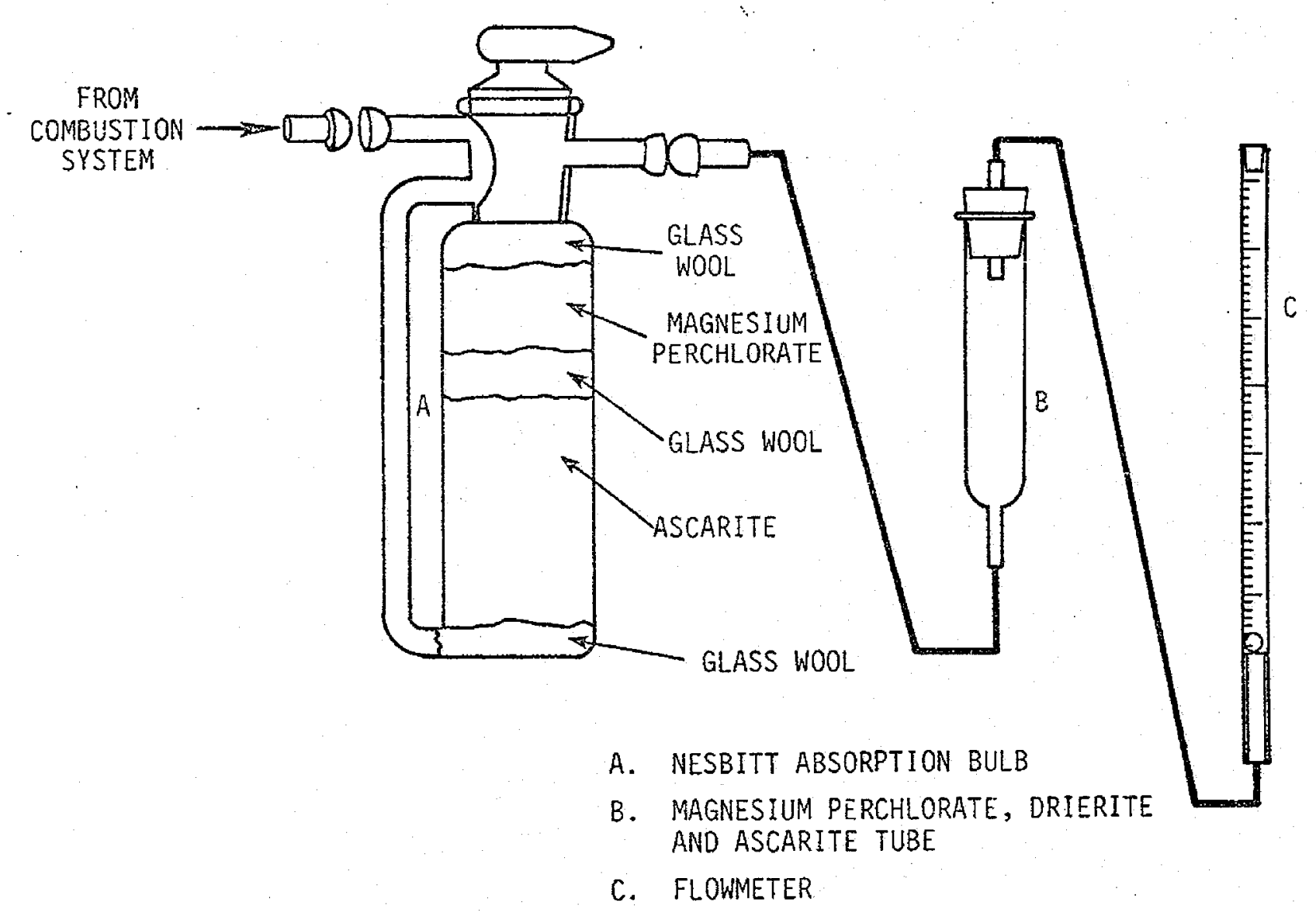

Fig. 2. Gravimetric System. 

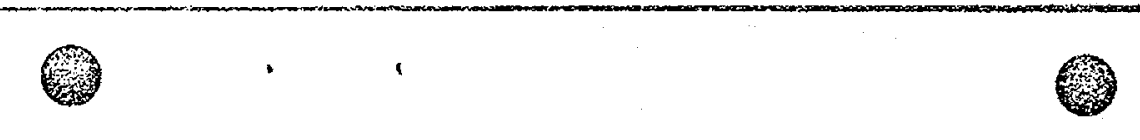

궁

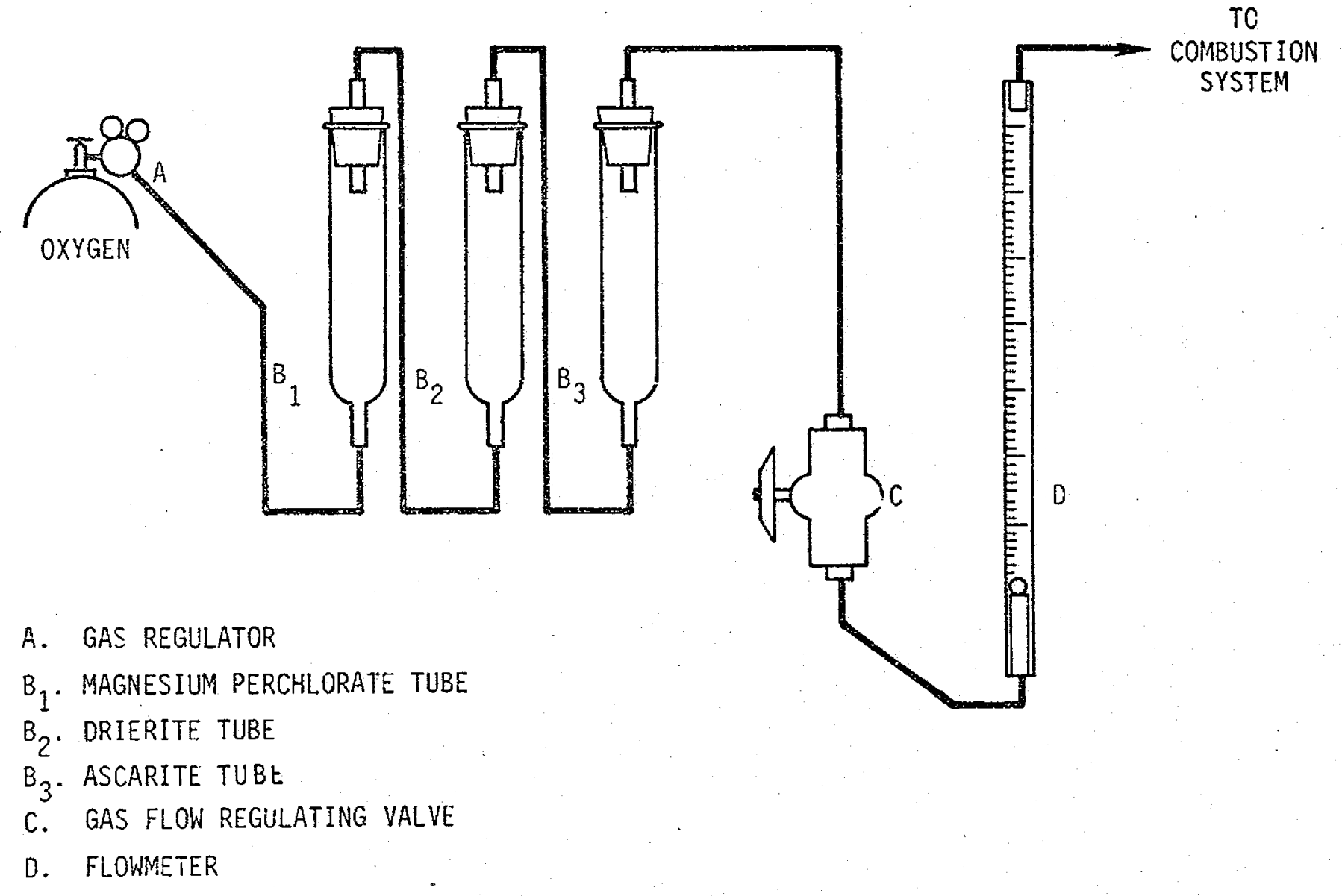

Fig. 3. Oxygen Purification System. 


\subsection{Reagents and Standards.}

1. Ascarite, 8 to 20 mesh.

2. Copper granules, 30 mesh.

3. Copper rings, I.ECO No. 550-184 or equivalent.

4. Cupric oxide, reagent grade."

Cupric oxide is used in the catalyst furnace (Fig, 1) to ensure that any carbon monoxide formed during combustion is converted to carbon dioxide.

5. Drierite, indicating.

6. Iron chips, LECO No. 501-077 or equivalent.

7. Magnesium perchlorate, anhydrous.

8. Manganese dioxide, LECO No. 50I-060 or equivalent.

.. 9. Cxygen, ultra high purity grade* or equivalent.

- 10. Tin, granular, LECO No. 501-076 or equivalent.

11. Calibration standard as spectfied by RDT F 2-8.

4.6 Calibration. The calibration frequency shall be in accordance with RDT F 2-8. To calibrate the method, analyze the calibration standard by following 4.7. Calculate the calibration factor using 4.8.2.

4.7 Analysis. Care shall be taken to avold carbon contamination of reagents and laboratory equipment. Prior to making the initial analysis, condition the furnace tube and absorption bulb by taking a sample through Steps 1 through 13 without making any measurements (omit Step 2, for examp1e).

4.7.1 Procedure for Analysis. A blank shall be determined at least once in each 8 -h shift in which total carbon analyses are made. The long-term average blank should be less than $1.5 \%$ of the long-term average amount of carbon dioxide weighed in the analyses. If any individual blank varies from the long-term average by more than $\pm 20 \%$, investigate and correct the cause before continuing the analysis of samples. Use the long-term average blank in calculating the concentration of carbon in samples.

$*$ See Section 2.3 . 
1. Add $2 \mathrm{~g}$ of $\mathrm{tin}, 1$ copper ring ( $0.5 \mathrm{~g}$ ), and $1.2 \mathrm{~g}$ of copper granules ( 30 mesh) to the zircon crucible.

To determine a blank, perform Steps 1 through 15, omitting Steps 2 and 3 .

Prefiring of the crucibles above $1000^{\circ} \mathrm{C}$ is recomended to minimize blanks.

These quantities of fiux and coupler*, fncluding the $3 \mathrm{~g}$ of iron chips added in Step 4, have been found satisfactory. Since furnaces may have different power outputs and coupling characteristics, the quantities of flux and coupler and fron chips required may differ among furnaces.

2. Weigh the crucible and its contents to the nearest $0.1 \mathrm{mg}\left(\mathrm{S}_{1}\right)$.

3. Add 150 to $200 \mathrm{mg}$ of sample in powder form to the welghed crucible and reweigh to the nearest $0.1 \mathrm{mg}\left(\mathrm{S}_{2}\right)$.

If a sample is in pellet form, crush to a powder using the procedure given in 4.7 .3 .

4. Cover the sample with $3 \mathrm{~g}$ of iron chips.

5. Cover the crucible with a porous ceramic cover.

6. Load the crucible into the induction furnace.

7. Purge the crucible and its contents with oxygen for 2 min.

The flow rate of the gas should be about $0.51 / \mathrm{min}$.

8. Weigh $\left(W_{1}\right)$ the closed absorption bulb, using the weighing technique given in 4.7 .2 .

Before taking the initial weight of the absorption bulb, condition it by purging with oxygen for $1 \mathrm{~h}$ at $0.51 / \mathrm{min}$.

After obtaining the initial weight of the absorption bulb, do not touch it with the hands until all analyses have been completed. Lintless nylon gloves or dry chamois should be used to handle the absorption bulb.

*A coupler in induction heating is a material In which electrical currents can be induced to provide heat in a material through resistance heating. A coupler is required when the sample material itself is not a coupler, as is the case with boron carbide. 
9. Place the absorption bulb into position in the appaxatus.

10. Open the absorption bulb to the system and readjust the oxygen flow to $0.5 \mathrm{l} / \mathrm{min}$, if necessary.

11. Turn on the induction furnace.

The induction furnace should be preset at its highest grid current setting so that the maximum temperature can be obtained. Follow the manufacturer's recommended procedure for operating the furnace.

12. Burn the sample for $8 \mathrm{~min}$.

If the combustion is incomplete after $8 \mathrm{~min}$, investigate the flux and couples conditions to determine conditions that will give complete combustion;

13. Turn off the furnace and wat an additional 22 min, allowing the oxygen to continue flowing through the entire system.

14. Close the absorption bulb and remove it from the apparatus.

15. Weigh $\left(W_{2}\right)$ the bulb using exactly the same technique used in Step 8 .

\subsubsection{Procedure for Weighing the Absorption Bulb.}

1. Wipe the closed absorption bulb thoroughly and evenly with a moist chamois, being careful not to touch the bulb with the hands.

Wiping the absorption bulb with a moist chamois minimizes the adverse effects on weighing produced by static charges.

2. Place the bulb on the balance pan with the balance door open. If a single pan balance with two doors is used, open both doors.

3. Wait 3 min and close the door.

Leaving the balance door open decreases the amount of time required for the absorption bulb to come to equilibrium after it has been wiped with the moist chamois. The length of time required to reach equilibrium depends upon the relative humidity in the laboratory.

4. Weigh the bulb to the nearest $0.1 \mathrm{mg}$.

5. Repeat Steps 1 through 4 until constant weight is obtained. 
Constant weight is defined as a difference of no greater than $0.1 \mathrm{mg}$ between two successive weighings.

4.7.3 Procedure for Pellet Preparation. This procedure sha11 be used to prepare pellet samples for other analyses as well as this analysis, unless otherwise stated in a method:

1. Place the sample into a clean diamond (Plattner) mortar.

The pestle face and mortar cavity should be machined occasiona1ly to remove pits.

2. Crush the sample with a few, light hammer blows.

Do not crush and grind the boron carbide extensively because significant iron contamination can occur.

3. Transfer the crushed sample to the sieve and shake until the finer material has passed through the sieve and been collected.

4. Return the coarse material from the sieve to the mortar and repeat Steps 1 and 2 until the whole sample has passed through the sieve.

5. Remove iron particles by passing a magnet over the sieved powder.

6. Mix the sieve sample thoroughly.

A $\mathrm{V}$-blender can be used for mixing. Tests have indicated that $\mathrm{V}$-blending is necessary to obtain a homogeneous sample for the nitrogen and oxygen methods.

4.8 Calculations. Calculate the grams of carbon weighed, the calibration factor, and the weight percent of carbon in the sample using $4.8 .1,4.8 .2$, and 4.8 .3 .

\subsubsection{Grams of Caxbon Weighed.}

$$
G=\left[\left(W_{2}-W_{1}\right)_{s}-\left(W_{2}-W_{1}\right)_{b}\right](0.2729)
$$

where

$$
\begin{aligned}
G= & \text { grams of carbon weighed } \\
W_{2}= & \text { weight of absorption bul.b in grams after combustion } \\
& (\text { Step } 15 \text { of } 4.7 .1 \text { ) }
\end{aligned}
$$


where

$W_{1}=$ weight of absorption bulb in grams before combustion (Step 8 of 4.7 .1 )

$\left(W_{2}-W_{1}\right)_{s}=$ sample or standard measurement

$\left(W_{2} \sim W_{1}\right)_{b}=$ blank measurement.

\subsubsection{Calibration Factor.}

$$
F=\frac{\ddot{B}}{G}
$$

$F=$ calibration factor

$B=$ grams of carbon welghed from the calibration standard

$G=$ grams of carbon contained in calibration standard.

\subsubsection{Concentration of Carbonzin the Sample.}

$$
\text { Carbon }=\frac{G_{S}}{\left(S_{2}-S_{1}\right)(F)} \times 100
$$

where

Carbon $=$ weight percent of carbon

$G_{S}=$ grams of carbon weighed from the sample

$S_{2}=$ weight of crucible plus sample, grams (Step 3 of 4.7.1)

$s_{1}=$ weight of crucible, grams (Step 2 of 4.7 .1 )

$\mathrm{F}=$ calibration factor. $0.23 \%$.

4.9 Precision. The relative standard deviation of the method is 


\section{TOTAL BORON}

5.1 Application. This method is applicable to the determination of total boron in samples of boron carbide powder and pellets. The recommended amount of boron for each titration is $100 \pm 10 \mathrm{mg}$.

5. 2 Summary. Powdered boron carbide is mixed with sodium carbonate and this mixture is fused to decompose the boron carbide. The melt is dissolved in water, filtered to remove the insoluble residue, acidified, and heated to remove carbon dioxide. The boron, as boric acid, is titrated with standardized sodiun hydroxide using the mannitoboric acid procedure.

5.3 Interferences. Metals that form hydrous oxides may distort the end point of the titration. At the specification limits usually established for nuclear-grade boron carbide, however, such interference is not encountered from metal impurities.

\subsection{Appiaratus.}

1. Balance, analytical, capable of weighing to the nearest $0.05 \mathrm{mg}$.

2. Beakers, 400 and $600 \mathrm{~m} 1$, low boron glass.

3. Burners, Bunsen and Meker (alternate to muffie furnace).

4. Combination electrode, glass-calonel, semimicro.

5. Filter paper, open textured, very rapid filtering, for coarse and gelatinous precipitates. 1

6. Muffle furnace. 2

7. $\mathrm{pH}$ meter.

8. Platinum crucible, $30 \mathrm{ml}$, standard form with close ficting cover.

9. Polyethylene funnel.

\footnotetext{
${ }^{1}$ Whatman No. 41 filter paper has been used successfully for this methou.

${ }^{2}$ A furnace made by Deltech, Model DT $28-96$, has bes used successfully. IN
} 
10. Recording titrator.?

11. Temperature programmer, ${ }^{2}$

5.5 Reagents and Standards. Avoid purchasing reagents contained in glass to eliminate a possibje source of boron contamination. Store reagents in plastic containers.

1. Barium carbonate, powdered.

2. Hydrochloric acid, $12 \mathrm{M}(37 \%)$.

3. Mannitol.

4. Methyl red solution.

5. Nitric acid, $15.6 \mathrm{M}(70 \%), 1 \mathrm{M}$, and $0.1 \underline{\mathrm{M}}$.

Hydrochloric acid can be used as an alternate.

6. Potassium nitrate, crystals.

7. Sodium carbonate, powdered.

8. Sodium hydroxide, $0.25 \mathrm{~N}$, standardized, carbonate-free.

9. Calibration standards.

National Bureau of Standards boric acid (NBS SRM 951) is used to standardize the sodium hydroxide. Boron carbide sintered pellets are used to calibrate the total method, incluaing sample preparation. These pellets are from a batch of pellets analyzed sufficiently to demonstrate uniformity between pellets in total boron content, within the linits of measurement error, and to establish the nominal concentration of boron.

5.6 Calibration. The frequency of calibration shall be governed by RDT F 2-8. Standardize the $0.25 \mathrm{~N}$ sodium hydroxide by dissolving 560 to $700 \mathrm{mg}$ of NBS SRM 95J. weighed to the nearest $0.1 \mathrm{mg}$ in $100 \mathrm{ml}$ of freshly boiled and cooled water. Adjust the $\mathrm{pH}$ to 3 with $1 \mathrm{M}$ nitric acid

${ }^{1}$ A Sargent recording titrator, Model D, has been used successfully for this method. The use of a recording titrator is recommended because the presence of impurities, such as carbonate and aluminum, will be revealed by distortions in the titration curves at the end point. Such distortions may be overlooked when using manual titrations.

2R. I. Controls, Data-Trak, Mode1 FGE, has been used successfully. 
and titrate with the $0.25 \mathrm{~N}$ sodium hydroxide, beginning at Step 11 of 5.7.5. Calculate the normality of the sodium hydroxide using 5.8.5. The initial standardization requires at least six tftrations and the standard deviation must be $\leq 0.0002 \mathrm{~N}$. The standardization is checked at least once per month during which boron analyses are made.

Analyze the boron carbide calibration standard by following 5.7 and calculate the result using 5.8. Calculate the percent recovery using 5.8 .6 and take the action shown in Table 1 .

Table 1. Calibration Action Requirements

$\begin{array}{ll}\text { Recovery Range, Percent } & \text { Status-Action } \\ 99.85 \text { to } 100.15 & \begin{array}{l}\text { No change in callbration; } \\ \text { make no correction of } \\ \text { sample results. }\end{array} \\ 99.5 \text { to } 99.84 \text { or } & \begin{array}{l}\text { Calibration shift; cor- } \\ \text { rect sample results (see } \\ 5.8 .4 \text { ) }\end{array} \\ <99.5,>100.5 & \begin{array}{l}\text { Possible error in stan- } \\ \text { dard analysis; evaluate } \\ \text { the situation. }\end{array}\end{array}$

5.7 Analysis. Precautions shall be taken to avoid boron contamination from reagents, glassware, and perhaps other sources. If care is used in procuring reagents and if low boron glassware is used, boron contamination should be negligible. However, a blank to check for boron contamination shall be determined at least once a week and whenever a new bottle of any reagent is used. Lerner* points out that the titration of reagents alone does not give a true blank. He recommends titrating a given amount of boric acid with and without reagents; the difference, if any, represents the txue blank.

5.7.1 Reagent Blank. The reagent blank is determined at least once a month during which boron analyses are made and whenever a new bottle of any reagent is used. A running average is used in the calculation of boron results.

* See Appendix A.II. 
1. Take a crucible through the analysis, starting at Step $I$ of $5,7.2$ and omitting step 2 .

2. Calculate the reagent blank using 5.8.3.

\subsubsection{Sample Preparation.}

1. Add $2 \mathrm{~g}$ of sodium carbonate to a $30 \mathrm{ml}$ platinum crucible and let the sodium carbonate stand exposed to room atmosphere until constant weight is obtained.

The sodium carbonate equilibrates with the moisture in the air.

2. Weigh into the crucible from 0.13 to $0.15 \mathrm{~g}$ of sample in powder form, weighed to the nearest $0.05 \mathrm{mg}$.

Pellets are crushed to a powder using 4.7.3.

3. Weigh into the crucible $100 \pm 10 \mathrm{mg}$ of potassium nitrate.

This step is not used if the sample is to be fused using a burner $(5.7 .4)$.

4. Mix the materials in the crucible throughly with a small diameter plastic rod or a short length of wire.

5. Add an additional $2 \mathrm{~g}$ of sodium carbonate to the crucible, covering the mixture completely.

The sample is ready for fusion by using either a muffle furnace or burnex $(5.7 .3$ or 5.7 .4$)$.

\subsubsection{Fusion by Muffle Furnace.}

1. Place a lid on the crucible and place into the furnace.

2. Do one of the following if a programmable furnace is used:

a. Use a $150^{\circ} \mathrm{C} / \mathrm{h}$ heating rate until $900^{\circ} \mathrm{C}$ is reached; hold $900^{\circ} \mathrm{C}$ for $2 \mathrm{~h}$ and remove the crucible immediately, letting it cool to room temperature.

b. Increase the tempexature to $1000^{\circ} \mathrm{C}$ using the $150^{\circ} \mathrm{C} / \mathrm{h}$ heating rate and hold at $1000^{\circ} \mathrm{C}$ for $20 \mathrm{~min}$; remove the crucible immediately and let it cool to room temperature. 
3. Do the following if a manually controlled (nonprogrammable electronic control) furnace is used:

a. Have the temperature of the furnace at $300^{\circ} \mathrm{C}$ when putting in the crucible (Step 1).

b. Reset the temperature controller to $600^{\circ} \mathrm{C}$ and let the temperature reach $600^{\circ} \mathrm{C}$.

c. Increase the temperature $50^{\circ} \mathrm{C}$ every $20 \mathrm{~min}$ until $1000^{\circ} \mathrm{C}$ is reached and keep the crucible at this temperature for 20 min.

d. Remove the crucible immediately and let it cool to room temperature.

4. Proceed to Step 1 of 5.7.5.

5.7.4 Fusion by Burner. If this fusion technique is used, potassium nitrate is not needed and step 3 of 5.7 .2 can be eliminated.

1. Place a lid on the crucible and heat with a low flame of a Bunsen burner for $15 \mathrm{~min}$.

2. Continue heating for another 75 min while gradually increasing the temperature of the flame until the mixture is completely mo1ten.

3. Replace the Bunsen flame with a full Meker flame and continue heating until decomposition of the boron carbide is completed.

Most samples require about $20 \mathrm{~min}$.

4. Allow the melt to cool to room temperature.

5.7.5 Titration of Boron. This subsection includes a precipitation of hydrolyzable metals from a basic solution containing sodium carbonate. This separation is adequate for boron carbides having metailic impurity contents no greater than those found in nuclear-grade materials. For "dixtier" boron carbide, precipitation using barium carbonate provides a better separation (see 5.7.6). For the sodium carbonate separation, proceed as follows:

1. Place the crucible and 1id into a $400 \mathrm{mI}$, low boron glass beaker and add enough watex to cover the crucible and lid.

2. Allow the melt to dissolve.

The time required to dissolve the melt can be reduced by heating and stirring. 
An alternate approach is to let the melt dissolve overnight while the beaker sits in a warm location. If this is done, go from step 3 to step 5, omitting step 4.

3. Remove the crucible and lid from the beakex; rinse both carefully with water, adding the rinse to the beaker.

4. Stir the solution and allow it to stand for at least $2 \mathrm{~h}$.

The solution can be warmed and then allowed to stand for several hours to improve the filtering characteristics of the precipitate.

After the precipitate settles, the supernate should be colorless.

5. Separate the precipitate by filtration through an opentextured, very rapid, filter paper using a polyethylene funnel and collect the filtrate in a $600 \mathrm{ml}$, low-boron glass beaker.

6. Rinse the filter paper and precipitate thoroughly with hot water and collect the rinses with the filtrate.

7. Acidify the filtrate with nitric acid to a $\mathrm{pH}$ of $3.0 \pm 0.1$.

8. Cover the beaker and boil the solution gently for 15 min.

Dissolved carbon dioxide is removed.

9. Allow the solution to cool.

If a blank is being determined, proceed at Step 10; otherwise, proceed at Step 11 .

10. BIank determination.

Add 560 to $700 \mathrm{mg}$ of the NBS SRM 951 standard weighed to the nearest $0.1 \mathrm{mg}$ to the beaker containing the blank and stir the solution to dissolve the boric acid; add a second similarly weighed portion of the standard to another beaker containing $100 \mathrm{ml}$ of freshly boiled and cooled water to which nitric acid has been added to give of $\mathrm{pH}$ of $3 \pm 0.1$.

Analyze each solution as described in Steps 11 and 12.

11. Titrate slightly beyond the first potentlometric end point with the standardized $0.25 \mathrm{~N}$ sodium hydroxide. 
If the end point inflection on the titration curve is distorted or if there are multiple inflections that are severe enough to prevent a clear determination of the end point, carbonate or hydrolyzable metals are probably present. The best procedure at this point is to start the analysis over with a new sample. The titrated solution can be salvaged, however, by adjusting the $\mathrm{pH}$ to 3.0 with dilute acid and then following the barium caxbonate separation procedure $(5.7 .6)$. Once mannitol has been added at Step .12 , the titrated solution cannot be salvaged and a new sample must be started.

12. Add $20 \mathrm{~g}$ of mannitol and continue the titration past the second end point.

13. Calculate the results using 5.8 .

\subsubsection{Barium Carbonate Separation.}

1. Place the crucible and lid into a $400 \mathrm{ml}$, low-boron glass beaker and add enough water to cover the crucible and lid.

2. Add $6.5 \mathrm{ml}$ of $12 \mathrm{M}$ hydrochloric acid and 3 drops of methyl red.

If the sodium carbonate from 5.7 .2 and the $12 \mathrm{M}$ hydrochloric acid are measured carefully, the solution will be slightly acidic when the melt has dissolved. If not acidic, add 12M hydrochloric acid until it becomes acidic and then add 4 drops of excess.

3. Remove the crucible and lid from the beaker; rinse both carefully with water, adding the rinses to the beaker.

If the melt has not dissolved completely, gently heat the solution.

4. Add $1.3 \mathrm{~g}$ of barium carbonate to the solution.

The $1.3 \mathrm{~g}$ of barium carbonate can be added only if the sodium carbonate and hydrochloric actd were carefully measured (see Step 2). Otherwise, the barium carbonate js added until the solution is basic and then an excess of $1 \mathrm{~g}$ is added.

5. Cover the beaker with a watch glass and bring the solution to a boil.

Let the precipitate digest for $30 \mathrm{~min}$ at a temperature just below the boiling point of the solution.

6. Proceed at Step 5 of 5.7 .5 . 
5.8 Calculations. Calculate the weight percent of boron in the samples and control standards, determine the reagent blank, calculate the normality of the sodium hydroxide, and calculate the percent recovery of the calibration standard using the appropriate equations below.

5.8.1 End Points. Cajculate the end points from the two potentiometric breaks using the second dertvative technique by noting the $\mathrm{pH}$ changes for equal increments of titrant near the end point. Subtract the $\mathrm{pH}$ change preceding the largest $\mathrm{pH}$ change from the largest. Subtract the $\mathrm{pH}$ change following the largest from the largest. Divide the first of these second derivatives by their sum. Multiply the quotient obtained by the increment of titrant. Thts fraction of an increment is then added to the milliliters of titrant noted at the beginning of the largest pH change to determine the end point as given by Equation 4.

mI titrant at end point $=\left[\frac{B-A}{(B-A)+(B-C)} \times D\right]+E$

where

$A=p H$ change preceding largest $\mathrm{pH}$ change

.. $\quad B=$ largest $\mathrm{pH}$ change

$\mathrm{C}=\mathrm{pH}$ change following largest $\mathrm{pH}$ change

$\mathrm{D}=$ increment of titrant used

$E=$ mllijiters of titrant added at the beginning of the largest $\mathrm{pH}$ change.

An example is shown in Table 2.

Table 2. Calculation Example

\begin{tabular}{llcl}
\hline $\begin{array}{l}\mathrm{m} 1 \mathrm{NaOH} \\
\text { Added }\end{array}$ & $\mathrm{pH}$ & $\begin{array}{c}\text { pH Change } \\
\text { (First } \\
\text { Derivative) }\end{array}$ & $\begin{array}{c}\text { Second } \\
\text { Derivative }\end{array}$ \\
\hline 0.50 & 5.6 & & \\
0.60 & 5.8 & 0.2 & $1.0(\mathrm{~B}-\mathrm{A})$ \\
$0.70(\mathrm{~s})$ & 6.5 & $0.7(\mathrm{~A})$ & $0.8(\mathrm{~B}-\mathrm{C})$ \\
0.80 & 8.2 & $1.7(\mathrm{~B})$ & \\
0.90 & 9.1 & $0.9(\mathrm{C})$ & \\
1.00 & 9.8 & 0.7 & \\
\hline
\end{tabular}


5.8.2 Volume of Sodium Hydroxide Used. Calculate the volume of sodium hydroxide using Equation 5.

$$
\mathrm{T}=\mathrm{S}-\mathrm{F}
$$

where

$T=$ milliliters of sodium hydroxide used

$S=$ milliliters of sodium hydroxide used at the second end point

$F=$ milliliters of sodium hydroxide used at the first end point. Equation 6 .

\subsubsection{Reagent Blank. Calculate the reagent blank using}

$$
R=T_{a}-T_{c}\left(\frac{W_{a}}{W_{c}}\right)
$$

where

$R=$ reagent blank, milliliters of sodium hydroxide

.. $\quad \mathrm{T}_{\mathrm{a}}=$ milliliters of sodium hydroxide used in the titration of the standard with reagents

$\mathrm{W}_{\mathrm{a}}=$ grams of the standard citrated with reagents

$T_{c}=$ milliliters of sodium hydroxide used in the titration of the standard without reagents

$W_{c}=$ grams of the standard titrated without reagents

5.8.4 Concentration of Boron in the Sample. Calculate the concentration of boron in the sample using Equation 7 .

$$
\text { Boron }=\frac{(T S-R) N A}{W_{S}} \times 100 \times \frac{1}{P R}
$$

where

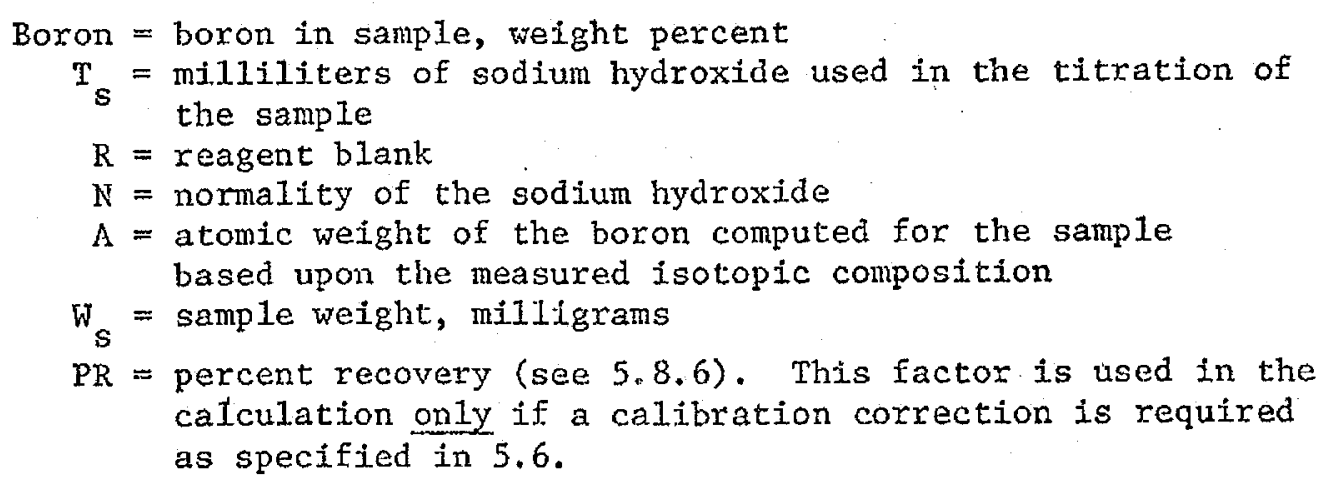


5.8.5 Normality of Sodium Hydroxide. The normality of the sodium hydroxide is calculated using Equation 8.

$$
N=\frac{W x}{T_{x} M}
$$

where

$N=$ normality of the sodium hydroxide

$\mathrm{W}_{\mathrm{x}}=$ milligrams of the NBS standard titrated

$\mathrm{T}_{\mathrm{x}}=$ milliliters of sodium hydroxide used in the titration of the standard

$M=$ moleculax weight of the boric acid.

5.8.6 Percent Recovery. The percent recovery is calculated using Equation 9 .

$$
P R=\frac{K}{L} \times 100
$$

where

,

$\mathrm{PR}=$ percent recovery

$\mathrm{K}=$ weight percent of boron calculated from the analysis of the calibration standard

$L=$ nominal weight percent of boron established for the calibration standard (see Step 9 of 5.5). $0.15 \%$.

5.9 Precision. The relative standard deviation of the method is 


\section{BORON ISOTOPIC COMPOSITION}

6.1 Application. This method is applicable to the determine of boron isotopic composition of boron carbide powder and pellets containing natural to highly enriched boron. About $25 \mathrm{mg}$ of sample are required for each analysis.

6.2 Summary. Boron isotopic ratios are measured in boron carbide by thermal ionization mass spectrometry without prior chemical separation of boron. Boron is converted to sodium borate by fusion of the boron carbide with sodium hydroxide or sodium carbonate directly on the tantalum filament of the mass spectrometer. The loaded filament is transferred to the mass spectrometer where boron isotopic ratios are measured using the $\mathrm{Na}_{2} \mathrm{BO}_{2}{ }^{+}$ion. When mixing the boron carbide and sodium hydroxide or sodium carbonate, a sodium-to-boron ratio of $1: 1$ is maintained, which gives a stable ion emission within a few minutes after operational vacuum is attained. There is no apparent bias caused by selective volatilization of boron-10.

6.3 Intexferences. Impurity elements, at the specification limits usually estabijshed for nuclear-grade boron carbide, do not interfere. Strontium is a potential interference and it is an impurity element in the tantalum filament material. At the temperature used to ionize sodium borate, however, the strontium impurity in the filament does not volatilize to cause a high bias at mass 88 . Care shall be taken to prevent contamination from extraneous boron.

\subsection{Apparatus.}

1. Mass spectrometer.

Commercial instruments are available that meet or exceed the following requirements:

a. Source, thermal ionization using singJe filaments.

A vacuum lock is recommended to maintain source vacuum, which increases sample throughput.

b. Analyzer, with a vacuum system capable of producing a resolving power of at least 400 and an abundance sensitivity at mass 100 of at least 20,000 .

Resolving power is defined as $M / \Delta M$, where $\Delta M$ is the width, in atomic mass units, of a peak at mass $M$ at $5 \%$ of $i t s$ height. Abundance sensitivity is defined as the ratio of total ion current at mass $M$ to its contribution at mass M-1. 
c, Detector, Faraday cup, electron multipliex, or scintillator photomultiplier.

Data acquisition can be accomplished by a potentiometric recorder or a pulse counting system.

2. Mass spectrometer accessories.

The following items are required:

a. Filaments, tantaluin ribbon, nominaliy 0.001 in. $(0.025 \mathrm{~mm})$ thick, $0.030 \mathrm{in} .(0.76 \mathrm{~mm})$ wide, with optional v-groove.

Filaments shall be prepared and stored in a manner to minimize contamination and they shall be cleaned before use.

b. Forming $j i g$, used to form filaments into the configuration required by the mass spectrometer used and to hold the filaments in place for welding.

c. Spot welder, used to weld the filament ribbons to the support posts.

Welds should be made carefully to ensure good electrical contact, which is necessary for beam stability.

d. Sample loading unit, used to heat filaments to at least $800^{\circ} \mathrm{C}$.

A system permitting an electrical current to pass through the filament is required.

3. Mixer mill. ${ }^{2}$

4. Plastic pipet.

Use a $5 \mu I$ pipet with a changeable plastic barre1. ${ }^{2}$ Use a pipet only once and then discard it.

5. Plastic vial and ball, $13 \mathrm{~mm}$ outside diameter by $25 \mathrm{~mm}$ long vial and $95 \mathrm{~mm}$ diameter ball.

\footnotetext{
${ }^{1}$ A Spex Industries Mixer Mill, Model 5100, has been used for this method.

${ }^{2} \mathrm{~A}$ Kimble automatic pipet (No. 56300) with disposable polypropylene tips has been used for this method.
} 


\subsection{Reagents and Standards.}

1. Acetone.

2. Distilled water.

3. Isopropy1 alcohol.

4. Sodium carbonate, $0.14 \mathrm{M}$.

5. Sodium hydroxide.

Pulverize in stainless steel containers with stainless steel balls in a mixer mill and store in a desiccator.

6. Toluene.

7. Calibration standard.

The standard shall be as specified by RDT F 2-8. This standard is NBS SRM 951 (boric acid) or 1ts replacement.

6.6 Calibration. Calibration frequency shall be governed by RDT F 2-8. Periodic attention shall be given to bias and linearity, and to counting dead time when an jon counting technique is used. These factors shall be determined when the mass spectrometer is first used and they shall be checked whenever a callbration result is obtained that significantly deviates from the accepted value. These factors shall also be checked at periodic intervals of not greater than 3 months.

6.7 Analysis. This section contains a procedure for cleaning the filament, a procedure for sample preparation and filament loading, and a brief instruction for mass spectrotietric measurements.

6.7.1 Filament Cleaning. Filament assemblies are made according to a procedure that is appropriate for the mass spectrometer used.

1. Clean the filament assembly by sequentially dipping it in toluene, isopropyl alcohol, and distilled water.

2. Rinse the assembly twice with acetone.

3. Dry the assembly under a heat lamp.

6.7.2 Sample Preparation and Filament Loading. Consideration shall be given to boron contamination from reagents and othex sources. Sources of natural boron contamination can be checked by using NBS boron-10 enriched boric acid (SRM 952) as an internal standard. Step I is the instruction for sample preparation. Steps 1 through 5 are 
Instructions for fusing the sample with sodium hydroxide and steps 6 through 9 are instructions for an alternate fusion with sodium carbonate.

1. Weigh $25 \pm 2 \mathrm{mg}$ of sample in powder form and transfer it to a plastic vial.

For pellet samples, crush to a powder using the procedure in 4.7.3. Sample materials prepared for other analyses can be used if care is taken to prevent cross contamination between samples, particularly between samples of differing boron isotopic compositions.

To obtain a representative sample if the original sample is in powdered form, thoroughly blend the buik sample before taking the $25 \mathrm{mg}$ aliquot.

A quantitative transfer is not required because isotopic ratios only are being determined.

2. Add $72 \pm 2 \mathrm{mg}$ of pulverized sodium hydroxide from the desiccator to the vial containing the sample (Step 1).

3. Add a plastic ball and immediately close the vial.

Avoid atmospheric moisture pickup. Moisture interferes with good mixing.

4. Mix for 1 min on the mixer mill.

5. Transfer about $0.1 \mathrm{mg}$ of the mixture to a filament.

Proceed to Step 10 for the fusion.

6. Weigh $5 \pm 0.2 \mathrm{mg}$ of sample in powder form and transfer it to a plastic vial. See the notes at Step $I$.

7. Add $1.25 \mathrm{ml}$ of $0.14 \mathrm{M}$ sodium carbonate solution to the vial containing the sample (Step I).

8. Slurry the mixture with the tip of a plastic pipet until a uniform suspension is obtained.

9. Transfer about $5 \mu l$ of the slurry to a filament.

10. Heat the filament gradually just to the point were the filament glows brightly. 
The bright glow is caused by the exothermic reaction of tantalum with sodium hydroxide or sodium carbonate. The fusion produces sodium borate and the melt tightly adheres to the filament.

\subsubsection{Mass Spectrometric Measurement.}

1. Insert the filament assembly into the mass spectrometer.

2. Evacuate the system to about $5 \times 10^{-7} \operatorname{torr}(67 \mu \mathrm{Pa})$.

3. Heat the sample by passing an electrical current through the filament until a stable beam of $\mathrm{Na}_{2} \mathrm{BO}_{2}$ ions is obtained.

4. Scan the spectrum repeatedly in both directions over the mass range desired until at least nine spectra have been obtained.

6.8 Calculation. Determine the boron isotopic composition fxom the mass spectra recorded. Calculate the 89:88 peak height ratio from the average peak heights. Correct this ratio for mass bias and subtract 0.00075 to correct for oxygen-17.

- 6.9 Precision. The standard deviation of the boron-11 to boron 1.0

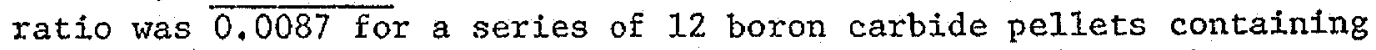
natural boron. The average ratio obtained was 4.0506 , which corresponds to a boron-10 isotopic abundance of $19.80 \pm 0.03$. 
Page 32 of 118 of D0114201

$$
\begin{array}{lc}
\text { RDT } & \text { F 11-2T } \\
\text { PAGE } & 28
\end{array}
$$




\section{SOLUBLE CARBON}

7.1 Application. This method is applicable to the determination of soluble carbon in samples of boron carbide pellets. The lower limit of the method is $0.02 \%$ soluble carbon with a $100 \mathrm{mg}$ sample.

7.2 Summary. After crushing to a powder, the sample is reacted with sodium dichromate in sulfuric acid and the carbon is oxidized to carbon dioxide and measured manometrically. The conditions selected for this method are empirical and it is assumed that only carbon in forms other than boron carbide is oxidized under the conditions prescribed. It is therefore important that the apparatus and analysis conditions are used exactly as described in this method.

7.3 Interferences. At the specification limits for impurities usually established for nuclear-grade boron carbide, interferences are insignificant. The apparatus includes traps to remove water carried with the carbon dioxide before the manometric measurement.

\subsection{Apparatus.}

1. Soluble carbon apparatus as show in Fig. 4.

A few of the components are given below with dimensions. The letters in parentheses refer to Fig. 4 .

a. Calibrated volumes (N and 0$), 200$ and $100 \mathrm{mI}$.

b. Carbon dioxide trap (L), 2 mm inside diameter capillary U-tube.

The tube is inverted. It is constructed so that side arms are located $32 \mathrm{~mm}$ below the top of the inverted $U$ and the legs extend $150 \mathrm{~mm}$ into liquid nitrogen in the Dewar (M).

c. Condenser (H), Friedrichs, about $200 \mathrm{~mm}$ long, supplied with $5^{\circ} \mathrm{C}$ water cooled by a refrigerated system.

d. Reactor tube (D), $45 \mathrm{~mm}$ outside diameter by $180 \mathrm{~mm} 10 \mathrm{ng}$, with a delivery tube for nitrogen.

The shape shall be conical with the end of the delivery tube being within 1 to $2 \mathrm{~mm}$ of the bottom. This configuration is required to provide adequate and reproducible stixring of the boron carbide during the analysis. The sample port is a $28 / 15$ Teflon coated ball and socket joint.

e. Water trap (J), dry ice, and acetone, $30 \mathrm{~mm}$ outside diameter by $250 \mathrm{~mm}$ long, filled with $3 \mathrm{~mm}$ glass beads. 


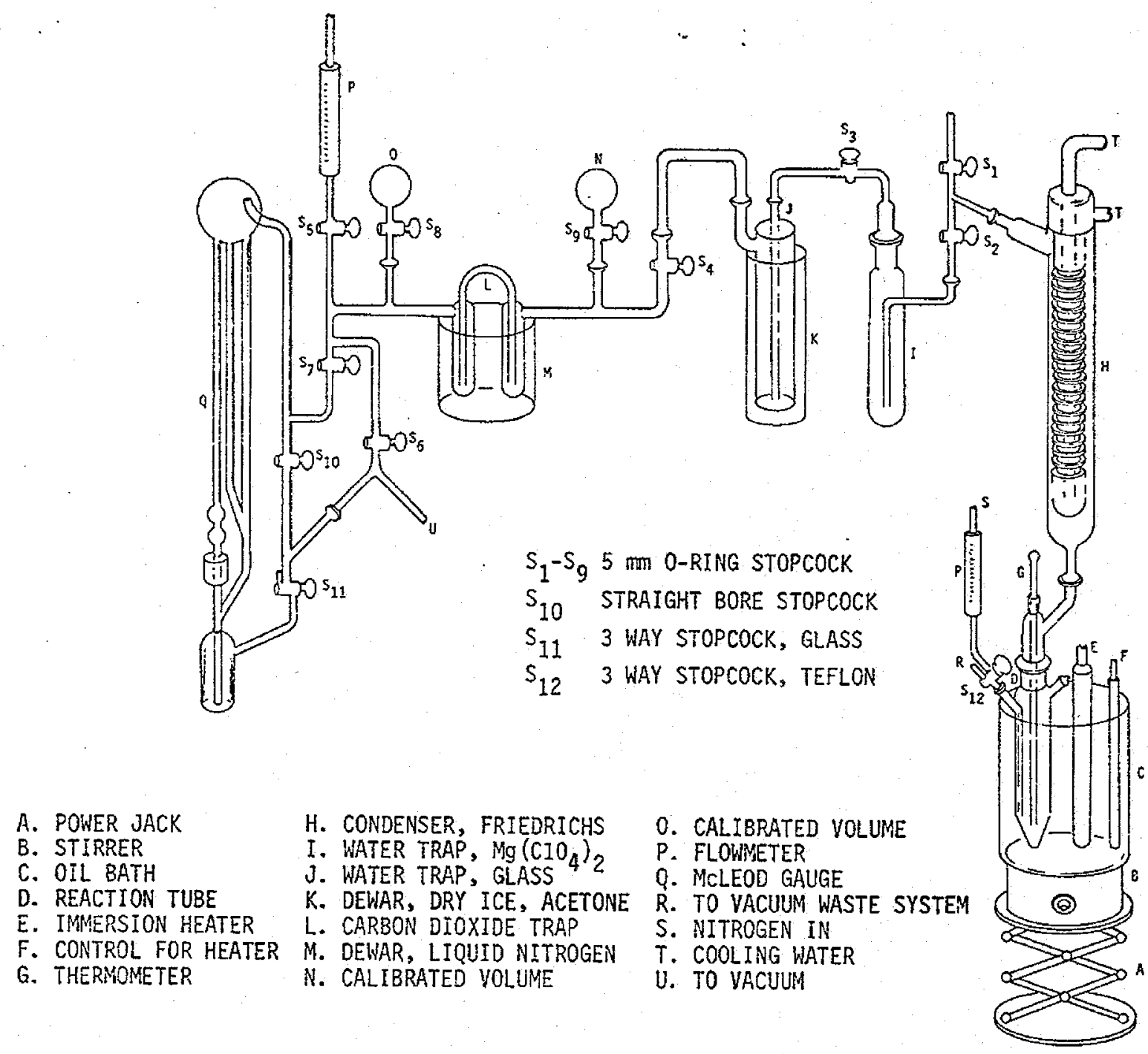

$\begin{array}{ll}0 & 0 \\ 0 & 0 \\ 0 & -1\end{array}$

Fig. 4. Soluble Carbon Apparatus. 
f. Water trap (I), magnesium perchlorate, $40 \mathrm{~mm}$ outside diameter by $180 \mathrm{~mm}$ long, with an extra-coarse frit on the bottom of the inlet tube.

2. Tímer.

7.5 Reagents and Standards.

1. Acetone.

2. Dry ice, crushed.

3. Liquid nitrogen.

4. Magnesium perchlorate, anhydrous.

5. Mercury, triple distilled or equivalent.

6. Nitrogen, prepurified grade or equivalent.*

7. Reaction solution.

Add slowly with stixring $350 \mathrm{ml}$ of $18 \mathrm{M}$ sulfuric acid $(96 \%)$ to $150 \mathrm{ml}$ of distilled water containing $\overline{10} \mathrm{~g}$ of sodium dichromate dihydrate. Store in a glass container. Storage in polyethylene containers causes gradually increasing blanks because of a slow reaction between the reaction solution and the polyethylene.

CAUTION: In case of accldental contact with the skin, rinse prompty whth running cold water to avold severe burns.

7.6 Calibration. The volume of the gas measuring part of the apparatus is calibrated. This gas measuring system contains the volume from $S_{4}$ to $S_{5}, S_{6}$ and $S_{10}$ and $i t$ includes the McLeod gauge and the calibrated volumes $N$ and 0 . This total volume of the system is symbolized as $\mathrm{Z}$. In this procedure, volumes $\mathrm{Z}-(\mathrm{N}+\mathrm{O}), \mathrm{O}$, and $\mathrm{N}$ are symbolized as $v_{1}, v_{2}$, and $v_{3}$ respectively. Determine the three volumes required (which are $v_{1}, V_{2}$, and $V_{3}$ ) as follows (refer to Fig. 4):

1. Calculate the volume of $N\left(V_{3}\right)$ from the weight of the water required to fill N. Attach $\mathrm{N}$ (a glass bulb) to the apparatus.

The volume of $O\left(V_{2}\right)$ can be obtained likewise, although this volume can be obtained also by using the following steps.

$*$ See Section 2.3. 
2. Flush the apparatus with nitrogen by following Steps 6 and 7 of 7.7 , but also by opening $S_{8}$ and $S_{9}$, at step 7 .

3. Open $s_{1}$, and close $s_{2}, s_{4}, s_{5}, s_{10}$, and $s_{11}$.

4. Reduce the pressure of the gas measuring system by opening $\mathrm{S}_{6}$ until the pressure has been reduced to about $20 \operatorname{torr}(2.7 \mathrm{kPa})$.

5. Close $S_{6}$ and open $S_{7}$.

6. Control the height of mercury in the McLeod gauge by cautiously opening $S_{11}$ to the atmosphere. Read and record the pressure on the McLeod gauge. (See Step 18 of 7.7).

This pressure is $P_{1}$.

7. Slowly open $s_{11}$ to vacuum and close $s_{9}$.

8. Open $S_{6}$ and $S_{10}$ to evacuate the system (excluding volume $N$ ).

9. Close $s_{6}, s_{8}, S_{10}$, and $s_{11}$ and open $s_{9}$.

The gas remaining in $N$ now expands into the evacuated portion of the system.

10. Cautiously open $S_{11}$ to atmosphere. Read and record the pressure on the McLeod gauge. (See Step 6 above).

This pressure is $P_{2}$.

11. Slowly open $S_{11}$ to vacuum.

12. Close $S_{11}$ and open $S_{8}$.

13. Cautiously open $S_{11}$ to atmosphere. Read and record the pressure on the McLeod gauge.

This pressure is $P_{3}$.

14. Calculate $V_{1}$ and $V_{2}$ using Equations 10 and 11 .

$$
\begin{aligned}
& v_{1}=\frac{v_{3} P_{1}-v_{3} P_{2}}{P_{2}} \\
& v_{2}=\frac{v_{3} P_{1}-\left(v_{3} P_{3}+v_{1} P_{3}\right)}{P_{3}}
\end{aligned}
$$


7.7 Analysis. When each iten of equipment is irst mentioned in this procedure, it is identified by a letter that refers to Fig. 4. A reagent blank shall be determined at least once in each $8-\mathrm{h}$ shift in which soluble carbon analyses are made. In terms of milligrams of carbon, a range in the blank of 0.04 to 0.06 over several weeks has been typically obtained. An individual blank should be within \pm 0.02 of the long-term average. A reagent blank is determined by following steps 1 through 22 , omitting the sample at step 3.

1. Start heating the oil bath (C), turn on the water (T) to the condenser $(\mathrm{H})$, and turn on the refrigerated cooling unit.

The oil bath must reach a temperature of $102^{\circ} \mathrm{C}$ before being used at step 9.

2. Prepare a bath of dry ice and acetone in a Dewar flask (K) and place it in position.

Slowly add crushed dry ice to an acetone-water mixture until a slush is formed. Use about $10 \mathrm{~m} 1$ of water for each $400 \mathrm{ml}$ of acetone used.

.. 3. Weigh to the nearest $0.1 \mathrm{mg}$ a small capsule made from aluminum foil and add 25 to $100 \mathrm{mg}$ of powdered sample to the capsule; close the capsule and reweigh.

A piece of foil, about $40 \mathrm{~mm}$ by $20 \mathrm{~mm}$, is rolled into a cylinder around a glass rod,

Pellets are prepared using 4.7.3.

The sample weight is obtained by difference.

4. Place the capsule into the reaction tube (D).

5. Add $25 \mathrm{ml}$ of the reaction solution to the reaction tube and close the sample port.

6. Start the nitrogen gas flow with $S_{1}$ open, $S_{12}$ opened to the reaction tube, and $s_{2}$ closed. Flush for at least 2 min.

The flow rate should be about $160 \mathrm{mI} / \mathrm{min}$.

At this point, stopcocks $S_{2}$ through $S_{9}$ must be closed. $S_{10}$ and $S_{11}$ are open to vacuum.

7. Close $s_{1}$ and open $s_{2}, s_{3}, s_{4}$, and $s_{5}$; let the nitrogen purge the apparatus for $3 \mathrm{~min}$.

8. Place a Dewar flask containing liquid nitrogen (M) around the carbon dioxide trap (L) and wait for $2 \mathrm{~min}$. 
9. Place the oil bath, at a temperature of $102^{\circ} \mathrm{C}$, around the reaction tube and start the timer.

To heat the sample in a reproducible manner, a liquid hot-bath must be used. Heating tapes or heating mantles are not suitable. With a bath temerature of 100 to $102^{\circ} \mathrm{C}$, it takes less than 10 min for the temperature of the reaction solution to reach 98 to $101^{\circ} \mathrm{C}$. A 1 to $2^{\circ} \mathrm{C}$ temperature drop between the bath and reaction solution is expected. Either the temperature of the reaction solution or the bath may controlled.

10. Maintain the temperature of the oill bath at $102^{\circ} \mathrm{C}$ for $60 \pm 1$ min.

11. Remove the oil bath; close $S_{2}$ and open $S_{1}$.

12. Close $s_{4}, s_{5}, s_{10}$, and $s_{11}$. Open $s_{8}, s_{9}$ and $s_{6}$ to vacuum.

13. Evacuate the apparatus for $3 \mathrm{~min}$, opening $S_{7}$ during the last minute. Then close $\mathrm{S}_{6}, \mathrm{~S}_{8}$, and $\mathrm{S}_{9}$.

14. Open $S_{11}$ to atmosphere and adjust the middle column of mercury on the McLeod gauge to index point $c_{0} *$

The adjustment is made by opening $S_{11}$ to either the atmosphere or vacuum as required to adjust the column. Final adjustment must be made by opening $s_{11}$ to the atmosphere.

15. Read and record the pressure $\left(\mathrm{P}_{B}\right)$ from the left-hand column of mercury on the Mcleod gauge.

This pressure is blank $\left(\mathrm{P}_{\mathrm{B}}\right)$.

16. Slowly open $s_{11}$ to vacuum and then close $s_{11}$.

CAUTION: Open $S_{11}$ to vacuum slowly to avoid blowing mercury from the McLeod gauge into the gas measuring system.

17. Remove the liquid nitrogen from the carbon dioxide trap and heat the trap to room temperature by immersing in warm water.

The frozen carbon dioxide is evaporated and it expands as a gas through volume $V_{1}$ of the gas measuring system (see 7.6).

*The term "index point" is used with Todd Universal Vacuum Gauge, 3-scale McLeod gauge ('Todd Scientific Co.). 
18. Slowly open $S_{11}$ to the atmosphere and adjust the left-hand column of mercury to one of the following, depending upon the pressure leve1:

a. Adjust to index point A to read the pressure on the righthand column of mercury.*

b. Adjust to index point $B$ to read the pressure on the middle column of mercury.*

19. Read and record the pressure $\left(P_{S}\right)$ of the carbon dioxide,

If the pressure is too high to read, use volumes $0\left(v_{2}\right)$ and $N$ $\left(v_{3}\right)$ as necessary. Record which volumes are used in the gas measuring system (see 7.6).

20. Measure and record the room temperature near the gas measuring section.

21. Slowly open $S_{10}$ and $S_{11}$ to vacuum to evacuate the McLeod gauge.

$S_{10}$ and $S_{11}$ may be left open to evacuate the McLeod gauge continuously during Steps 3 through 11 .

22. Discard the contents of the reaction tube to waste by opening $\mathrm{S}_{12}$ to vacuum $(\mathrm{R})$ and inse the reaction tube with distilled water.

23. Repeat Steps 3 through 22 to analyze additional samples.

7.8 Calculations. The amount of carbon dioxide is calculated from pressure, volume, and temperature measurements using Equation 12 for both samples and reagent blanks.

$$
\mathrm{n}=\mathrm{PV} / \mathrm{RT}
$$

where

$$
\begin{aligned}
\mathrm{n}= & \text { mi.cromoles of carbon dioxide } \\
\mathrm{P}= & \text { pressure measured by mercury manometer, (torr) }=\mathrm{P}_{\mathrm{S}}-\mathrm{P}_{\mathrm{B}} \text { (Steps } \\
& 15 \text { and } 19 \text { of } 7.7) \\
\mathrm{R}= & \text { gas constant, } 0.0624 \text { (torr) (m1)/(mol) }\left({ }^{\circ} \mathrm{K}\right) \\
\mathrm{T}= & \text { temperature of the gas in } \mathrm{K}[\mathrm{Step} 20 \text { of } 7.7] \\
\mathrm{V}= & \text { volume occupied by the gas in mililiters (sum of volumes } \mathrm{V}_{1}, \\
& \left.\mathrm{~V}_{2} \text { and } \mathrm{V}_{3} \text { used; see } 7.6 \text { and Step } 19 \text { of } 7.7\right)
\end{aligned}
$$

*The term "index point" is used with Todd Universal Vacuum Gauge, 3--scale Mcleod gauge (Todd Scientific Co.). 
Within the pressure range measured, the deviation of carbon dioxide from the ideal gas equation is insignificant.

1. Calculate $\mathrm{n}$ for the sample and reagent blank using Equation 12 .

2. Calculate the concentration of soluble carbon in the samples using Equation 13.

$$
\text { Carbon }=\frac{\left(n_{s}-n_{b}\right)(12)\left(10^{-6}\right) \times 100}{W_{s}}
$$

where

Carbon $=$ soluble carbon in the sample, weight percent

$n_{s}=$ micromoles of carbon dioxide in sample

$n_{b}=$ micromoles of carbon dioxide in reagent blank

$w_{s}=$ grams of sample, (Step 3 of 7.7)

. 3. To simplify the calculations, a calibration curve of weight of carbon versus pressure can be prepared for each combination of volumes $V_{1}, V_{2}$, and $V_{3}$.

7.9 Precision. Three laboratories analyzed a batch of boron carbide pellets.with a mean result of $0.83 \%$ soluble carbon and pooled rela- IC tive standard deviation for a single measurement of $8.6 \%$. 


\section{SOLUBLE BORON}

8.1 Application. This method is applicable to the determination of soluble boron in samples of boron carbide pellets. The lower limit is about $0.02 \%$ soluble boron for a $1 \mathrm{~g}$ sample.

8.2 Sumary: Soluble boron is extracted from two portions of a sample by refluxing separately with hydrochloric and nitric acids. The method is based upon the assumption that hydrochloric acid extracts only boron oxide and nitric acid extracts both boron oxide and elemental boron. Each extract is purified from hydrolyzable metals by precipitation and the filtrates are analyzed for boron by titration with standardized sodium hydroxide using the mannitoboric acid procedure. This method is empirical; therefore, it is important that the apparatus and analysis conditions used are exactly as described in this method.

8.3 Interferences. Metals that form hydrous oxides distort the end point of the strong acid titration. These types of metals are present in nuclear-grade boron carbide at concentration levels requiring separation from the boron when determining soluble boron. This method, therefore, includes a precipitation separation for those metallic impurities.

\subsection{Apparatus.}

1. Allihn condenser, $200 \mathrm{mI}$ jacket with a $24 / 40$ standard taper (inner) joint at one end.

2. Beaker, 400 and $600 \mathrm{ml}$, 1owmboron glass.

3. Electrode pair, glass and calomel.

4. Erlenmeyer flask, $200 \mathrm{~m} .1$, low-boron glass, with a $24 / 40$ standaro taper (outer) joint at the neck.

5. Filter paper, $\mathrm{S} \& \mathrm{~S}$ No. 589 (Blue Ribbon) and Whatman No. 41 or ic their equivalents.

6. pH meter.

7. Polyethylene funnel.

8. Recording titrator.*

*A Sargent recording titrator, Model D, has been used successfully in this method. The use of a recording titrator is recomended because the presence of impurities, such as carbonate and aluminum, will be revealed by distortions in the titration curves at the end point. Such distortions may be overlooked when using manual titrations. 
8.5 Reagents and Standards.

1. Hydrochloric acid, $3 \underline{M}$ and $0.1 \mathrm{M}$.

2. Mannito1.

3. Nitric acid, 3M, 1.6M, and $0.1 \mathrm{M}$.

4. Sodium hydroxide, 10M.

5. Sodium hydroxide, $0.1 \mathrm{~N}$, standardized, carbonate-free.

6. Calibration standard.

The standard shall be as specified by RDT F 2-8. This standard, used to standardize the 0 . 1N sodium hydroxide, is NBS SRM 951 (boric acid) or its replacement.

8.6 Calibration. The frequency of calibration shall be governed by RDT F 2-8. Dissolve 225 to 280 ing of NBS SRM 951 weighed to the nearest $0.1 \mathrm{mg}$ in $100 \mathrm{ml}$ of freshly boiled and cooled distilled water. Adjust the $\mathrm{pH}$ to 3 with $1 \mathrm{M}$ hydrochloric acid and titrate with the $0.1 \mathrm{~N}$ sodium hydroxide, beginning at Step 16 of 8.7.2. Calculate the normality of the sodium hydroxide using 8.8.5. The Initial standardization shall require at least six titrations and the standard deviation shall be $0.0001 \mathrm{~N}$ or Iess.

8.7 Analysis. The analyst must be aware that boron contamination can come from reagents, glassware, and perhaps other sources. If care is used in procuring reagents and if low-boron glassware is used, boron contamination should be negligible.

8.7.1 Reagent Blank. The reagent blank is determined at least once a month during which soluble boron analyses are made and whenever a new bottle of any reagent is used. A running average is used in the calculation of soluble boron results.

1. Add $100 \mathrm{ml}$ of $1.6 \mathrm{M}$ nitric acid to a $200 \mathrm{ml}$ flask and $100 \mathrm{ml}$ of $0.1 M$ hydrochloric acj.d to a second flask.

2. Take each flask through the analysis, starting at Step 3 of 8.7 .2 .

3. Calculate the reagent blank using 8.8 .3 .

\subsubsection{Sample Analysis.}

I. Weigh two separate $1 \mathrm{~g}$ samples in powder form to the nearest 1 ing and transfer them quantitativeIy to separate $200 \mathrm{ml}$. flasks fitted with Allihn condensers. 
Pellets are crushed to a powder using 4.7 .3 .

2. Add $100 \mathrm{ml}$ of boiling $1.6 \mathrm{M}$ nitric acid to one flask and $100 \mathrm{ml}$ of boiling $0.1 \mathrm{M}$ hydrochloric acid to the other flask. Immediately attach each flask to a condenser after adding the acid.

Take both samples through the remainder of the procedure.

Exceptions or special treatments required for either sample are given at the appropriate steps.

3. Gently boil under reflux for $4 \mathrm{~h}$.

4. Remove the hot plate and let the solution cool to amblent temperature with the condenser attached.

The flask containing nitric acid should be cooled rapidly with ice water to minimize oxidation of the boron carbide.

5. Rinse the condenser with 10 to $20 \mathrm{ml}$ of water.

6. Filter the solution through $S \& S$ No. 589 filter paper and collect the filtrate in a $400 \mathrm{ml}$ beaker.

The filtrate contains solubilized boron.

A retentive filter paper is necessary to retain the undissolved sample, although undissolved boron carbide does not affect the results.

7. Rinse the flask and the filter with $0.1 M$ hydrochloric acid or water.

Water may cause some samples to peptize and pass through the filter. This will not affect the results.

8. Adjust the pHI of the solution while stirring to about 11 using IOM sodium hydroxide and then adjust back to a $\mathrm{pH}$ between 6.0 and 6.5. using dilute acid.

9. Let the solution stand for at least $2 \mathrm{~h}$.

The solution can be warmed and then aljowed to stand for several hours or overnight to improve the filtering characteristics of the precipitate.

After the precipitate settles, the supernate should be colorless.

10. Filter the solution through whatman No. 41 filter paper and collect the filtrate in a $600 \mathrm{ml}$ beaker. 
11. Rinse the filter paper and precipitate thoroughly with hot water and collect the rinses with the filtrate.

12. Acidify the filtrate with dilute acid to a $\mathrm{pH}$ of $3.0 \pm 0.1$.

13. Cover the beaker and boil the solution gently for $15 \mathrm{~min}$. Dissolved carbon dioxide is removed.

14. Let the solution cool to ambient temperature.

If a blank is being determined, proceed at Step 15; otherwise proceed at Step 16 .

15. Blank determination.

Add 225 to $280 \mathrm{mg}$ of the NBS SRM 951 standard weighed to the nearest $0.1 \mathrm{mg}$ to each beaker containing a blank and stir the solution to dissolve the boric acid. Add a similiar weighed portion of the standard to another beaker containing $100 \mathrm{ml}$ of freshly boiled and cooled water to which a few ml of $0.1 \mathrm{M}$ hydrochloric acid have been added to give a $\mathrm{pH}$ of $3.0 \pm \overrightarrow{0.1}$.

Analyze each of the above solutions as described in Steps 16 and 17 .

16. Titrate slightly beyond the first potentiometric end point with the standardized $0.1 \mathrm{~N}$ sodium hydroxide.

If the end point inflection on the titration curve is distorted or if there are multiple inflections that are severe enough to prevent a clear determination of the first end point, carbonate or hydrolyzable metals probably are present. The precipitation separation can be modified using the barium carbonate procedure given in 5.7.6. A longer boiling time or sparging with an inert gas can improve the removal of carbon dioxide.

17. Add $10 \mathrm{~g}$ of mannitol and continue the titration past the second end point.

18. Calculate the results using 8.8 .

8.8 Calculations. Calculate the weight percent of nitric acidsoluble and hydrochlorjc acid-soluble boron in the samples, determine the reagent blank, and calculate the normality of the sodium hydroxide using the appropriate equations below. 
8.8.1 End Points. Calcylte the end points from the two potentiometric breaks using the second derivative technique by noting $\mathrm{pH}$ changes for equal increments of titrant near the end point. Subtract the $\mathrm{pH}$ change preceding the largest $\mathrm{pH}$ change from the largest. Subtract the $\mathrm{pH}$ change following the largest from the largest. Divide the first of these second derivatives by their sum. Multiply the quotient obtained by the increment of titrant. This fraction of an increment is then added to the ml of titrant noted at the beginning of the largest pH change to determine the end points as given by Equation 14.

$$
\text { ml titrant at end point }=\left[\frac{B-A}{(B-A)+(B-C)} \times D\right]+E
$$

where

$$
\begin{aligned}
& \mathrm{A}=\mathrm{pH} \text { change preceding largest } \mathrm{pH} \text { change } \\
& \mathrm{B}=\text { largest } \mathrm{pH} \text { change } \\
& \mathrm{C}=\mathrm{pH} \text { change following largest } \mathrm{pH} \text { change } \\
& \mathrm{D}=\text { increment of titrant used } \\
& \mathrm{B}=\mathrm{mI} \text { of titrant added up to the beginning of the largest } \mathrm{pH} \\
& \quad \text { change. }
\end{aligned}
$$

- An example is shown in Table 3.

Table 3. Calculation Example

\begin{tabular}{llll}
\hline $\begin{array}{l}\text { mI NaOH } \\
\text { Added }\end{array}$ & $\mathrm{pH}$ & $\begin{array}{c}\text { pH Change } \\
\text { (First } \\
\text { Derivative) }\end{array}$ & $\begin{array}{c}\text { Second } \\
\text { Derivative }\end{array}$ \\
\hline 0.50 & 5.6 & & \\
0.60 & 5.8 & 0.2 & $1.0(\mathrm{~B}-\mathrm{A})$ \\
$0.70(\mathrm{E})$ & 6.5 & $0.7(\mathrm{~A})$ & $0.8(\mathrm{~B}-\mathrm{C})$ \\
0.80 & 8.2 & $1.7(\mathrm{~B})$ & \\
0.90 & 9.1 & $0.9(\mathrm{C})$ & \\
1.00 & 9.8 & 0.7 & \\
\hline
\end{tabular}

8.8.2 Volume of Sodium Hydroxide Used. Calculate the volume of sodium hydroxide used fxom Equation 15.

$$
T=S-F
$$

where

$T=$ milliliters of sodium hydroxide used

$\mathrm{S}=$ milliliters of sodium hydroxide used at the second end point

$F=$ williliters of sodjum hydroxide used at the first end point. 
Equation 16 .

8.8.3 Reagent B].ank. Calculate the reagent blank using

$$
R=T_{a}-T_{c}\left(\frac{W_{w}}{W_{c}}\right)
$$

where

$\mathrm{R}=$ reagent $\mathrm{blank}$, mI of sodium nydroxide

$T_{a}=$ milliliters of sodium hydroxide used in the titration of the standard with reagents

$\mathrm{W}_{\mathrm{a}}=$ grams of the standard titrated with reagents

$T_{c}=$ milliliters of sodium hydroxide used in the titration of the standard without reagents

$W_{c}=g r a m s$ of the standard titrated without reagents.

8.8.4 Concentration of Boron in the Sample. Calculate the concentration of boron in the sample using Equation 17.

$$
\text { Boron }=\frac{\left(T_{s}-R\right) N A}{W_{S}} \times 100
$$

where

Boron $=$ weight percent boron in sample as nitric acid-soluble or hydrochloric actd-soluble

$T_{S}=$ milliliters of sodium hydroxide used in the titration of the sample

$\mathrm{R}=$ reagent $\mathrm{blank}$

$N=$ normality of the sodiun hydroxide

$A=$ atomic welght of the boron compuced for the sample based upon the measured isotopic composition

$\mathrm{W}_{\mathrm{S}}=$ sample welght, milligrams.

8.8.5 Normality of the NaOH. Calculate the normality of sodium hydroxide using Equation 18.

where

$$
N=\frac{W_{x}}{T_{x} M}
$$

$\mathrm{N}=$ normality of the sodium hydroxide

$W_{x}=$ mililigrams of the NBS standard titrated

$\mathrm{T}_{\mathrm{x}}=$ milliliters of sodium hydroxide used in the titration of the standard

$M=$ molecular weight of the boric actd. 
8.9 Precision. The pooled xelative standard deviations when three laboratories analyzed a single batch of boron carbide pellets were 6.5 and $4.6 \%$ for nitric acid-soluble boron and hydrochloric acid-soluble boron, respectively. In the same order, pooled mean results were 0.69 and $0.50 \%$ boron. 
Page 48 of 118 of D0114201

$\begin{array}{lc}\text { RDT } & \text { F } 11-2 T \\ \text { PAGE } & 44\end{array}$

6

$?$

$\%$

BLANK FAGE

?

C 


\section{ELUORIDE}

9.1 Application. This method is applicable to the determination of fluoride in samples of boron carbide powder and pellets. Between 1 and $100 \mathrm{\mu g}$ of fluoride are required for an analysis.

9.2 Summary. A stream of moist gas is passed over a mixture of powdered sample and $\mathrm{U}_{3} \mathrm{O}_{8}$ accelerator heated at 1000 to $1100^{\circ} \mathrm{C}$. The pyrohydrolytic reaction releases fluoride as hydrofluoric acid, which volatilizes and collects in the conciensate. The condensate is analyzed for fluoride with a fluoride-selerive electrode in a saturated solution of boric acid. The condensate cit? be analyzed also for chloride (see Method 10).

9.3 Interferences. At the specification Iimits for impurities usually established for nuclear-grade boron carbide, interference effects are insignificant. Because variations in both $\mathrm{pH}$ and ionic strength of solutions affect the response of the electrode to fluoride ion activity, the measurements are made in saturated boric acid solutions.

\subsection{Apparatus.}

I. FIuoride-selective electrode. 1

2. Mixer milit.

3. $\mathrm{pH} /$ specific-ion meter. ${ }^{2}$

4. Polyethylene sample container.

Cut a 2 oz $(30 \mathrm{ml})$ polyethylene bottle in half and use the botton half for the sample container.

5. Pyrohydrolysis apparatus.

See Method 10 (Fig. 5) for a description of this apparatus.

6. Reference electrode, saturated calomel.

${ }^{1}$ An Orion fIuoride-selective electrode, Mode1 94-09, has been found satisfactory for this method.

${ }^{2}$ An Orion specific-ion meter, Model 401, has been found satisfactory for this method. 


\subsection{Reagents and Standards.}

1. Accelerator, $\mathrm{U}_{3} \mathrm{O}_{8}$, powdered, $<1 \mu g$ fluoride per gram.

Prepare by air calcining uranium dioxide at $400^{\circ} \mathrm{C}$ or by oxidizing uranium metal in the following manner: Slowly air oxidize the metal starting at $300^{\circ} \mathrm{C}$ and raising the temperature gradua11y to $800^{\circ} \mathrm{C}$ over several days. Then ignite the oxide for 20 min at $1000^{\circ} \mathrm{C}$ in moist argon (conditions for pyrohydrolysis). These two preparations provide $\mathrm{U}_{3} \mathrm{O}_{8}$ with satisfactory accelerator characteristics, which are thought to be dependent upon the surface area of the oxide.

2. Argon, prepurified grade or equivelent.*

3. Boric acid, powder and a saturated solution in distilled water.

4. Distilled water, fluoride-free, $<0.1$ ug of fluoride per gram.

5. Calibration standards.

Standards shall be as specified in RDT F 2-8. These standards are boron carbide powder to which known amounts of fluoride have been added.

6. Fluoride standards.

Prepare a $1.00 \mathrm{mg}$ of fluoride per milliliter standard using sodium fluoride, previously dried at $110^{\circ} \mathrm{C}$, and distilled water, Dilute $1.00 \mathrm{ml}$ of this standard to $200.0 \mathrm{ml}$ with a saturated solution of boric acid (this standard contains $100 \mathrm{\mu g}$ of fluorfde per $20 \mathrm{ml}$ ). Dilute $1.0 .0 \mathrm{ml}$ and $20.0 \mathrm{ml}$ of this second standard to separate $200.0 \mathrm{ml}$ volumes with a saturated solution of boric acid (these standards contain 5 and $10 \mu \mathrm{g}$ of fiuoride per $20 \mathrm{ml}$, respectively). Store the above standards in polyethylene contalners.

9.6 Calibration. The method, from sample preparation through the fluoride measurement, shall be calibrated with the calibration standards. Calibration frequency shall be governed by RDT F 2-8. The fluoride electrode is calibrated with the fluoride standards (9.5, Item 6) prior to the sample analyses.

* See Section 2.3 . 


\section{electrode as follows:}

\subsubsection{Fluoride Electrode Calibration. Calibrate the fluoride}

1. Turn the function switch of the specific-ion meter to the "F" position and let it stabilize for $30 \mathrm{~min}$ before continuing.

2. Rinse the electrodes (fluoride-selective electrode and saturated calomel electrode) with distilled water and dry by blotting them with absorbent tisste.

3. Transfer 5 to $7 \mathrm{ml}$ of the $10 \mu \mathrm{g}$ be fluoride per $20 \mathrm{ml}$ standard into a clean and dry polyethylene sample container and immerse the electrodes in the solution.

Make certain that no air bubbles are trapped at the bottom of the fluoride electrode.

4. Wait 1 to $2 \mathrm{~min}$ and then adjust the calibration control of the meter to read 100 on the red meter scale with the slope adjust setting at 100 percent and the temperature compensator control knob set at the temperature of the solution.

5. Remove the electrodes; rinse them with distilled water and dry by blotting with absorbent tissue.

It is not necessary to switch the meter to "Off" when removing the electrodes.

6. Transfer 5 to $7 \mathrm{ml}$ of $100 \mu \mathrm{g}$ of fluoride per $20 \mathrm{ml}$ standard into a clean and dry polyethylene sample container and immerse the electrodes.

Make certain that no air bubbles are trapped at the bottom of the fluoride electrode.

7. Wait for 1 to $2 \mathrm{~min}$ and then adjust the temperature compensator control so that the meter reads exactly 1000 on the red scale.

This step adjusts the slope of the electrode response over the concentration range of 10 to $100 \mathrm{\mu g}$ of fluoxide per $20 \mathrm{ml}$.

8. Rotate the slope indicator so that the temperature-compensator control again reads the same temperature as in Step 4.

The slope indicator should read between 90 and $105 \%$ in terms of the percent theoretical Nernst slope; 1 not, determine the source of the problem. 
9. Repeat Step 3 with the $5 \mu \mathrm{g}$ of fluoride per $20 \mathrm{mI}$ standard.

The meter should read $50 \pm 3$; if not, repeat starting at Step 1 .

10. Multiply all readings by 0.1 before recording.

11. Leave the electrodes immersed in the $10 \mathrm{\mu g}$ of fluoride per $20 \mathrm{ml}$ standard and leave the function switch of the meter in the " $F$ " position in preparation for measuring fluoride during the analysis of samples and calibration standards.

9.6.2 Method Calibration. Using at least five calibration points ranging between 1 and $100 \mathrm{~kg}$ of fluoride, calibrate the method as follows:

1. Analyze weighed portions of the calibration standards and a reagent blank according to 9.7 .

2. Subtract the micrograms of fluoride measured in the reagent blank from the micrograms of fluoride measured in each standard.

The micrograms of fluoride per $20 \mathrm{ml}$ obtained in Step 14 of 9.7 are the amounts of fluoride in the reagent blank and standards.

3. Prepare a calibration curve by plotting on linear graph paper the micrograms of fluoride measured versus the micrograms of fluoride in the calibration standards.

9.7 Analysis.* Care sha1l be taken to avoid fluoride contamination of reagents and laboratory equipment.

1. Prepare a sample and reagent blank as follows:

a. Crush pellet samples to a powder using the procedure in 4.7.3.

b. Line two sample boats with $3 \mathrm{~g}$ of $\mathrm{U}_{3} \mathrm{O}_{8}$.

c. Weigh 1 to $2 \mathrm{~g}$ of powdered sample to the nearest $0.01 \mathrm{~g}$ and mix thoroughly with $3 \mathrm{~g}$ of $\mathrm{U}_{3} \mathrm{O}_{8}$ accelerator in a mixer mill.

*Steps 1 through 9 are the same as in Method 10. Both fluoride and chloride quantitatively collect in the condensate at Step 9. 
d. Quantitatively transfer this mixture to one of the sample boats and spread it uniformly along the length of the boat.

e. Add $3 \mathrm{~g}$ of $\mathrm{U}_{3} \mathrm{O}_{8}$ accelerator to the second sample boat and spread it uniformly along the length of the boat.

This second boat, which is used for the measurement of the reagent blank, is taken through Steps 2 through 15.

At least two reagent blanks shall be determined in each $8-\mathrm{h}$ shift in which analyses are made, one at the start and the other in the middle of the shift. If the fluoride exceeds $1 \mathrm{\mu g}$ in the blank, find and eliminate the source of contamination before continutng sample analyses.

2. Prepare the pyrohydrolysis apparatus for use as follows:

a. Turn on the tube furnace and allow it to reach 1000 to $1100^{\circ} \mathrm{C}$.

To avoid delay, the furnace should be turned on early.

Whatever temperature is used within the above range, the same temperature within $\pm 10^{\circ} \mathrm{C}$ must be used for both samples and standards.

b. Turn on the cooling water to the condenser on the pyrohydrolytic tube.

c. Add distilled water to the water heater and turn on the heater to boil the water.

Start this step early to avoid delaying analyses.

d. Turn on the argon and adjust its flow to about $190 \mathrm{mI} / \mathrm{min}$.

e. Adjust the argon flow and water temperature such that $15 \pm 2 \mathrm{ml}$ of condensate is produced in about $20 \mathrm{~min}$ of operation.

3. Open the pyrohydrolytic tube.

4. Place a collection vessel containing $2 \mathrm{ml}$ of the saturated boric acid solution and $1.5 \mathrm{~g}$ of boric acid into position.

The tip of the hang-down tube should be at least $10 \mathrm{~mm}$ below the surface of the boric acid solution. 
5. Insert a sample boat into the pyrohydrolytic tube and immediately close the tube.

The sample boat shall be placed in the center of the hot zone of the furnace.

6. Collect $15 \pm 2 \mathrm{ml}$ of condensate.

The time required should be abrut $20 \mathrm{~min}$.

7. Remove the collection vessel.

8. Open the pyrohydrolytic tube, remove the sample boat, and transfer the spent sample to a waste container.

9. Dilute the condensate to $20.0 \mathrm{ml}$ with distilled water and mix thoroughly.

This solution can serve for the determination of chloride (see Method 10).

10. Rinse the electrodes with distilled water and dry by blotting thern with absorbent tissue.

11. Transfer 5 to $7 \mathrm{ml}$ of the diluted condensate into a dry, clean polyethylene container.

12. Immerse the electrodes into the dilute condensate and swirl the solution around the electrodes.

Make certain that no air bubbles are trapped at the bottom of the fluoride electrode.

The function switch of the meter should be in the "F" posttion.

13. Let the reading stabilize for 1 to $2 \mathrm{~min}$.

14. Multiply the reading on the red scale by 0.1 to obtain micrograms of fluoride per $20 \mathrm{ml}$ of the diluted condensate.

Record the value obtained.

15. Turn the function switch to the "Off" position and leave the electrodes immersed in the $10 \mathrm{\mu g}$ of fluoride per $20 \mathrm{ml}$ of standard. 
9.8 Calculations. Calculate the 1 icrograms of fluoride per gram of sample as follows:

1. Subtract the micrograms of fluoride measured in the reagent blank from the micrograms of fluoride measured in the sample.

2. Obtain the corresponding "corrected" micrograms of fluoride from the calibration curve (Step 3 of 9.6.2).

3. Calculate the concentration of fluoride in the sample using Equation 19 ,

$$
\text { Fluoride }=\frac{F_{C}}{W}
$$

where

Fluoride = microgxams of fluoride per gram of sample

$F_{c}=$ micrograms of fluoride from Step 2 above

$\mathrm{W}=$ sample weight, grams.

9.9. Precision. The relative standard deviation obtained from a single batch of boron carbide containing $11 \mathrm{\mu g}$ of fluoride per gram was $13 \%$. 


\section{CHLORIDE}

10.1 Application. This method is applicable to the determination of chloride in samples of boron carbide powder and pellets. Between 4 and $100 \mathrm{\mu g}$ of chloride are required for an analysis.

10.2 Summary. A stream of moist argon is passed over a mixture of powdered sample and $\mathrm{U}_{3} \mathrm{O}_{8}$ accelerator heated at 1000 to $1100^{\circ} \mathrm{C}$. The pyrohydrolytic reaction releases chloride as hydrochloric acid, which volatilizes and collects in the condensate. The condensate is analyzed for chloride with an automatic chloride titrator that coulometrically generates silver ion to form insoluble silver chloride. The end point is sensed amperometrically and the generating current is stopped automatically at a preset increment of indicator current. Since the rate of generating silver ion is constant, the titration time is proportional to the amount of chloride precipitated. The condensate can be analyzed for chloride by other methods and also for fluoride (see Method 9).

10.3 Interferences. At the specification limits for impurities usually established for nuclear-grade boron carbide, interference effects are insignificant. Bromide and iodide, if present, would be measured as chloride. Care should be taken at all times to prevent contamination from extraneous chloride.

' 10.4 Apparatus.

1. Automatic chloride titrator.*

2. Mixer mill.

3. Pyrohydrolysis apparatus.

This apparatus consists of the following components. See Fig. 5 .

a. Flowmeter, capable of measuring a gas flow of up to $250 \mathrm{ml} / \mathrm{min}$.

b. Water heater, flask in which water is boiled by either a hot plate or immersion heater.

c. Tube furnace, capable of maintaining a temperature of $1100^{\circ} \mathrm{C}$, with a 180 to $300 \mathrm{~mm}$ long by about $32 \mathrm{~mm}$ diameter heating chamber having the heating element extending to near the furnace ends.

*An Aminco-Cotlove, American Instrument Co., chloride titrator has been found satisfactory for this method. 


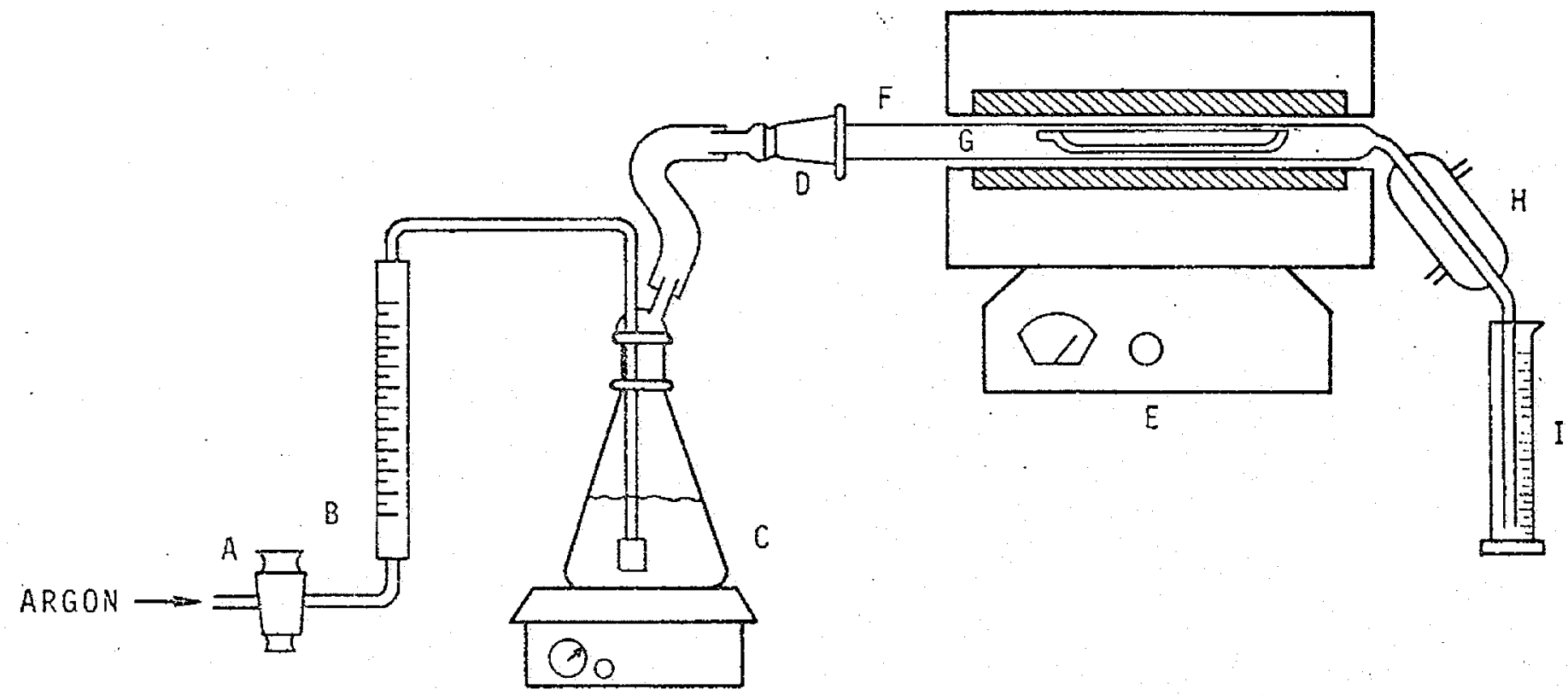
A. STOPCOCK
B. FLOWMETER
C. WATER HEATER
D. 29/42 STANDARD TAPER JOINTS
E. TUBE FURNACE
F. PYROHYDROLYTIC TUBE
G. SAMPLE BOAT
H. WATER CONDENSER
I. COLLECTION VESSEL

Fig. 5. Pyrohydrolysis Apparatus. 
d. Pyrohydrolytic tube, fused silica or nickel, $30 \mathrm{~mm}$ diameter by about $350 \mathrm{~mm}$ long with a $29 / 42$ standard taper (inner) joint on one end.

To the opposite end is sealed a hang-down tube with a condenser. The condenser is attached to the hang-down tube $10 \mathrm{~mm}$ from the top. The hang-down tube is $6 \mathrm{~mm}$ outside diameter and the condenser is $150 \mathrm{~mm}$ long, $25 \mathrm{~mm}$ outside diameter. The distance that the pyrohydrolytic tube extends outside of the furnace to the hang-down tube is $\leq 10 \mathrm{~mm}$. This distance is critical in preventing the formation of a boric acid plug in the top end of the hang-down tube.

e. Sample boat, fused silica or nickel with a capacity to hold at least $6 \mathrm{~g}$ of $\mathrm{U}_{3} \mathrm{O}_{8}$ and $2 \mathrm{~g}$ of sample.

f. Collection vessel, a graduated cylinder or graduated centifuge tube with a volume or about $25 \mathrm{mI}$.

\subsection{Reagents and Standards.}

.. 1. Accelerator, $\mathrm{U}_{3} \mathrm{O}_{8}$, powdered, <1 $\mathrm{kg}$ of chloride per gram.

Prepaxe by air calcining uranium dioxide at $400^{\circ} \mathrm{C}$ or by oxidizing uxanium metal in the following manner: Slowly air oxidize the metal staxting at $300^{\circ} \mathrm{C}$ and raising the temperature gradually to $800^{\circ} \mathrm{C}$ over several days. Then ignite the oxide for 20 min at $1000^{\circ} \mathrm{C}$ in moist argon (conditions for pyrohydrolysis). These two preparations provide $\mathrm{U}_{3} \mathrm{O}_{8}$ with satisfactory accelerator characteristics, which are thougint to be dependent upon the surface area of the oxide.

2. Axgon, prepurified grade or equivalent.*

3. Boric acid, powder and a saturated solution in distilled water.

4. Distilled water, chloride-free, $<0.1 \mathrm{\mu g}$ chloride per gram.

5. Gelatin solution.

(See the Operations Manual for the chyoride titrator.)

6. Nitric-acetic acid solution, IM nitric acid, $4 \mathrm{M}$ acetic acid containing 20 to $30 \mu g$ of chloride per milliliter of solution.

*See Section 2.3. 
7. Silver cleaning paste.

(See the operations manual for the chloride titrator.)

8. Calibration standards.

Standards shall be as specifled by RDT F 2-8. These standards are boron carbide powder to which known amounts of chloride have been added.

9. Chloride standard, about $1 \mathrm{mg}$ of chloride per milliliter.

Prepare a solution with an accurately known concentration using sodium chloride, previously dried at $110^{\circ} \mathrm{C}$, and distilled water.

10.6 Calibration. The method, from sample preparation through the chloride titration, shall be calibrated with the calibration standards specified by RDT F 2-8. Calibration frequency shall be governed by RDT F 2-8. The chloride titrator shall be calibrated with the $1 \mathrm{mg}$ of chloride per millilitex of chloride standard prior to sample analyses.

10.6.1 Chloride Titrator Calibration. Calibrate the chloride titrator as follows. If the silver electrodes are not bright, start at Step 1; otherwise start at Step 2.

1. Clean the silver electrodes with silver cleaning paste and wash thoroughly with distilled water.

The first one or two chloride measurements made after this cleaning step may not be satisfactory.

clean only if necessary.

2. Pipet $5.0 \mathrm{~m} 1$ of the saturated boric acid solution into a clean, dry, $10 \mathrm{ml}$ titration cell.

3. Pipet $1.00 \mathrm{ml}$ of the nitric-acetic acid solution containing chloride into the cell.

Since this chloride constitutes a significant blank, the amount of acid solution added shall be accurately pipetted. Chloride is added to the nitric-acetic acid solution to improve the sensitivity of the titration by adding sufficient chloride to exceed the solubility product of silver chloride. otherwise, a significant error occurs when titrating a few microgxams of chloride.

4. Pipet $50.0 \mathrm{\mu l}$ of the $1 \mathrm{mg}$ of chloride per milliliter of chloride standard into the cell. 
5. Add 2 drops of the gelatin solution.

6. Rinse the electrodes with distilled water.

7. Place the titration cell into position on the chloride titrator.

8. Begin stirring by turning the titrate switch to the "1" position.

9. Set the timer counter to zero.

10. Begin the titration by turning the titrate switch to the "2" position.

11. Record the time when the counter stops.

12. Repeat Steps 2,3 , and 5 through II to determine a calibration blank.

13. Calculate the calibration factor using 10.8.1. 10.6 .2 Method Calibration. Using at least five calibration
points ranging between 4 and $100 \mu g$ of chloride, calibrate the method as follows:

1. Take welghed portions of the calibration standards and a reagent blank through the conplete analysis (10.7).

2. Calculate the amount of chloride in each portion using 10.8.2.

3. Prepare a calibration curve by plotting on linear graph paper the micrograms of chloride measuited versus the micrograms of chloride in the calibration standards.

10.7 Analysis.* Extreme care shall be taken to avoid chloride contamination of reagents and laboratory equipment.

1. Prepare a sample and reagent blank as follows:

a. Crush pellet samples to a powder using the procedure given in 4.7 .3 .

b. Line two sample boats with $3 \mathrm{~g}$ of $\mathrm{U}_{3} \mathrm{O}_{8}$.

*Steps 1 through 9 are the same as in Method 9. Both chloride and fluoride quantitatively collect in the condensate at step 9. 
c. Weigh 1 to $2 \mathrm{~g}$ of powdered sample to the nearest $0.01 \mathrm{~g}$ and mix thoxoughly with $3 \mathrm{~g}$ of $\mathrm{U}_{3} \mathrm{O}_{3}$ accelerator in a mixer mill.

d. Quantitatively transfer this mixture to one of the sample boats and spread it uniformly along the length of the boat.

e. Add $3 \mathrm{~g}$ of $\mathrm{U}_{3} \mathrm{O}_{8}$ accelerator to the second sample boat and spread it uniformly along the length of the boat.

This second boat, which is used for the measurement of the reagent blank, is taken through steps 2 through 12 .

A least two reagent blanks shall be determined in each $8-\mathrm{h}$ shift in which analyses are made; one at the start and the other in the middle of the shift. If the chloride exceeds $2 \mathrm{\mu g}$ in the blank, find and eliminate the source of contamination before continuing sample analyses.

2. Prepare the pyrohydrolysis apparatus for use as follows:

a. Turn on the tube furnace and allow it to reach 1000 to $1100^{\circ} \mathrm{C}$.

The furnace can be turned on early to avoid delaying analyses.

- Whatever temperature is used within the above range, the same temperature within $\pm 10^{\circ} \mathrm{C}$ must be used for both samples and standards.

b. Turn on the cooling water to the condenser on the pyrohydrolytic tube.

c. Add distilled water to the water heater and turn on the heater to boil the water.

Start this step early to avold delaylng analyses.

d. Turn on the argon and adjust its flow to about $190 \mathrm{ml} / \mathrm{min}$.

e. Adjust the argon flow and water tempeature such that $15 \pm 2 \mathrm{~m} 1$ of condensate is produced $\mathrm{in}$ about $20 \mathrm{~min}$ of operation.

3. Open the pyrohydrolytic tube.

4. Place a collection vessel containing 2 ml of the saturated boric acid solution and $1.5 \mathrm{~g}$ of borlc actd inco position. 
The tip of the hang-down tube must be at least $10 \mathrm{~mm}$ below the surface of the boric acid solution.

5. Insert a sample boat into the pyrohydrolytic tube and immediately close the tube.

The sample boat must be placed in the center of the hot zone of the furnace.

6. Collect $15 \pm 2 \mathrm{ml}$ of the condensate.

The time required should be about $20 \mathrm{~min}$.

7. Remove the collection vessel.

8. Open the pyrohydrolytic tube, remove the sample boat, and transfer the spent sample to a waste container.

9. Dilute the condensate to $20.0 \mathrm{ml}$ with distilled water and $\mathrm{mix}$ thoroughly.

This solution can serve for the determination of fluoride (see Method 9).

10. Pipet $5.00 \mathrm{ml}$ of diluted condensate into a clean, dry $10 \mathrm{ml}$ titration cell.

11. Pipet $1.00 \mathrm{ml}$ of the nitric-acetic acid solution into the cell.

12. Do steps 5 through 11 of 10.6.1.

10.8 Calculations. Calculate the calibration factor, the micrograms of chloride titrated, and the concentration of chloride in the sample using the appropriate equations below.

10.8. I Calibration Factor. Calculate the calibration factor using Equation 20.

$$
F=\frac{c 1}{T_{s t}-T_{c b}}
$$

where

$$
\begin{aligned}
F= & \text { calibration factor } \\
C I= & \text { micrograms of chloride added from the chloride standard (Step } \\
& 5 \text { of } 10.6 .1 \text { ) } \\
T_{S t}= & \text { titration time of standard (Step } 11 \text { of } 10.6 .1 \text { ) } \\
T_{c b}= & \text { titration time of calibration blank (Step } 12 \text { of } 10.6 .1 \text { ). }
\end{aligned}
$$


10.8.2 Micrograms of Chloride Titrated. Calculate the chloride titrated using Equation 21 .

$$
\mu g \text { Chloride }=\frac{\operatorname{VF}\left(T_{s}-T_{r b}\right)}{A}
$$

where

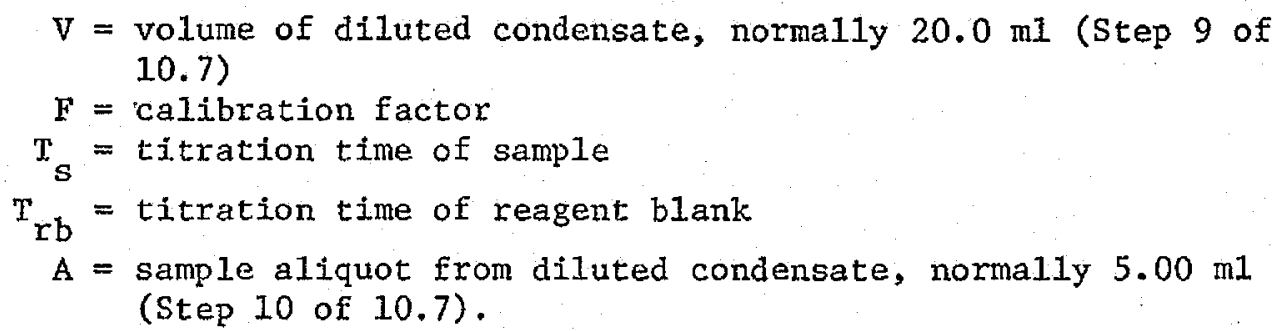

10.8.3 Concentration of Chloride in Sample. Calculate the concentration of chloride in samples as follows:

1. Calculate micrograms of chloride titrated (Equation 21).

2. Obtain the corresponding "corrected" micrograms of chloride from the calibration curve (Step 3 of 10.6.2).

3. Calculate the chloride concentration in the sample using Equation 22.

$$
\text { Chloride }=\frac{\mathrm{C} 1}{W}
$$

where

$$
\begin{aligned}
\text { chloride } & =\text { micrograms of chloride per gram of sample } \\
\mathrm{C} 1_{c} & =\text { micrograms of chloride from Step } 2 \text { above } \\
\mathrm{W} & =\text { sample weight, grams. }
\end{aligned}
$$

10.9 Precision. The relative standard deviation obtained from a single batch of boron carbide containing 21 hg of chloride per gram was $22 \%$. 


\section{GENERAL METALI.IC IMPURITIES BY A PHOTOGRAPHIC METHOD}

11.1. Application. This method is applicable to the determination of general metallic impurities in samples of boron carbide powder and pellets. The concentration ranges of the impurity elements determined by this method generally range from 0.04 to 4 times the specification limits for nuclear-grade boron carbide.

11.2 Summary. In this spectrographic method, boron carbide samples in powdered form are mixed with a spectroscopic buffer of germanium dioxide and graphite. Excitation is done in a d-c arc by a total burn technique. The concentrations of the Impurity elenents are determined by visual comparison of selected line densities from the samples and standards for a semiquantitative analysis and by a microdensitometric comparison for a quantitative analysis.

11.3 Interferences. Interference effects depend primarily upon the resolving power of the spectrograph and the selection of the analytical lines.

\subsection{Apparatus.}

1. Boron carbide mortar, with $40 \mathrm{~mm}$ dlameter by $20 \mathrm{~mm}$ deep cavity mortar and a boron carbide-tipped pestle.

2. Comparator, projection type having a magnification of at least $15 X$.

3. Diamond (Plattner) mortar.

4. Excitation source, d-c arc source capable of providing spectrographic conditions required for step 12 of 11.7 .

5. Graphite electrodes.*

a. Anode, cupped, with center post, machined from $6.1 \mathrm{~mm}$ diameter by $32 \mathrm{~mm}$ long rod. The annular cup around the center post is $3.0 \mathrm{~mm}$ deep, $2.2 \mathrm{~mm}$ inside diameter, and $5.1 \mathrm{~mm}$ outside diameter.

b. Cathode, $3.2 \mathrm{~mm}$ diameter, flat-end.

*AGKSP grade, National Carbon Co., has been used successfully. Anodes (cupped with center post) can be obtained as a special order item from supplier of graphite electrodes. 
6. Microdensitometer with repeatability of $0.2 \%$ of the full scale reading for transmittance values between 5 and $90 \%$.

7. Mixer mill capable of handling $50 \mathrm{~mm}$ long by $22 \mathrm{~mm}$ diameter vials. 1

8. Packing tool fabricated from tantalum or niobium. See Fig. 6 .

9. Photographic plates, Kodak SA-1.

10. Photographic processor capable of maintaining a development tempexature of $20^{\circ} \mathrm{C}$ controlled to $\pm 0.3^{\circ} \mathrm{C}$.

11. Plastic funne1. ${ }^{2}$

12. Plastic vial and balls.

Two sizes of vials: $25 \mathrm{~mm}$ long by $13 \mathrm{~mm}$ diameter and $50 \mathrm{~mm}$ long by $22 \mathrm{~mm}$ diameter; $3.2 \mathrm{~mm}$ diameter balls.

13. Sample mixer, dental amalgamator type for $25 \mathrm{~mm}$ long by $13 \mathrm{~mm}$ diameter vials.

14. Spectrograph having a reciprocal linear dispersion of $5 \mathrm{R} / \mathrm{mm}$ $(0.5 \mu \mathrm{m} / \mathrm{m})$ or less, a resolving power of 23000 or greater, and a wavelength range of 2500 to $4000 \AA$ (250 to $400 \mathrm{~nm}$ ).

11.5 Reagents and Standards.

1. Germanium dioxide, $99.999 \%$ purity. ${ }^{3}$

2. Graphite powder. ${ }^{4}$

3. Calibration standards,

Standards shall be as specified by RDT F 2-8. Each standard is a blend of 14 metal impurities in a matrix of boron carbide, germanium dioxide, and graphite, which is the same matrix as that obtained by treating samples according to Steps $I$ through

\footnotetext{
${ }^{1}$ A Spex Industries Mixer MiJ.1, Model 5100, has been used for this method. ${ }^{2}$ Spex Industries No. 3001 has been used for this method. ${ }^{3}$ Germanium dioxide of this purity has been obtained from Eagle-Picher Industries, Inc.

${ }^{4}$ Graphite, SP-2, grade, National Carbon Co., has been used successfully.
} 
Page 67 of 118 of D0114201

RDT

F 11-2 T

PAGE 63

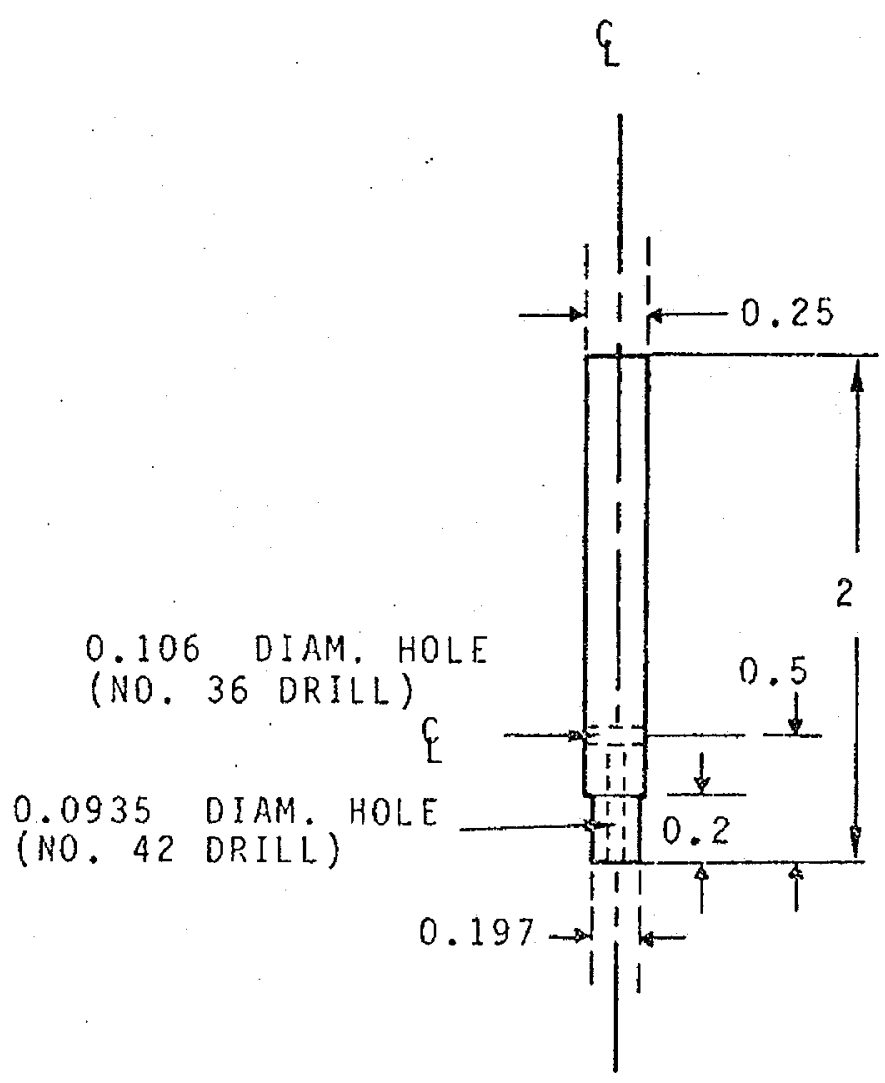

DIMENSIONS IN INCHES

Fig. 6. Packing Tool. 
8 of 11.7. The 14 metal impurities are the 11 usually specified for nuclear-grade boron carbide and three (copper, vanadium, and zirconium) that have also been found in boron carbide.

11.6 Calibration. Calibration frequency shall be governed by RDT F 2-8. For spectrographs equipped with photographic plates or films, samples shall be compared to a full set of calibration standards processed along with samples for each plate or film. Both visual comparison and microdensitometric techniques shall be used in this method as detailed jn 11.8.

11.6.1 Visual Comparison. A reconmended scheme for visual comparison is the following:

1. Prepare a master calibration plate with at least one exposure of each calibration standard starting at Step 9 of 11.7.

2. For each sample plate, also process one each of the calibration standards (starting at Step 9 of 11.7) along with samples (starting at Step 1 of 11.7 ).

- 3. Determine exposure correction factors for each impurity by visually comparing the densities of the analytical lines (see 11.8.1) of the calibration standards on the sample plate with the same lines on the naster calibration plate or film.

11.6.1 Microdensitometric Measurement. For microdensitometric measurement, prepare a calibration curve for each analytical line from the full set of calibration standards for each plate. Use these curves only for the sample recorded on the same plate. Detalls are given in 11.8.2.

\subsection{Analysis.}

1. Combine $300 \mathrm{mg}$ of germanium dioxide and $900 \mathrm{mg}$ of graphite powder in a $50 \mathrm{~mm}$ long by $22 \mathrm{~mm}$ diameter vial containing four plastic balls.

The processing of calibration standards starts at Step 9.

2. Mix for 2 min in the mixer mill.

Start analysis of pellets samples at Step 3 and powder samples at Step 7.

3. Crush the sample pellet in a diamond (Plattner) mortar, using light hammer taps and taking fine naterial out of the mortar during the operation. 
The cycle of light hammer taps and removal of fine material should continue until the whole pellet is crushed. Grinding action must be avoided; otherwise, iron contamination of the sample might occur.

4. Reduce further the particle size of the crushed sample in a boron carbide mortar by using a rocking motion of the pestle.

5. Transfer the sample to a plastic vial and shake the vial to mix the sample.

6. Transfer a $100 \mathrm{mg}$ portion of sample to the boron carbide mortar and grind to a fine powder.

7. Combine $15 \mathrm{mg}$ of sample in powder form and $135 \mathrm{mg}$ of the germanium dioxide-graphite powder mixture from step 1 in a $25 \mathrm{~mm}$ by $13 \mathrm{~mm}$ dianeter vial containing two plastic balls.

8. Mix for $45 \mathrm{~s}$ on the sample mixer.

9. Weigh out $20 \pm 0.2 \mathrm{mg}$ portions of the sample mixture from Step 8.

10. Transfer each portion to the cavity of an electrode using the plastic funnel, tapping the side of the electrode during the transfer to settle the material in the cavity.

The number of electrodes prepared depends on the exposure required for the particular spectrograph used.

11. Pack the charge in each electrode with the packing tool.

12. Make exposures of each charge in appropriate regions of the spectrum using the conditions in Table 4 as guidelines.

13. Develop the plate for $5 \mathrm{~min}$ in $\mathrm{D}-19$ developer at $20 \pm 0.3^{\circ} \mathrm{C}$; rinse for 15 to $20 \mathrm{~s}$ in short stop; fix for $3 \mathrm{~min}$ in a rapid fixer; wash for 5 min in running tan water, and dry.

11.8 Calculations. This section has two parts; instructions for calculating concentrations by visual comparison, and instructions for calculating the concentration by microdensitometric comparison. Obtain the concentrations of the metal impurities in the sample using the appropriate instructions.

\subsubsection{Visual Comparison.}

1. Place the sample plate and the master calibration plate in the comparator. 
Table 4. Exposure Guidelines

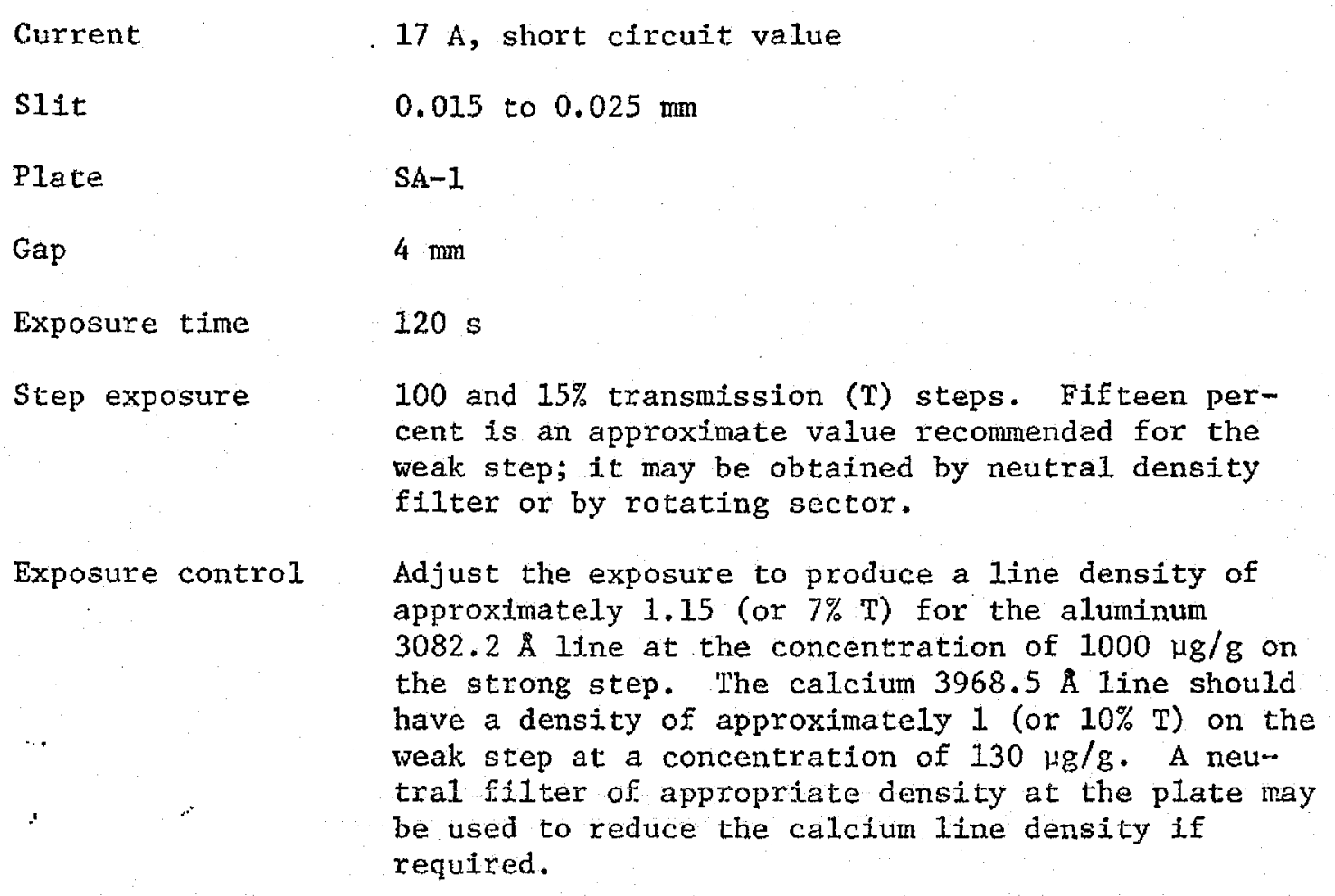

2. Visually compare the densities of the analytical lines for the calibration standards on the sample plate with the same lines on the master calibration plate to obtain exposure correction factors for each impurity element. Recommended analytical lines are given in Table 5 .

3. Visually compare the densities of the analytical lines for the samples with the same lines on the master calibration plate and estimate the impurity element concentrations in micrograms per gram of sample.

4. Correct the estimated concentrations with the exposure correction-factors determined in Step 2.

5. If the measured concentration of an impurity other than chromium, iron, manganese, or nickel is $25 \%$ or more of the specification value, proceed with a microdensitometric evaluation of that concentration. For chromium, iron, manganese, and nickel proceed with a microdensitometrfc evaluation if the oncentration of any of these elements exceeds $500 \mathrm{\mu g} / \mathrm{g}$. 
Table 5. Analytical Lines for Visual Comparison

\begin{tabular}{|c|c|c|c|c|c|}
\hline Element & & Analytical Line $(\AA)^{a}$ & Concentrati & ion Range, & $(\mu g / g)$ \\
\hline A1 & & $\begin{array}{l}3082.2 \\
3092.7\end{array}$ & $\begin{array}{l}90 \mathrm{t} \\
50 \mathrm{t}\end{array}$ & $\begin{array}{l}\text { to } 4,000 \\
\text { to } 4,000\end{array}$ & \\
\hline $\mathbf{B i}$ & & $\begin{array}{l}3067.7 \\
2898.0\end{array}$ & $\begin{array}{r}25 \mathrm{t} \\
500 \mathrm{t}\end{array}$ & $\begin{array}{ll}\text { to } 1,000 \\
\text { to } 1,000\end{array}$ & \\
\hline $\mathrm{Ca}$ & & $\begin{array}{l}3968.5 \\
3179.3\end{array}$ & $\begin{array}{r}50 \mathrm{t} \\
450 \mathrm{t}\end{array}$ & $\begin{array}{l}\text { to } 450 \\
\text { to } 4,000\end{array}$ & \\
\hline Co & & $\begin{array}{l}3453.5 \\
3044.0\end{array}$ & $\begin{array}{r}50 \mathrm{t} \\
200 \mathrm{t}\end{array}$ & $\begin{array}{l}\text { to } 2,000 \\
\text { to } 2,000\end{array}$ & \\
\hline $\mathrm{Cr}$ & & $\begin{array}{l}2835.6 \\
2843.2\end{array}$ & $\begin{array}{l}200 t \\
200 t\end{array}$ & $\begin{array}{l}\text { to } 4,000 \\
\text { to } 4,000\end{array}$ & \\
\hline $\mathrm{Cu}$ & & $\begin{array}{l}3274.0 \\
3247.5\end{array}$ & $\begin{array}{l}20 t \\
20 t\end{array}$ & $\begin{array}{l}\text { to } 20,000 \\
\text { to } 20,000\end{array}$ & \\
\hline $\mathrm{Fe}$ & $\therefore$ & $\begin{array}{l}2599.4 \\
2746.5\end{array}$ & $\begin{array}{r}200 \mathrm{t} \\
1,000 \mathrm{t}\end{array}$ & $\begin{array}{l}\text { to } 20,000 \\
\text { to } 20,000\end{array}$ & \\
\hline $\mathrm{Mg}$ & & $\begin{array}{l}2795.5 \\
2802.7\end{array}$ & $\begin{array}{l}20 \mathrm{t} \\
20 \mathrm{t}\end{array}$ & $\begin{array}{l}\text { to } 2,000 \\
\text { to } 2,000\end{array}$ & \\
\hline Mn & & $\begin{array}{l}2576.1 \\
2801.1\end{array}$ & $\begin{array}{l}50 \mathrm{t} \\
50 \mathrm{t}\end{array}$ & $\begin{array}{l}\text { to } 2,000 \\
\text { to } 2,000\end{array}$ & \\
\hline $\mathrm{Ni}$ & & $\begin{array}{l}3012.0 \\
3002.5\end{array}$ & $\begin{array}{l}40 t \\
40 t\end{array}$ & $\begin{array}{l}\text { to } 4,000 \\
\text { to } 4,000\end{array}$ & \\
\hline $\mathrm{Si}$ & & $\begin{array}{l}2881.6 \\
2514.3\end{array}$ & $\begin{array}{l}150 t \\
300 t\end{array}$ & $\begin{array}{l}6,000 \\
\text { to } 12,000\end{array}$ & \\
\hline$T i$ & & $\begin{array}{l}3088.0 \\
3234.5\end{array}$ & $\begin{array}{l}50 t \\
50 t\end{array}$ & $\begin{array}{ll}\text { to } & 2,000 \\
\text { to } & 2,000\end{array}$ & \\
\hline $\mathrm{V}$ & & $\begin{array}{l}3110.7 \\
3118.4\end{array}$ & $\begin{array}{l}40 \mathrm{t} \\
40 \mathrm{t}\end{array}$ & $\begin{array}{l}\text { to } 4,000 \\
\text { to } 4,000\end{array}$ & \\
\hline $\mathrm{Zr}$ & & $\begin{array}{l}3392.0 \\
3438.2\end{array}$ & $\begin{array}{r}40 \mathrm{t} \\
100 \mathrm{t}\end{array}$ & $\begin{array}{l}\text { to } 4,000 \\
\text { to } 4,000\end{array}$ & \\
\hline
\end{tabular}

$a \AA=0.1 \mathrm{~nm}$ 


\subsubsection{Microdensitometry.}

1. Calibrate the photographic emulsion by the two-step method given in ASTM E 116.

Calibrations are recommended for the wavelength regions 2500 to 2750,2800 to 3300,3375 to 3475 , and 3960 to $3980 \AA$.

2. Measure the transmittance of the analytical lines given in Table 6, using the strong step or the weak step as stated, for both the calibration standards and the samples.

3. Measure the background associated with each line.

4. Prepare a calibration curve for each analytical line as follows:

a. Convert the transmittances of the lines and their backgrounds to intensities using the emulsion calibration curve.

b. Correct each line intensity by subtracting its corresponding background intensity.

c. Plot the corrected intensities versus concentrations (micrograms per gram) on $\log -\log$ paper.

5. Calculate the concentration of each impurity in the samples as follows:

a. Obtain the corrected line intensity for each line by following steps $4 \mathrm{a}$ and $4 \mathrm{~b}$.

b. Convert the corrected intensities to concentrations (micrograms per gram) using the appropriate calibration curves.

An extrapolation of 1.5 times the intensity of the highest calibration standard and 0.67 times the intensity of the lowest may be used. For such cases, indicate "extrapolation" with the reported concentration.

11.9 Precision. The relative standard deviation is $15 \%$ or 1 ess for microdensitometric measurements and a factor of two ( $-50 \%$ to $+100 \%)$ for visual comparison measurements. 
Table 6. Analytical Lines for Microdensitometry

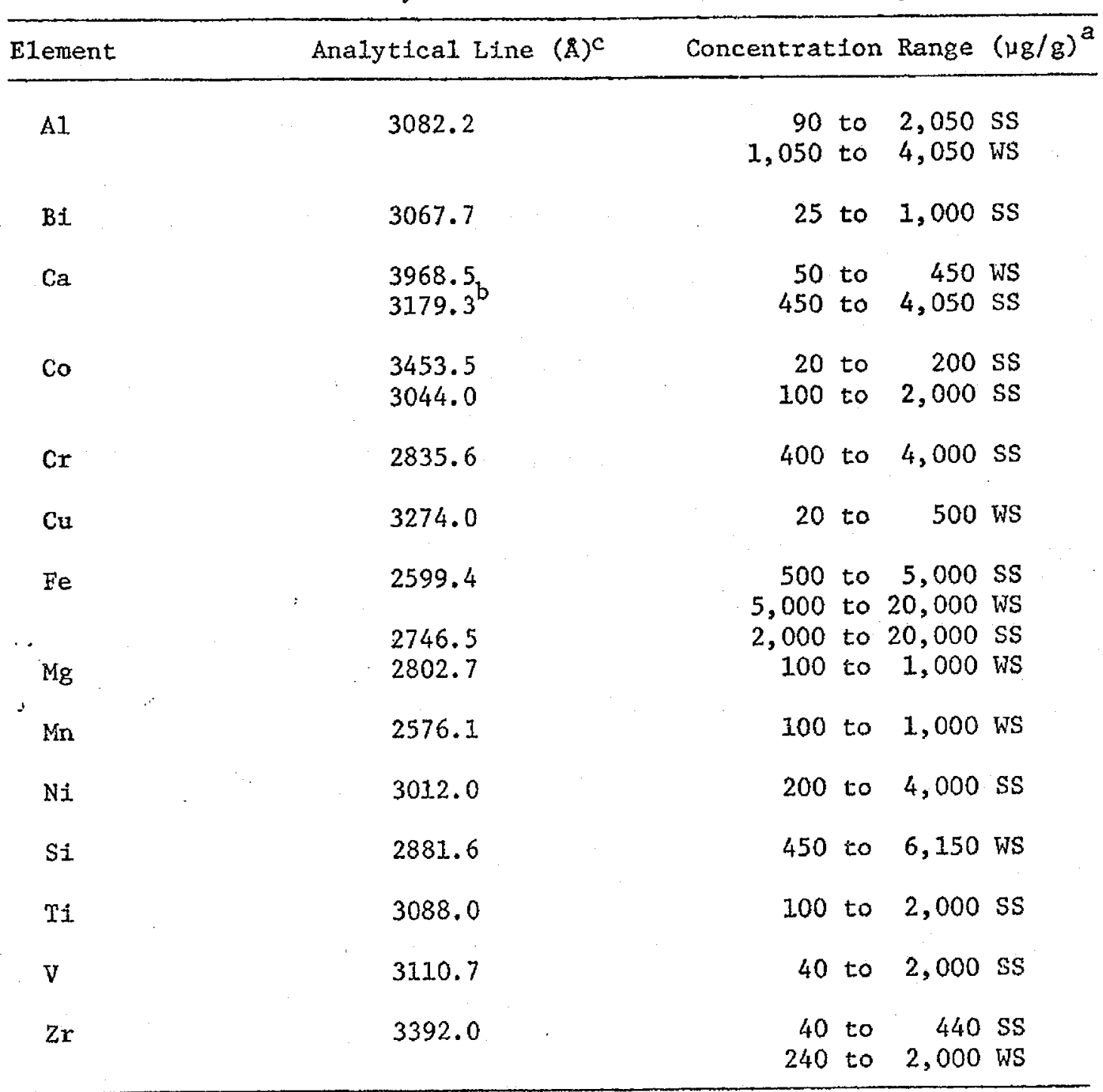

${ }^{a}$ SS means strong (dark) step of the spectrum; WS means weak (Iight) step.

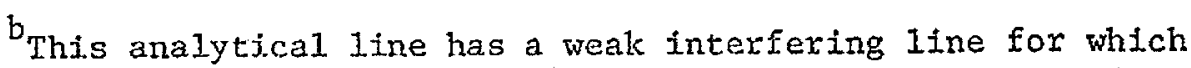
no correction is made because it is considered to contribute an equal intensity for samples as well as calibration standards.

$c_{\AA}=0.1 \mathrm{~nm}$. 
12. GENERAL METALLIC IMPURTTIES BY A DIRECT READER METHOD

12.1 Application. This method is applicable to the determination of general metallic impurities in samples of boron carbide powder and pellets. From 20 to $5000 \mu \mathrm{g}$ of impurities per gram of sample can be determined.

12.2 Sumary. Impurity elements are determined by a direct readIng emission spectrometer using a mixture of germanium oxide and graphite as a buffer. Concentrations of impurity elements are printed out directly in micrograms per gram after computer calculation of the data supplied from the spectrometer.

\subsection{Interferences. No interferences are expected.}

\subsection{Apparatus.}

1. Boron carbide mortar and pestle.

2. Computer, 1 PDP $8 / \mathrm{L}$, Digital Equipment Corp.

3. Counter electrode, National AGK SP, Type SP 9006 graphite rod (ASTM E 130, lype C-6) or equivalent.

4. Diamond (Plattner) mortar.

5. Direct reading optical emission spectrometer. ${ }^{2}$

6. High speed digital readout system. ${ }^{2}$

7. Mixer, Wig-I-Bug, with plastic vials and balls, Crescent Dental Manufacturing Co. ox equivalent.

8. Mixex mill.

9. Power supply. ${ }^{2}$

10. Sample electrode, National AGK SP, Type SP 9036 or equivalent.

11. Teletypewriter, ${ }^{3}$ Teletype Corp., ASR 35.

${ }^{2}$ A PDP $8 / L$, Digital Equipment Corp., computer has been used successfully.

${ }^{2}$ Baird-Atomic equipment has been found satisfactory.

${ }^{3}$ The Teletype Corp., ASR 35, has been found satisfactory. 


\subsection{Reagents and Standards.}

1. Spectroscopic buffer.

Combine $2 \mathrm{~g}$ of germanium dioxide (99.99\% purity) and $6 \mathrm{~g}$ of graphite powder (SP-2 Grade, National Carbon Co.) in a plastic vial containing a plastic ball. Mix for 10 min on the mixer mill.

2. Calibration standards.

Standards shall be as specified by RDT F 2-8. Each standard is a blend of metal impurities in a matrix of boron carbide, germanium dioxide, and graphite. The metal impurities are those specified for nuclear-grade boron carbide and several others that have also been found in boron carbide.

12.6 Calivration,* The standards are analyzed by following 12.7.2. Calibrate as follows.

12.6.1 Calibration Check. Analyze at least one standard with each set of samples. If the results of the calibration check do not agree with previous calibrations, investigate and resolve the problem before completing the analysis of samples.

12.6.2 Standardization. Standardize the instrument each day that samples are analyzed. Set the sample identification switch on the digital readout system to $1 B$.

12.6.3 Initial Calibration. Analyze each standard in the scaler count mode and plot counts versus concentration for each impurity element. Feed points from the curves into the computer to determine coefficients for each curve. The calibration data are stored in the computer.

\subsection{Analysis.}

12.7.1 Sample Preparation. Steps 1 through 5 are used to reduce pellets to powder. For powder samples, begin their preparation at Step 6 .

1. Crush a pellet in diamond (Plattner) mortar using a few, light hammex blows.

Grinding action must be avoided to prevent iron contamination of the sample.

$*$ This method is based upon the Baird-Atomic, Model HB-2, direct reading emission spectrometer. 
2. Remove the finer material.

3. Repeat Steps 1 and 2 until several hundred milligrams of the finer material is obtained.

4. Reduce the particle size of finer crushed material in the boron carbide mortar by using a rocking motion of the pestle.

5. Grind a $100 \mathrm{mg}$ portion from Step 4 to a fine powder in the boron carbide mortar.

6. Combine $20 \mathrm{mg}$ of powdered sample with $180 \mathrm{mg}$ of the spectrom scopic buffer in a plastic vial containing a plastic ball.

7. Mix for $45 \mathrm{~s}$ on the Wig-L-Bug mixer.

\subsubsection{Sample Analysis. *}

1. Weigh duplicate $20 \mathrm{mg}$ portions of powdered sample into separate sample electrodes.

2. Make duplicate exposuxes of each sample using the conditions given in Table 7.

Table 7. Exposure Requirements

\begin{tabular}{ll}
\hline Reference voltage & Constant voltage \\
Elush & $5 \mathrm{~s}$ \\
Pre-arc & $0 \mathrm{~s}$ \\
Exposure & $40 \mathrm{~s}$ \\
Sanple identification & MB \\
Background subtract & Off \\
Program sequence & $\mathrm{A}$ \\
Matrix & 1 \\
Arc power & 6 \\
Current & $15 \mathrm{~A}$ \\
Source selector & DC \\
Spark power & Low \\
Ignition & Momentary \\
Analytical gap & $4 \mathrm{~mm}$ \\
\hline
\end{tabular}

*This method is based upon the Baird-Atomic, Mode1 $\mathrm{HB}-2$, dixect reading emission spectometer. 
12.8 Calculations. The computer nakes all the calculations. Report to two significant figures the values printed out on the teletypewiter in micrograms per gram.

12.9 Precision. The relative standard deviation is a factor of two $(-50 \%$ to $+100 \%)$. 


\section{GAS CONTENT}

13.1 Application. This method is applicable to the determination of the gas content of samples of boron carbide pellets. Depending upon the blank, the lower Iimit ranges between 0.01 and $0.03 \mathrm{ml} / \mathrm{g}$ standard temperature and pressure (STP) with a $1 \mathrm{~g}$ sample. The upper IImit is dependent upon the capacity of the gas measuring section.

13.2 Summary. The sample is heated by induction in a tungsten crucible at $1000^{\circ} \mathrm{C}$. The evolved gas is pumped into the gas measuring section where the pressure and temperature are measured at a known volume. From these data, the milliliters per gram of gas at STP is calculated. The apparatus is designed so that a sample of the gas can be taken for an analysis of composition.

13.3 Interferences. With the exception of water, which may partially react with the tungsten crucible to produce hydrogen, interferences are not expected. The gases normally released obey the ideal gas laws sufficiently to permit simple ratio conversion of pressure and temperature to standard conditions.

.. $\quad 13.4$ Apparatus.

1. Induction generator. 1

CAUTION: Care sha11 be taken to avoid contact with high frequency induction leads to prevent burns and electrical shocks.

2. Outgassing section, Fig. 7 and 8 .

CAUTION: Care shall be taken while operating stopcocks and handling the apparatus when the system is undex high vacuum.
a. Furnace tube, fused-silica, water cooled.
b. Pellet loading arm.
c. Mercury diffusion pump. ${ }^{2}$
d. Crucible ratsing and lowering device. See Fig. 8.
e. Thermocouple gauge.
f. Tungsten crucible with tantalum bail.

\footnotetext{
1The Lepel, 2.5 kW, generator has been found satisfactory for this method. 2 The NRC, G-2-M, mercury diffusion pump has been found satisfactory for the vacuun outgassing section.
} 


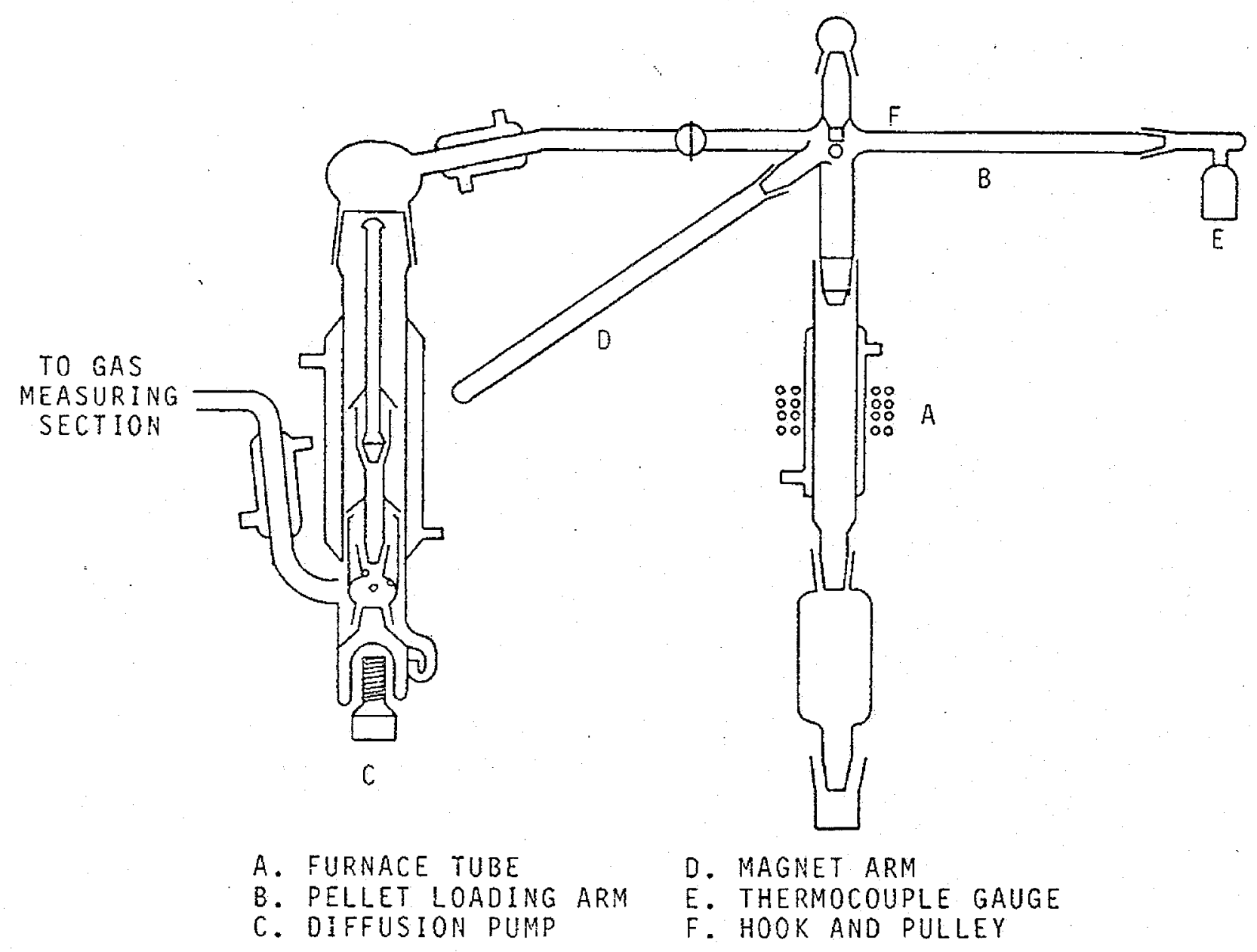

晃 召

B. PELLET LOADING ARM

THERMOCOUPLE GAUGE

F. HOOK AND PULLEY

Fig. 7. Outgassing Section. 

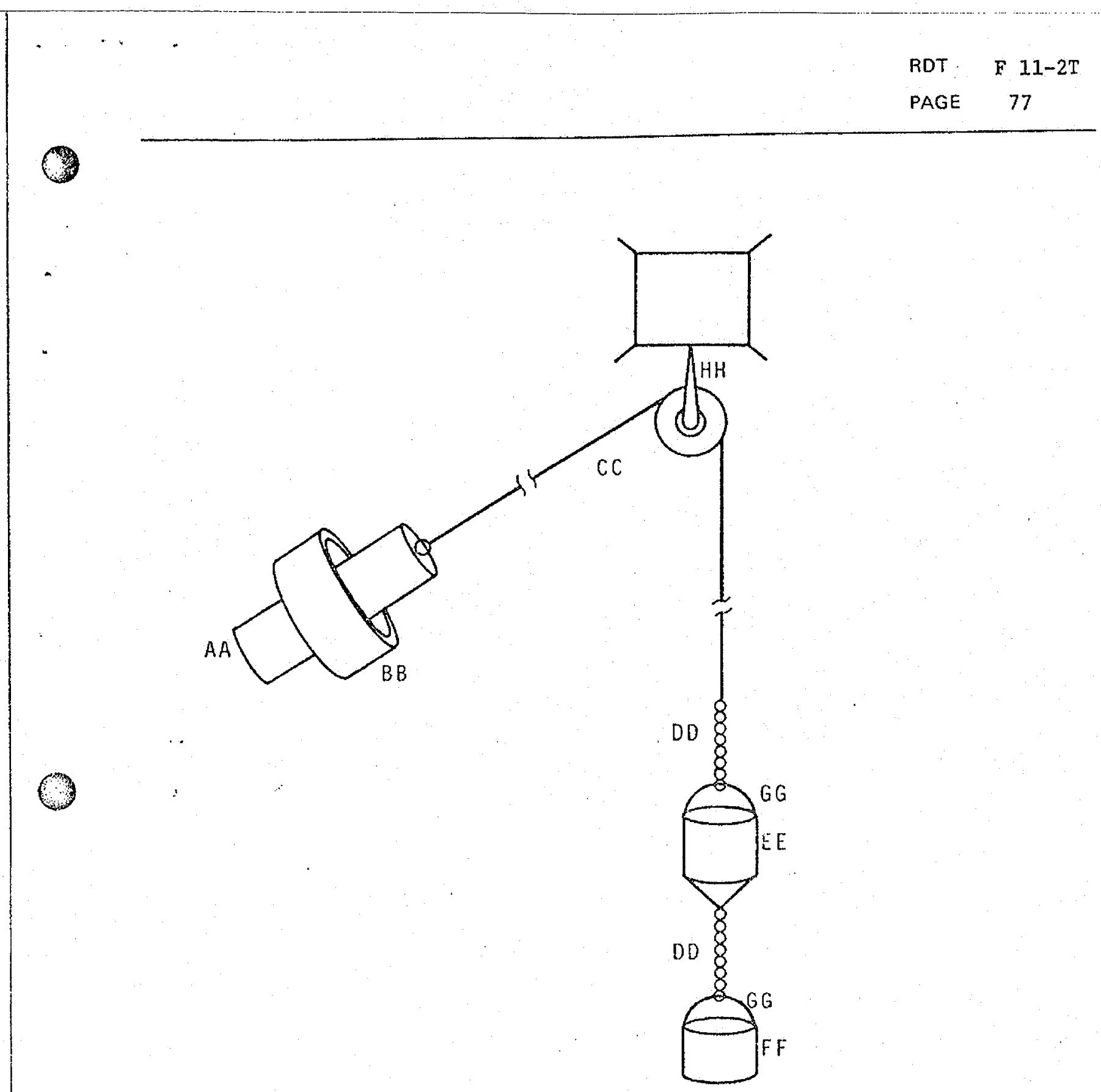

AA. MAGNET (LOCATED IN ARM "D", FIG. 7)

BB. RING MAGNET (AROUND "AA"-OUTSIDE ARM "O")

CC. GOLD CHAIN

DD. TANTALUM CHAIM

EE. TUNGSTEN CRUCIBLE

FF. NICKEL CYLINDER

GG. TANTALUM BAIL

HH. HOOK ANO PULLEY (SEE "F", FIG. 7)

Fig. 8. Crucible Raising and Lowexing Device. 
g. Copper induction coil, $5 \mathrm{~mm}$ tubing covered with glass tape.

3. Gas measuring section, Fig. 9.

The volume betreen the mercury diffusion pump " $L$ " and valves " $U$ " and " $V$ " is calibrated and equals $V_{1}$ in the calculation.

CAUTION: Care shall be taken while operating stopcocks and handling the apparatus when the system is under high vacuum. Mercury vapor is hazardous to health and any mercury spilled from the apparatus shall be removed immediately.

a. Vacuum pumps, mechanical.

b. Mercury diffusion pump, capable of pumping with a forepressure up to 5 torr $(670 \mathrm{~Pa}) .1$

c. Stopcocks and valves located as shown in Fig. 9.

The arrangement of stopcocks " $G$ ", " $H$ ", and " $J$ " permits the vacuum outgassing sections to be vented and pumped down independent of the gas measuring section.

d. Mcleod gauge. 2

e. Toepler pump.

A toepler punp is included so that gas samples can be taken for analysis by mass spectrometry if desired.

f. Thermocouple gauge.

g. Calibrated expansion bulb.

h. Oil diffusion pump.

1. Cold trap.

A cold trap is placed between the ofI diffusion pump and the system to prevent backstreaming of ofl vapor.

j. Residual gas analyzer (RGA). Optional.

${ }^{1}$ The NRC, G-3-M, mexcury diffusion pump has been found satisfactory for this purpose.

${ }^{2}$ The CVC, 3-range, type GM 100A, Mcleod gauge has been found satisfactory. 

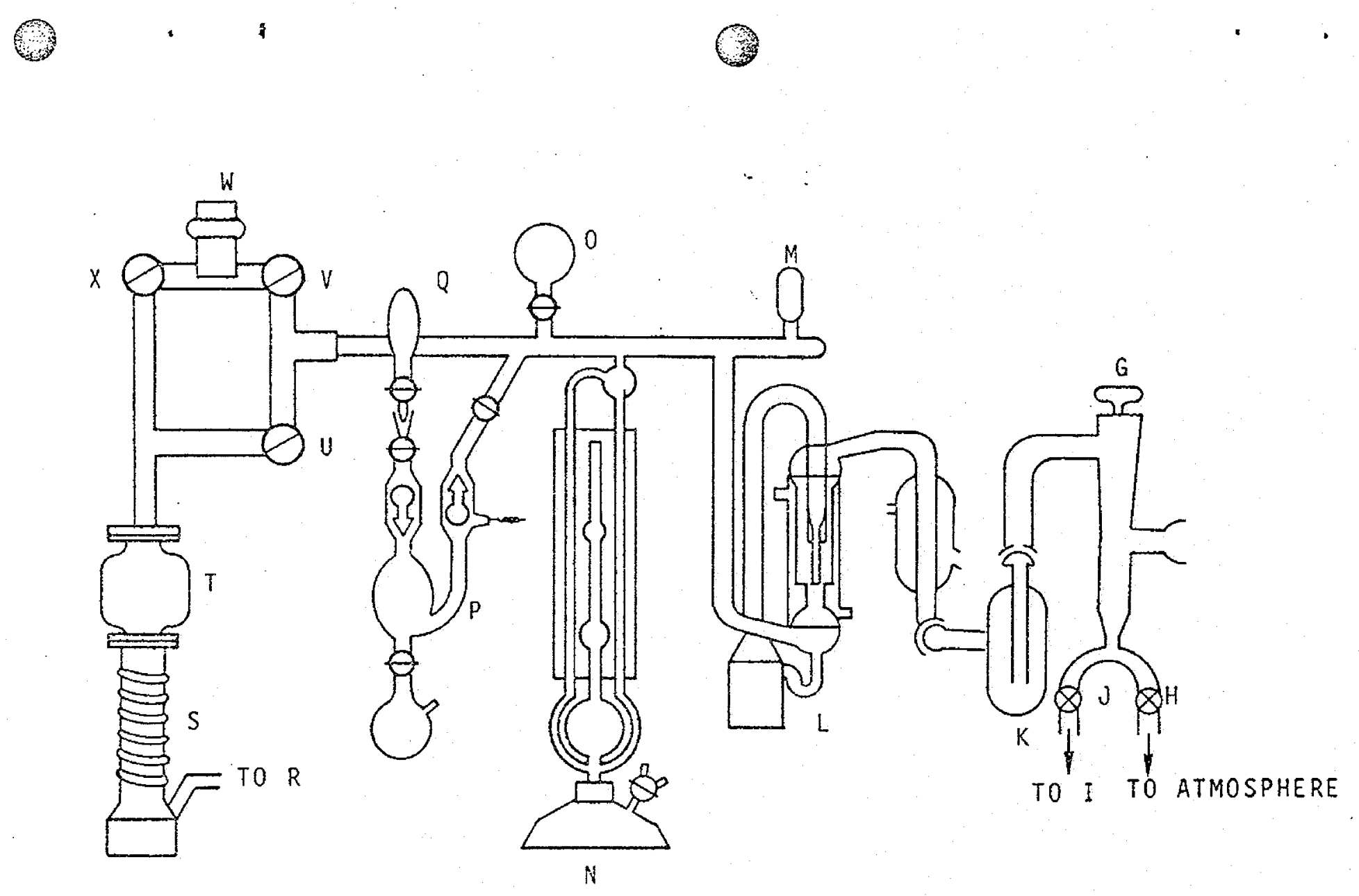
G. STOPCOCK
H. STOPCOCK
I. MECHANICAL VACUUM PUMP
P. TOEPLER PUMP
J. STOPCOCK
K. WATER TRAP
L. MERCURY DIFFUSION PUMP
M. THERMOCOUPLE GAUGE
N. MCLEOD GAUGE
0 . CALIBRATED EXPANSION BULB
0 . SAMPLING BULB
R. MECHANICAL VACUUM PUMP
S. OIL DIFFUSION PUMP
T. COLD TRAP
U. VALVE
V. VALVE
W. RGA SPECTROMETER TUBE
$X$. VALVE.

Fig. 9. Gas Measuring Section. 


\subsection{Reagents and Standards.}

1. Liquid nitrogen.

2. Magnesium perchlorate, anhydrous, for the water trap.

13.6 Calibration. No calibration standards are avallable to calibrate the method. Two techniques can be used to calibrate the gas measuring paxt of the apparatus. One is to measure the volume of each component and then add the volumes to get total volume. The second and more accurate technique is to introduce known volumes of gas Into the system and measure these in the same manner as samples.

\subsection{Analysis.}

1. Evacuate the gas measuring section (Fig. 9) including the expansion bulb "O", toepler pump " $P$ ", and sampling bulb "Q" by turning on the mechanical pump " $R$ ", opening valve " $U$ ", and opening the appropriate stopcocks to "O", "P", and "Q". Stopcock "G" is closed.

Once evacuated, the gas measuring section is normally kept under vacuum through continuous operation of the mechanfcal pumps.

Steps 1 through 13 provide for loading samples into the apparatus and for establishing a blank (Step 13) before samples are analyzed.

2. Turn on diffusion pumps " $L$ " and "S" when the pressure has decreased to less than 500 millitorr $(67 \mathrm{~Pa})$.

3. Fill cold trap " " with liquid nitrogen.

4. Weigh samples to the nearest $1 \mathrm{mg}$.

5. Open stopcock "H" (FIg. 9).

The outgassing section (Fig, 7) must be at atmospheric pressure.

6. Load pellet samples into arm " $\mathrm{B}$ " (Fig. 7) and seal the end cap on " $B$ " with black wax.*

7. Allow the black wax to cool and close stopcock "II".

\footnotetext{
*Hard wax sealing compound, high vacuum, Apiezon $W$ or equivalent.
} 
8. Evacuate the outgassing section through stopcock "J" with mechanical pump " $I$ " (Fig. 9).

9. Turn on diffusion pump "C" (Fig. 7) when the pressure is less than 500 millitorx $(67 \mathrm{~Pa})$.

10. Close stopcock " $J$ " and the stopcocks to the expansion bulb " 0 ", toepler pump "P", and sampling bulb "Q"; open stopcock "G" (Fig. 9).

The outgassing section is now opened to the gas measuring section.

11. Position the crucible in furnace tube "A" (Fig. 7) within the area enclosed by the induction coil.

12. Turn the induction generator on when the pressure in the system is less than 1 millitorr $(0.13 \mathrm{~Pa})$.

13. Heat the crucible to $1000^{\circ} \mathrm{C}$ and continue heating until an outgassing leak rate of $\leq 1$ millitorr $(0.13 \mathrm{~Pa}) / \mathrm{min}$ is reached with valve "U" closed.

This outgassing leak rate is the blank. A blank of $\leq 1$ millitorr $(0.13 \mathrm{~Pa}) / \mathrm{min}$ is essential for samples having gas contents of $\leq 0.05 \mathrm{ml} / \mathrm{g}$. Higher blanks are satisfactory for samples with higher gas contents. The acceptability of a blank is a mattex of judgement.

The system is now ready for the sample analysis.

14. Open valve "U".

15. Turn off the induction generator and allow the crucible to cool for at least $5 \mathrm{~min}$.

16. Raise the crucible to the funnel mouth at the top of the furnace tube (Fig, 7).

17. Push a sample from arm "B" into the crucible.

Samples are pushed along arm " $\mathrm{B}$ " by an aluminum nail with an iron head, which is manipulated from the outside with a magnet.

18. Move the crucible into the area enclosed by the induction coll and close valve " $\mathrm{Ut}$.

19. Turn on the juduction generator and heat the crucible to $1000^{\circ} \mathrm{C}$. 
20. Take pressure readings on the McLeod gauge " $\mathrm{N}$ " every 5 min until the readings are constant or the rate of increase equals the blank rate.

21. Record the pressure $\left(\mathrm{P}_{\mathrm{T}}\right)$ and turn off the generator. The time required to obtain $\mathrm{P}_{\mathrm{T}}$ is usually less than $30 \mathrm{~min}$.

22. Record the temperature $(\mathrm{P})$ from a thermometer placed adjacent to the gas measuring section.

23. Optiona1. Determine composition of the gas with a residual gas analyzer or sample the gas for mass spectrometric analysis.

If the RGA is to be used, open valves " $V$ " and " $\mathrm{X}$ " and make the analysis. If a gas sample is to be taken instead, use the toepler pump "P" and sarapling bulb "Q". See Fig. 9.

24. Open valve "U" to evacuate the system.

25. Dump the spent sample to the bottom of "A" after the crucible has cooled for at least 5 min.

To dump the sample, the crucible is inverted as follows: hold the cylinder "FF" (Fig. 8), which hangs below the crucible, stationary against the wall of the bottom section of the furnace tube " $A$ " and lower the crucible past the cylinder. The cylinder is held against the finterior wall with a magnet held against the outside wall.

26. Repeat Steps 16 through 25 for subsequent pellet samples.

13.8 Calculations. Calculate the gas content using Equation 23.

$$
\mathrm{m} 1 / \mathrm{g}(\mathrm{STP})=\frac{\mathrm{P}_{1} \mathrm{~V}_{1} \mathrm{~T}_{2}}{\mathrm{~T}_{1} \mathrm{P}_{2} \mathrm{~W}}
$$

where

$$
\begin{aligned}
& P_{1}=P_{T}-P_{B} \\
& P_{T}=\text { pressure from sample (Step } 21 \text { of } 13.7 \text { ) } \\
& \left.P_{B}=\text { pressure of blank (Step } 13 \text { of } 13.7\right) \\
& \left.V_{1}=\text { system volume (see } 13.4, \text { Item } 3\right) \\
& \left.T_{1}={ }_{S}\left({ }^{\circ} \mathrm{C}\right)+273 \text { (Step } 22 \text { of } 13.7\right)
\end{aligned}
$$




\section{WATER}

14.1 Application. This method is applicable to the determination of water in samples of boron carbide pellets. The range of the method is from five to several thousand micrograms of water.

14.2 Sumnary. Water is removed from the sample by heating at $400^{\circ} \mathrm{C}$. A carrier gas sweeps the water into an electrolytic cell containing phosphorus pentoxide to absorb the water. A potential applied across the cell causes the absorbed water to be electrolyzed. The total current is integrated and displayed digitally as micrograms of water.

14.3 Interferences. Hydrogen will give a high bias (see Step 2 of 14.7) as will ammonia, alcohols, and amines. Other organic compounds can coat the inside of the ce11, rendering it inactive. Samples shall be stored in a manner to prevent adsorption of atmospheric moisture.

\subsection{Apparatus.}

1. Analytical balance capable of weighing to $0.01 \mathrm{mg}$.

2. Gas dryer.

3. Gas flowmeter capable of measuxing a flow rate up to $150 \mathrm{~m} 1 / \mathrm{min}$.

4. Platinum boat, 10 by 30 by $5 \mathrm{~mm}$.

5. Water analyzer. 1

14.5 Reagents and Standards.

1. Magnesium perchlorate, anhydrous, for gas dryer,

2. Nitrogen, prepurified grade or equivalent. ${ }^{2}$

3. Sodium tartrate dihydrate crystals weighing from one to several milligrams.

\footnotetext{
${ }^{1}$ The Consolidated Electrodynamics Corp. water analyzex, Model 26-321 AMA, has been found satisfactory for this method.

${ }^{2}$ See Section 2.3 .
} 
This compound contains $15.6 \%$ water by wefght and is used as a contro1 standard.

14.6 Calibration. The analyzer is precalibrated electronically by the manufacturer; however, recalibration is necessary at least twice each year. Follow the manufacturer's recommended procedure for calibration. The control standard, which is sodium tartrate dihydrate, sha11 be analyzed at least once in each $8-\mathrm{h}$ shift in which samples are analyzed. Analyze the control standard as follows: ${ }^{1}$

1. Weigh accurately, using either a semimicro or micro balance, from 1 to $2 \mathrm{mg}$ of sodium tartrate dihydrate.

Use only very clear crystals to avoid low results that occur when using cloudy crystals.

2. Analyze the weighed sodium tartrate dihydrate using 14.7 with the following exception: use $125 \pm 5^{\circ} \mathrm{C}$ instead of the stated temperature at Steps $2,4,9$, and 15 .

Do not heat above $150^{\circ} \mathrm{C}$ because sodium tartrate dihydrate decomposition gives high results.

3. Calculate the percent water using 14.8.2. The contro1 limits are 14.8 to $16.4 \%$. If the result is outside, investigate and correct the problem before analyzing samples.

14.7 Analysis. ${ }^{2}$ The recommended location to make analyses is at the point where pellets are loaded into control rods. Since the water analyzer requires 1 ittle space, this approach is feasible, and t.t would avoid changes in the water content that can occur when pellets are removed from the fabrication line and sent to the laboratory for analysis.

1. Adjust the nitrogen flow rate to $100 \mathrm{ml} / \mathrm{min}$ at $5 \mathrm{psig}$ (35 $\mathrm{kPa})$.

The flow rate adjustment is not critjcal. Because the cell current is integrated as a function of time, the total water present is independent of the carrier gas flow rate. However, a flow rate less than $150 \mathrm{ml} / \mathrm{min}$ is recommended.

\footnotetext{
$I_{A}$ method of calibration using an infection of measured amounts of hydrogen that is converted to water has been, used. See LA-4622 (Appendix A.21).

${ }^{2}$ Note that the analyzer used must be capable of heating the sample at $400^{\circ} \mathrm{C}$ until all water is released and measured.
} 
2. Set the temperature contro11er at $400^{\circ} \mathrm{C}$.

This temperature was chosen because $400^{\circ} \mathrm{C}$ is considered to be high enough to release all water from the sample and yet low enough to minimize the reaction of hydrogen to form water if the sample contains absorbed hydrogen.

3. Place an empty platinum boat in the oven.

Platinum is preferred over nickel for boats because nickel may have an oxide-film coating that is a source of oxygen to react with hydrogen.

4. Start the timer and heat at $400^{\circ} \mathrm{C}$ until the count rate of the integrator decreases to a constant rate over a 10-min period.

The system must be dried sufficiently at this step to permit setting the zero of the analyzer at Step 5 . The count rate that indicates sufficient drying is determined by experience.

5. Set the zero of the instrument at a count rate of $0.6 \mu \mathrm{g} / \mathrm{min}$.

Consult the manufacturer's operation manual for instructions to set the zero.

6. Turn off the timer and set the integrator to zero.

7. Remove the boat when the oven reaches room temperature.

8. Replace the boat in the oven after about $10 \mathrm{~s}$ and turn on the timer.

The time interval between removal and replacement of the boat should be held constant for both the blank and the sample runs.

9. Heat at $400^{\circ} \mathrm{C}$ until the count rate of the integrator decreases to a constant rate of $0.6 \mathrm{\mu g} / \mathrm{min}$.

10. Record the reading $\left(\mathrm{R}_{b}\right)$ on the integrator and the time $\left(\mathrm{T}_{b}\right)$ required to complete 5 tep 9.

This reading is the blank $\left(R_{b}\right)$. If the analyzer is not used in a controlled environment, the blank wi11 vary from day-today, particularly if the humidity varies. Therefore, with samples containing less than $30 \mathrm{~kg}$ of vater, it is recomnended that a blank be run between each sample analysis.

11. Turn off the timer and reset the integrator to zero. 
12. Remove the boat when the oven reaches room temperature.

The time interval between removal and replacement of the boat should be held constant for both the blank and the sample runs.

13. Add a sample weighed to the nearest $1 \mathrm{mg}\left(\mathrm{W}_{S}\right)$ to the boat.

Whole pellets are taken for analysis.

For the control standard (sodium tartrate dihydrate), welgh to the nearest $0.01 \mathrm{mg}(14.6$, Step 1$)$.

14. Replace the boat in the oven.

15. Heat at $400^{\circ} \mathrm{C}$ until the count rate of the integrator decreases to a constant rate of $0.6 \mu \mathrm{g} / \mathrm{min}$.

16. Record the reading $\left(R_{s}\right)$ on the integrator and the time $\left(T_{s}\right)$ required to complete Step 15.

The reading and time are $R_{c}$ and $T_{c}$ respectively when a control standard is analyzed.

17. Stop the timer and reset the integrator to zero.

18. Repeat steps 12 through 18 for subsequent sample analyses.

14.8 Calculations. Calculate the micrograns of water per gram of sample and the weight percent of water in the control standard using the appropriate equation below.

14.8.1 Sample. Calculate the concentration of water in the sample using Equation 24.

$$
\text { Water }_{s}=\frac{R_{S}-(B)\left(T_{S}\right)}{W_{s}}
$$

where

$$
\begin{aligned}
\text { Watex }_{s} & =\text { micrograms of water per gram of sample } \\
R_{s} & =\text { micrograms of water from sample measurement } \\
B & =R_{b} / T_{b}, \text { see step } 10 \text { of } 14.7 \\
T_{s} & =\text { time required for sample measurement, minutes } \\
W_{s} & =\text { sample weight, grams. }
\end{aligned}
$$


14.8.2 Control Standard. Calculate the concentration of water in the control standard using Equation 25.

$$
\text { Water } c=\frac{R_{c}-(B)\left(T_{c}\right)}{\left(W_{c}\right)\left(10^{4}\right)}
$$

where

$$
\begin{aligned}
\text { Water } & =\text { weight percent water in control standard } \\
R_{c} & =\text { micrograms of water from control standard measurement } \\
B & =R_{b} / T_{b}, \text { see step } 10 \text { of } 14.7 \\
T_{c} & =\text { time required for control standard measurement, minutes } \\
W_{c} & =\text { control standard weight, grams. }
\end{aligned}
$$

14.9 Precision. Relative standard deviation ranges from about $20 \%$ for $30 \mathrm{\mu g}$ of water to about $5 \%$ above $100 \mathrm{\mu g}$ of water. 


PDT


15. NITROGEN BY SPECTROPHOTOMETRY

15.1 Application. This method is applicable to the determination of nitrogen in samples of boron carbide powder and pellets. From 25 to $1500 \mu \mathrm{g}$ of nitrogen can be determined in a $0.1 \mathrm{~g}$ sample.

15.2 Sumnary. The sample is mixed with lithium hydroxide and fused to decompose the boron carbide. The nitride nitrogen is converted to ammonia, which is trapped in a hydrosic Ioric acid solution. The ammonium ion is measured spectrophotometrically using the colored complex produced by Nessler reagent.

15.3 Interferences. Interference from material normally found in nuclear-grade boron carbide is not expected. Ammonia from extraneous sources will give a high bias.

\subsection{Apparatus.}

1. Analytical balance capable of weighing to $0.1 \mathrm{mg}$.

2. Combustion tube with combustion tube cap and delivery tube (see Fig. 10.)

3. Crucible, nickel. (See Fig. 11.)

4. Diamond (Plattner) mortar.

5. Flowmeter, Manostat No. 1044B or equivalent.

6. Induction furnace, Leco No, 523-100 or equivalent.

7. Porous lids, Leco No. 528-42 or equivalent.

8. Sieve, 100 mesh (U.S. Standard Sieve Sexies), 3 in. (76 mm) diameter, brass or stainless steel.

9. Spectrophotometer, UV to visible range, using $10 \mathrm{~mm}$ matched cells.

10. Tin capsules, Leco No. 501-059 or equivalent.

11. Variable transformer, Leco No. 521-084 or equivalent, used with the induction furnace.

12. V-Blender, $15 \mathrm{ml}$ volume. 


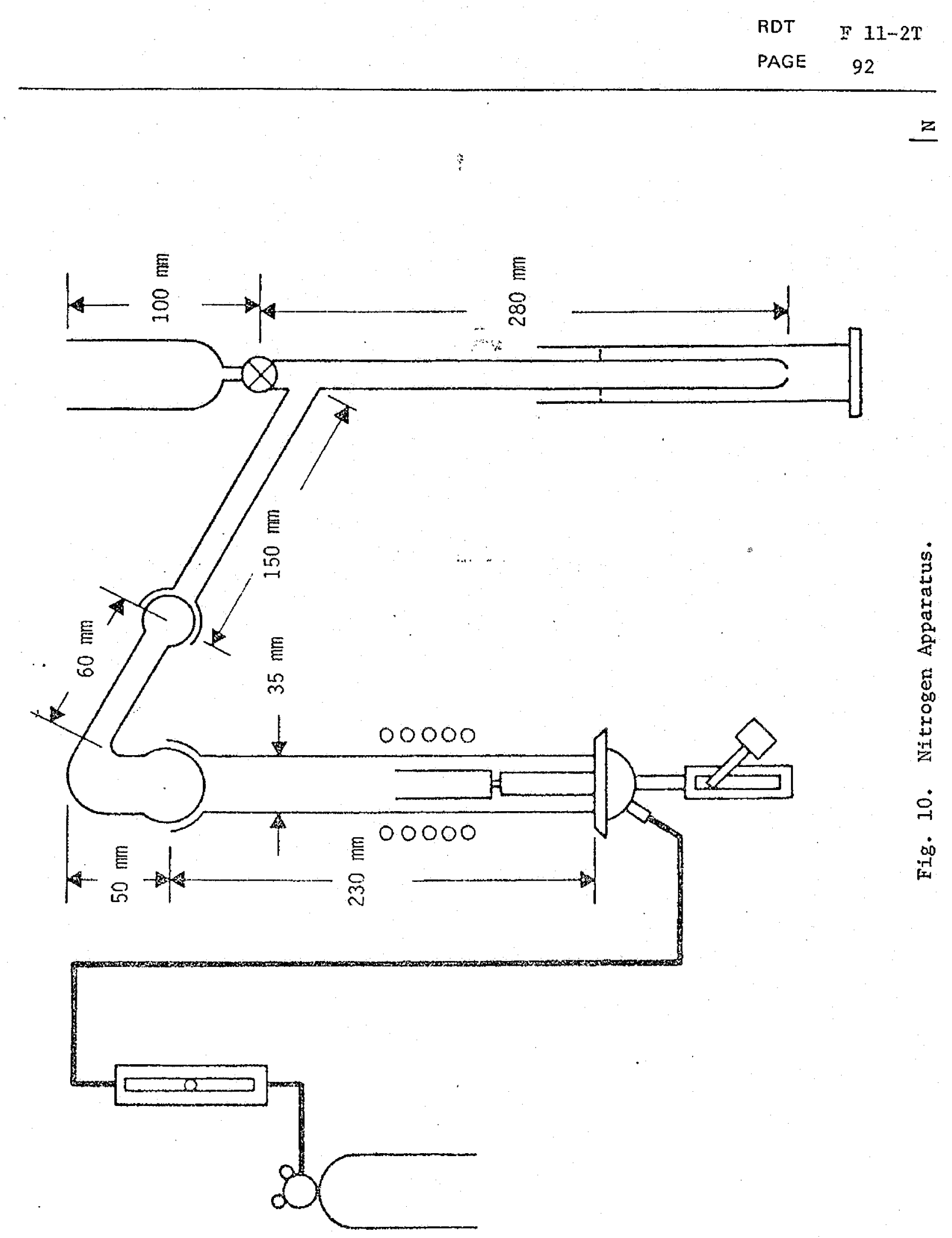




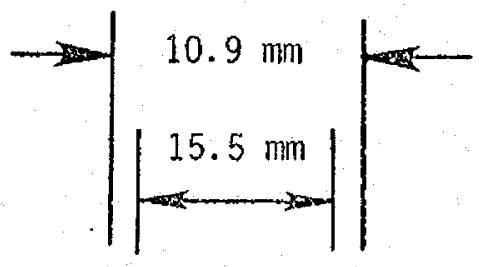

13

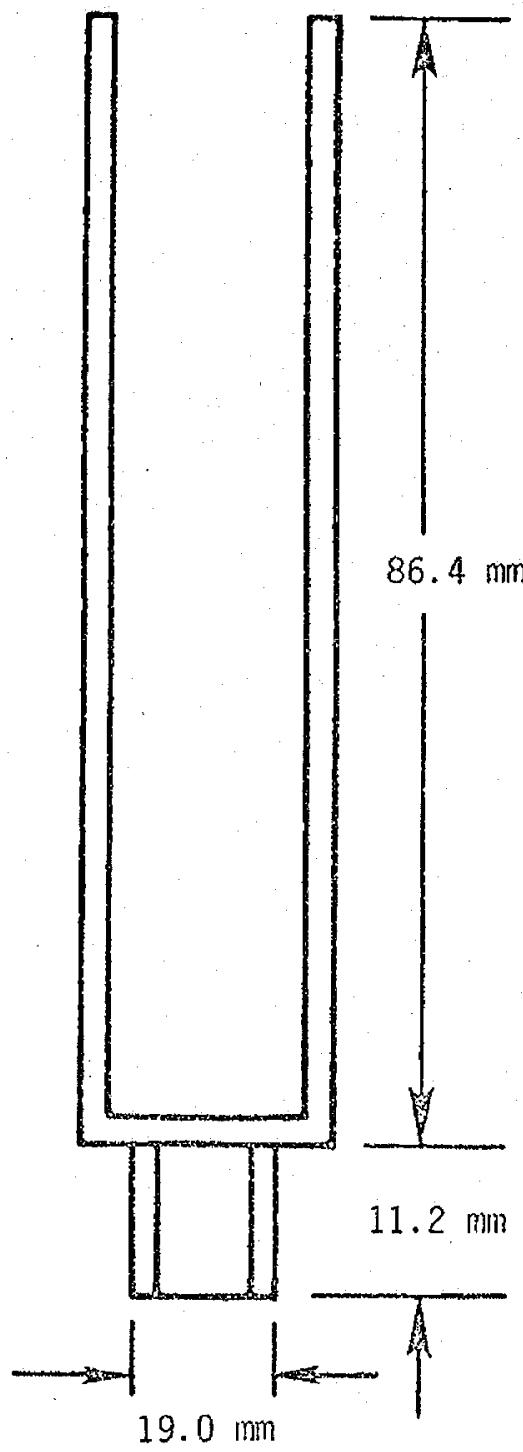


15.1 Reagents and Standards.

1. Argon, prepurified grade or equivalent.*

2. Deionized water, ammonia-free.

3. Hydrochloric acid, 12M (37\%).

4. Lithium hydroxide, anhydrois. .....

Lithium hydroxide is dried at $120^{\circ} \mathrm{C}$ and stored in a desiccator.

5. Nessler reagent.

Dissolve $100 \mathrm{~g}$ of mercuric iodide and $70 \mathrm{~g}$ of potassium iodide in a small quantity of ammonia-free water. Add this solution slowly, with stirring, to a cool solution of $160 \mathrm{~g}$ of sodium hydroxide in $150 \mathrm{ml}$ of ammonia-free water. Dilute to I liter with ammonia-free water and store in a dark glass bottle.

6. Calibration standard, boron nitride powder.

The boron nitride may be blended with boron carbide powder having a low residual nitrogen content.

15.6 Calibration. Using at least five calibration points ranging up to 1500 hg of nitrogen, calibrate the method as follows:

1. Analyze weighed portions of the calibration standard and a reagent blank by following 15.7. Subtract the absorbance reading of the reagent blank from the absorbance reading of each standard.

A secondary calibration of the spectrophotometer can be made using a standard solution of an ammonium salt.

2. Prepare a calibration curve by plotting absorbance versus micrograms of nitrogen. The curve will range up to $150 \mathrm{\mu g}$ of nitrogen.

3. A new calibration curve is not required each time nitxogen analyses are made, although at least one point on the calibration curve is checked during each 8-h. shift in which

* See Section 2.3. 
analyses are made. When checking a point, the method is in calibration if the result obtained falls within $\pm 10 \%$ of the curve. A.new calibration curve is made when the checks made on the curve begin to show a drift away from the curve, the results of two consecutive analyses of standards are outside of the $\pm 10 \% 1$ init, or a new batch of Nessler reagent is used.

15.7 Analysis. The laboratory atmosphere must be free of ammonia and other nitrogen-containing fumes to avofdrnitrogen contamination of glassware, reagents, and samples. A reagent blank is determined at least once in each $8-h$ shift in which analyses are made.

1. Determine a reagent blank by starting at Step 2 but omitting Step 5 (an empty tin capsule is added at Step 6).

If the absorbance of the reagent blank is greater than 0.08 , repeat the blank determination until a reproducible absorbance at or below 0.08 is obtained. If a satisfactory blank is not obtained, a probable cause is contamination. Replace reagents or eliminate the source of extrancous nitrogen, as necessary, to reduce the blank to an acceptable level.

2. Turn on the power to the induction furnace and allow 15 min for warm-up.

3. Clamp the combustion tube cap and delivery tube in place and adjust the argon flow rate to $0.41 / \mathrm{min}$.

The combustion tube, cap, and delivery tube must be clean.

4. Add $5 \mathrm{~g}$ of Iithium hydroxide to the cructble.

5. Add about $0.1 \mathrm{~g}$ of powdered sample to a tared tin capsule and weigh capsule and sample to the nearest $0.1 \mathrm{mg}$.

Prepare the powdered sample as given in 4.7 .3 .

6. Add the capsule containing sample to the crucible containing the 1ithium hydroxide.

7. Remove the cap from the combustion tube; place the crucible on the furnace pedestal in the induction furnace; place the porous cover on the crucible.

8. Clamp the cap and delivery tube back in place and let the argon sweep through the apparatus for at least $5 \mathrm{~min}$.

The ball and socket joints should be greased with silicone 1ubricant. 
9. Add $30 \mathrm{~m} 1$ of ammonia-free water and 2 drops of $12 \mathrm{M}$ hydrochloric acid to a $50 \mathrm{ml}$ cylinder.

The cylinder must be positioned in the apparatus such that the delivery tube is immersed below the surface of the acid solution.

10. Turn the grid tap setting to medium; turn on the high voltage.

11. Increase the plate current in sequential steps to increase the furnance temperature as given in Table 8.

Table 8. Plate Current Settings

\begin{tabular}{ccc}
\hline Variable Transformer Setting & Plate Current, mA & Minutes \\
\hline & & 160 \\
Med. 40 & 230 & 2 \\
Med. 96 & 250 & 2 \\
High 96 & 10 \\
\hline
\end{tabular}

The actual temperature obtatned at $250 \mathrm{~mA}$ should be measured and if the temperature is not about $750^{\circ} \mathrm{C}$, the upper current setting should be adjusted to obtain approximately $750^{\circ} \mathrm{C}$. The decomposition temperature should be between 700 and $750^{\circ} \mathrm{C}$.

The heating sequence depends upon sample characteristics Including particle size and solubility in lithium hydroxide. Some samples froth and blow out of the crucible. For these samples, loss can be eliminated by heating for longer periods at lower temperatures.

12. Turn off the furnance.

13. Remove the cap from the combustion tube and the cover from the crucible.

14. Remove the crucible and pour the molten lithiun hydroxide into a metal waste can; thoroughtly clean and dry the crucible.

15. Rinse the inside and outside of the delivery tube into the $50 \mathrm{ml}$ cylinder with amonia-fxee water.

16. Transfer the solution to a $50 \mathrm{ml}$ volumetric flask; rinse the cylinder several times with ammonia-free water, adding the rinses to the volumetric flask.

17. Dilute the solution to volume with ammonia-free water and mix thoroughly. 
18. Transfer $5.0 \mathrm{ml}$. of the solution to a second $50 \mathrm{ml}$ volumetric flask.

19. Add $1.0 \mathrm{ml}$ of the Nessler reagent to the flask.

20. Dilute the solution to volume with amonia-free water and mix thoroughly.

21. Let stand for 10 min and meastive the absorbance of the solution at $410 \mathrm{~nm}$ in a $10 \mathrm{~mm}$ cell using distilled water as the reference solution.

If the sample absorbance indicates an amount of nitrogen less than $25 \mu \mathrm{g}$ or greater than $150 \mu \mathrm{g}$ in the $5 \mathrm{mI}$ aliquot from Step 18, repeat Steps $18,19,20$, and 21, using an appropriate volume of sample solution at Step 18.

15.8 Calculations. Calculats the micrograms of nitrogen per gram of sample as follows:

1. Subtract the absorbance reading of the reagent blank from the absorbance reading of each sample.

2. Obtain the micrograms of nitrogen for each sample from the calibratjon curve.

3. Calculate the concentration of nitrogen in the sample using Equation 26.

$$
\text { Nitrogen }=\frac{\mathrm{s}}{\mathrm{W}}
$$

where

$$
\begin{aligned}
\text { Nitrogen } & =\text { micrograms of nitrogen per gram of sample } \\
s & =\text { micrograms of nitrogen from sample measurement } \\
W & =\text { sample weight, grams. }
\end{aligned}
$$

15.9 Precision. The pooled relative standard deviation obtained by four laboratories for a single boron caxbide powdex batch was $6 \%$ at a nitride nitrogen level of $0.3 \%$ (by weight). 


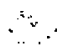

BLANK PAGE 


\section{NITROGEN BY GAS CHROMATOGRAPHY}

16.1 Application. This nethod is applicable to the determination of nitrogen in samples of boron carbide powder and pellets. From 5 to $2500 \mu \mathrm{g}$ of nitrogen can be determined in a $0.1 \mathrm{~g}$ sample.

16.2 Sumnary. Powdered or small pieces of boron carbide are fused with nickel at about $2600^{\circ} \mathrm{C}$ in a graphite crucible. The nitrogen is released in its elemental form and it is measured by gas chromatography, which is based upon the differences in thermal conductivity of gases.

16.3 Interferences. Nitrogen from the atmosphere will enter the nitrogen analyzer if the sample is improperly loaded and this will cause a high result. Amonia, nitrates, and other nitrogen-containing compounds from extraneous sources will cause ligh results.

\subsection{Apparatus.}

1. Analytical balance capable of weighing to $0.1 \mathrm{mg}$.

2. Njckel basket, LECO No. 763-065 or equivalent.

3. Nitrogen analyzer.*

- 4. Tin capsule, I.ECO No. 501-059 or equivalent.

\subsection{Reagents and Standards.}

1. Anhydrone, LECO No. 501-171 or equivaIent.

2. Ascarite, 20 to $30 \mathrm{mesh}$, LECO No. 183-001 or equivalent.

3. Ascarite, 8-20 mesh, LECO No. 501-166 or equivalent.

4. Helium, ultra high purity, $99.995 \%$

5. Molecular sieve, $5 \mathrm{~A}, 20$ to 30 mesh.

6. Phosphorus pentoxide, LECO No, 765-278 or equivalent.

7. Rare earth oxide, LECO No, 501-170 ox equivalent.

8. Sulfur absorber, JECO No. $763-770$ or equivalent.

9. Calibration standards.

*The LECO U014 sp Nitrogen Determinator, Model No. 875-034, has been found satisfactory. 
Standards are prepared by mixing weighed amounts of boron nitride with bor on carbide powder having less than $0.05 \%$ nitrogen. In addition, the following steel standards are used for instrument calibration and test: NBS SRM 346 and $133 \mathrm{a}$ and LECO NO. 501-551, No. 501-552, and No. 501-553.

\subsection{Calibration.*}

1. Prepare the instrunent for analysis. The analyzer must conform to the following:

a. Be sure that the water supply to the coolant circulator has not been shut off or disconnected; then turn on the coolant circulator power switch.

b. "DVM ON" switches must be on.

c. "AUX TURN ON" indicator must be on.

d. The "FunCTION SWITCH" switch must be in the "OPERATE" position.

e. The two circuit breakers must be on.

f. The "STD-BY" indicator must be green.

g. The "HELIUM BLANKET" indicator must be off.

h. The coolant circulator power switch must be on.

i. The furnace must be empty and closed.

j. The "OVEN INDICATOR" must be cycling on and off and the oven temperature must be approximately $45^{\circ} \mathrm{C}$.

k. The helium regulator must be set for $40 \mathrm{psig}(275 \mathrm{kPa})$.

1. Both the "MEASURE FIOW" and the "REFERENCE FLOW" rotometers must indicate the approximate flows.

2. Turn the "FUNCTION SELECT" switch to the "DVM ZERO" and adjust the digital voltmeter (DVM) zeros if necessary.

*This method is based upon the LECO U014 sp Nitrogen Determinator Model No. 875-934. If another analyzer is used, follow the manufacturer's recommended procedure. 
3. Depress the "STD-BY" switch. Turn the "FUNCTION SELECT" switch to the "OPERATE" position for approximately $30 \mathrm{~s}$. Then turn the "FUNCTION SELECT" switch to the "INTEG CHECK", position and note the time; at the end of 1 min note the reading.

The DVM reading must not change more than \pm 0.001 during this period. If it does, refer to the electronic checkout in the instruction manual.

4. Depress the "SID-BY" switch. Turn the "FUNCTION SELECT" switch to the operate position.

The "STD-BY" indicator should turn green.

5. Open the furnace.

The "PURGE" indicator will turn white and the "STD-BY" indicator will go off.

Inspect the interior of the upper electrode cavity with a minror and flashlight to make sure that no deposits of graphite or other material are present. Also inspect the lower electrode. The bottom interior of the lower cup must be free from all metal or graphite particles, A small jet of air is ideal for cleaning the bottom interior of the lower electrode. Use the proper brush and precautions should be taken to prevent scratching of the electrodes or the o-rings.

Do not insert your fingers or any metallic object near the safety thermostat mounted on the outside of the upper electrode. When power is applied, there is $115 \mathrm{~V}$ on these connections.

6. Place a LECO crucjble on the lower electrode assembly using tweezers.

To avoid contamination, do not touch the crucibles with your fingers.

7. Close the furnace.

The "PURGE" indicator will turn green.

The furnace must be kept closed at all times except when cleaning the interior of the furnace or loading the cructole. The furnace must be cleared before each analysis.

8. Depress the "OUT-GAS" swi.tch. 
The "OUT-GAS" indicator will be white during the outgas period and the "PURGE" indicator will be off.

The crucible current value is indicated on the "FURNACE POWER" meter and during outgas, the value should be between 850 and $950 \mathrm{~A}$. If not, refer to the procedure described in the installation section of the instruction manual.

9. Compensate for a normal nitrogen blank as follows:

a. Repeat Steps 4 through 3 .

b. The "OUT-GAS" Indicator must be green.

c. The empty outgassed crucible must be left in the furnace. Do not put a sample into the crucible at this time.

d. Depress the "ANALYZE" switch.

The "ANALYZE" Indicator will turn white and the "OUT-GAS" indicator will go off.

When the "ANALYZE indicator goes off, the "NITROGEN" indicator will turn green. The "BLANK" control must be adjusted before the "NII'ROGEN" indicator turns green.

e. Adjust the "NITROGEN BLANK" control while the "NITROGEN" indicator is white to maintain all zeros on the "NITROGEN" DVM.

f. Repeat this procedure with a minimum of three crucibles to establish the proper "NITROGEN BLANK" setting.

10. Calibrate the "SLOPE" adjustment as follows:

a. Repeat Steps 4 through 6 .

b. Place a steel calibration standard of a weight between 0.300 and $0.699 \mathrm{~g}$ into the loading head.

Be sure to handle the sample only with tweezers.

The sample form must be such that it can be contained in a cylinder $6 \mathrm{~mm}$ in diameter and $8 \mathrm{~nm}$ high.

c. Turn the "SAMPLE WETGHT COMPENSATOR" switches to the value of the weighed sample. 
d. Close the furnace.

e. Depress the "OUT-GAS" switch.

f. Push the "SAMPLE DROP" button after the "OUT-GAS" Indicator turns green.

This lets the standard fall into the crucible.

g. Depress the "ANALYZE" switch.

The "OUT-GAS" indicator will go off and the "ANALYZE" indicator will turn white.

The crucible current value should be slightly lower than duxing outgas (approximately $30 \mathrm{~A}$ lower). If the current is considerably lower, the sample may not have fallen into the crucible - check the loading head cavity.

$h$. Note the reading when the "NITROGEN" indicator turns green, but do not adjust the slope control.

i. Repeat this procedure for a minimun of three standards to determine the average reading.

$j$. If the average reading is within the tolerance stated for the sample, no adjustment is needed. If the average reading is above or below the tolerance for the nitrogen standard value, adjust the slope control to bring the average value within the tolerance.

The slope adjustment can be made only when the "NITROGEN" indicator is white.

Never attempt to open or close the furnace during "OUT-CAS" or "ANALYZE" (indicators white) because the furnace electrodes of the a-c switch will be severely damaged.

11. Prepare a calibration curve by repeating Step 10, except use the boron carbide calibration standards instead of a steel standard at Step 10b. The boron carbide is placed into a tin capsule; the ends are pinched closed and the capsule is placed into a nickel basket, which is then placed into the loading head.

a. Analyze at least five portions of the standards to provide calibration points ranging between 10 and $1000 \mathrm{\mu g}$ of nitrogen.

The amounts of standard taken should be bétween 0.06 and $0.15 \mathrm{~g}$. 
b. Deternine a tin capsule and nickel basket blank using one empty capsule and basket at Step $10 \mathrm{~b}$; make at least three determinations and calculate an average blank.

c. Subtract the average blank from each standard readout and prepare a calibration curve by plotting the net readouts versus micrograms of nitrogen using linear graph paper.

A new calibration curve is not required each time nitrogen analyses are made, although at least one point on the curve must be checked during each 8-h shift in which analyses are made. The method is in calibration if the result falls within $\pm 5 \%$ of the curve. A new curve is required if two consecutive results fall outside $\pm 5 \%$.

\subsection{Analysis.}

1. Repeat Steps 4 through 6 of 16,6 .

2. Place a sample weighing between 0.06 and $0.15 \mathrm{~g}$ into the loading head:

The sample form must be such that it can be contained in a cylinder $6 \mathrm{~mm}$ in diameter and $8 \mathrm{~mm}$ high.

Weigh powdered samples in tin capsules; pinch the ends in and place in a nickel basket. Weighed pieces are placed directly into a nickel basket.

Contamination of samples with nitrogen from air can be eliminated by weighing in an argon atmosphere.

For samples containing less than $0.5 \%$ nitrogen, the 0 to $1000 \mu \mathrm{g}$ range should be used; for more than $0.5 \%$, the 0 to $10,000 \mu \mathrm{g} / \mathrm{g}$ range should be used.

3. Turn the "SAMPLE WETGHT COMPENSATOR" switch to 0.5 .

4. Close the furnace.

5. Depress the "OU'I-GAS" switch.

6. Push the "SAMPLE DROP" button after the "OUT-GAS" switch turns green.

This lets the sample fall into the cructble.

7. Depress the "ANALYYZE" switch. 
The "OUT-GAS" Indicator wi11 go off and the "ANALYZE" indicator wil1 turn white.

The fusion current should be at least $850 \mathrm{~A}$, which requires the highest transformer top setting possible without causing crucible breakdown.

If current drops to zero during analysis, discard the result and repeat the analysis.

As soon as the "NITROGEN" Indicator turns green, the impulse furnace may be opened and the used crucible removed. The furnace can be cleaned and next sample introduced into the loading head.

When the "NITROGEN" indicator turns green, the micrograms of nitrogen wil1 be displayed on the DVM.

16.8 Calculations. Calculate the concentration of nitrogen in the sample using Equation 27.

$$
\text { Nitrogen }=\frac{(A-B)}{2 W}
$$

where

Nitrogen = nitrogen content in micrograms per gram

$A=$ micrograms of nitrogen determined from the DVM readout and the calibration curve

$B=$ average tin capsule blank, micrograms of nitrogen

$\mathrm{W}=$ sample weight, grams.

16.9 Precision. At the $0.7 \%$ level of nitrogen, a relative standard deviation of $1.7 \%$ was obtained from 9 replicate measurements. 
17. OXYGEN

17.1 Application. This method is applicable to the determination of oxygen in samples of boron carbide powder and pellets. Between 30 and $100 \mu \mathrm{g}$ oxygen are required per measurement.

17.2 Summary. Powdered boron carbide is fused with iron chips at $2600^{\circ} \mathrm{C}$ in a graphite crucible. Oxygen is evolved as carbon monoxide, which is converted to carbon dioxide when passed over heated rare earth oxide. The carbon dioxide is measured by thermal conductivity gas chromatography. A water analysis is required to correct the oxygen results for any water sorbed by the powdered material.

17.3 Interferences. Boron carbide (especially in powdered form) readily sorbs water, which contributes to the oxygen concentration. By analyzing samples for water, a correction for the water contribution can be made to minimize this bias. Sorbed gases such as carbon dioxide, carbon monoxide, oxygen, and sulfur dioxide also contribute to the total oxygen content; however, the extent of their contribution is unknown. Since all analyses are performed on powdered materials, which may readily sorb these gases, a high bias may result. To eliminate the possibility of this bias, analyses should be performed in an inert atmosphere enclosure, if possible.

\subsection{Apparatus.}

1. Crucibles, graphite, LECO No. $760-414$ or equivalent.

2. Oxygen analyzer. ${ }^{l}$

\subsection{Reagents and Standards.}

1. Anhydrone, LECO No. 501-171 or equivalent.

2. Ascarite, LECD No. 501-166 or equivalent.

3. Copper shot, 6 to 8 mesh, LECO No. 501-641 or equivalent.

4. Iron chips, EECO No. 501-077 or equivalent.

5. Nitrogen, prepurified grade or equivalent. ${ }^{2}$

6. Rare earth oxide, LECO No. 501-170 or equivalent.

IThe LECO RO-16 Oxygen Determinator, Model 738-400, has been found satisfactory.

${ }^{2}$ See Section 2.3 . 
7. Calibration standards.

The following standards are used for a primary and a secondary calibration:

a. Steel pins with certified oxygen contents, LECO No. 501-644, 645 , and 646 or equivalent.

b. Carbon dioxide, Coleman grade or equivalent.*

8. Control standards.

The following materials are used for control purposes:

a. Boric acid, NBS SRM 951 or boron trioxide, ultra high purity $(>99.99 \%)$.

b. Boron carbide, -100 mesh containing $<0.05 \%$ oxygen.

\subsection{Calibration.}

1. Primary and secondary calibrations are made during each $8-h$ shift in which oxygen analyses are made as follows:

a. Primary calibration. Analyze each of the calibration standards using the manufacturer's recommended procedure.

All standards must give values within their stated ranges before proceeding to step $b$.

b. Secondary calibration. Crosscheck primary calibration by using the built-in, calibrated, carbon dioxide, gas-dosing system following manufacturer's instructions.

The values obtained for the carbon dioxide injections should fall within the recommended levels before proceeding with the analysis of control standards and samples.

2. A control procedure is used during each 8 -h shift in which oxygen analyses are made. The procedure is as follows:

a. Determine the average total oxygen content of the boron carbide reagent by analyzing three portions of the reagent by following steps 2 through 8 of 17.7 .

The results should agree within $0.02 \%$ absolute.

*See Section 2.3 . 
Because the water content of the boron carbide reagent can vary, the total water content must be determined whenever oxygen analyses are made on the reagent.

b. Weigh 500 to $100 \mu g$ of botic acid or boron trioxide to $\pm 10 \mu \mathrm{g}$ and add it to $0.1 \mathrm{~g}$ of the boron carbide reagent; analyze by following Steps 3 through 8 of 17.7 and calculate the percent recovery using 17.8.2.

Proceed with the analyses of samples only after recoveries between 90 and $110 \%$ have been demonstrated for three consecutive samples.

\subsection{Analysis.}

1. Determine a system blank by following Steps 3 through 10, om 1 tting the sample in step 4.

Blanks shall be determined initially until a reproducibility of $\pm 3 \mu \mathrm{g}$ of oxygen is obtained. Repeat the blank measurement after every five samples.

Powdered samples are loaded by opening the furnace to add the material to the crucible; therefore, higher and more variable blanks are expected than those observed when analyzing steel standards which are dropped into an outgassed crucible in a closed furnace.

2. Weigh from 0.1 to $0.15 \mathrm{~g}$ of sample in the powdered form to the nearest $0.1 \mathrm{mg}$.

For pellet samples, crush to a powder using 4.7.3.

Experience has show that the oxygen in boron carbide pellets. is seldom distributed homogeneously. Since entire pellets cannot be analyzed, samples are crushed and sieved to obtain a moxe uniform material with respect to oxygen. Mixing should be done in a V-blender.

3. Add 2 g of iron chips to a graphite crucible; load and outgas by following the instruction manual.

4. Remove the outgassed crucible and quantitatively transfer the sample from Step 2 to the crucible.

Handle the crucible only with clean forceps.

5. Position the crucible in the furnace and close.

6. Depress the reset switch. 
This allows the sample to be purged with nitrogen to remove any oxygen introduced while loading the sample.

7. Complete the analysis by depressing the "analyze" switch.

Once the analyze switch is depressed, the entire operation is automatic.

8. Record the micrograms of oxygen from the digital voltmeter (DVM) readout and proceed to calculations.

9. Immediately make a moisture analysis on the sample material using Method 14 and record the mficrograms of water per gram of sample.

17.8 Calculations. Calculate the percent of oxygen in the samples and the percent recovery from control standards using 17.8.1, 17.8 .2 , and 17.8 .3 .

17.8.1 Samples. Calculate the oxygen content of samples using Equations 28 and 29 .

$$
\begin{aligned}
& \text { T. O. }=\frac{(A-B)\left(10^{-4}\right)}{S_{0}} \\
& \text { N.0. }=\text { T.0. }-(H)(8 / 9)\left(S_{0}\right)\left(10^{-4}\right)
\end{aligned}
$$

where

T.0. = total oxygen, weight percent

$A=$ tota1 micrograms of oxygen displayed on DVM (Step 8, 17.7)

$B=$ average system blank in micrograms of oxygen (Step $1,17.7$ )

$S_{0}=$ sample weight, grams

N.O. = net oxygen, weight percent (total oxygen minus oxygen contributed from the water present in the sample)

$\mathrm{H}=$ micrograms of water per gram sample (Step 9, 17.7). Equation 30.

17.8.2 Control Standards. Calculate the percent recovery using

$$
R=\frac{(A-B)-\left[\left(B_{A \cdot R}\right)\left(S_{R}\right)\right]}{o_{c}} \times 100
$$


where

$R=$ percent recovery

$A=$ total micrograms of oxygen displayed on DVM (Step 8 of 17.7)

$B=$ average system blank in micrograms of oxygen (Step $I$ of 17:7)

$B A,=$ average boron carbide reagent blank in total micrograms of oxygen per gram of reagent.

$\mathrm{S}_{\mathrm{R}}=$ grams of boron carbide reagent used

$O_{c}=$ micrograms of oxygen from boric acid or boron trioxide added to boron carbide reagent.

17.9 Precision. The relative standard deviation for samples ranging from 0.1 to $0.7 \%$ oxygen is about $11 \%$. 
RDT F 11-2 I

PAGE 112

琩

$\bullet$

BLANK PAGE

- 


\section{APPENDIX A}

\section{BIBLIOGRAPIFY}

This reference 1ist is presented to identify sources of information as an aid to the analyst. These document; do not invoke mandatory requirements for the analytical methods.

A.1 K.I. Aitken, F. Hart, and P. Reynolds, J. Sci. Instrum., 32, 190 (1955). Section 6.

A. 2 M. C. Burt, "Apparatus for Measuring Gas Release of Ceramic Nuclear Fuel Materials at High Temperatures," Ana1. Chem., 41, 459, March (1969). Section 13.

A. 3 E. Cotlove, H. W. Trantham, and R. L. Bowman, "An Instrument and Method for Rapid, Accurate, and Sensitive Titration of Chloride in Blologic Samples," J. Lab. Clin. Med., 5I, 461 (1958). Section 10.

A. 4 M. S. Frank and J. W. Ross, Jr, "Electrode for Sensing Fluoride Ion Activity in Solution," Science, 154, 1553 (1966). Section 9.

A. 5 N. H. Furman, Ed. Scott's Standard Methods of Chemical Analysts, 6th Ed., vol. 1, p. 231, D. Van Nostrand Co., Inc., Princeton, N. J., March (1962). Section 4.

A.6 N. H. Furman, Ed, Scott's Standard Methods of Chemical Analysis, 6th Ed., vol. 1 , p. 228, D. Van Nostrand Co., Inc., Princeton, N. J., March (1962). Section 8.

A.7 M. W. Goheen, Direct Isotopic Analysis of Boron in Boron Carbide, HEDL-SA-395, June (1972). Section 6 .

A. 8 I. R. Green, J. E. Still, and R. C. Chirnside, "The Determination of Carbon in the Less Common Metals and in Highly Alloyed Stainless Steels," Analyst, 87, 530, July (1962). Section 4.

A.9 F. A. Keidel, "Determination of Water by Direct Amperometric Measurement," Anal. Chem., 31, 2043 (1959). Section 14.

A.10 S. Kitahara, H. Asahara, and T. Atoda, "Method of DeterminIng Free Carbon in Boron Carbide," Rikagaku Kenkyusho Hokoku, 34, 339 (1958). [Translated for Oak Ridge National Laboratory as ORNL-tr-1778.] Section 7. 
A.11 M. W. Lerner, The Analysis of Elemental Boron, New Brunswick Laboratory, it. S. Atomic Energy Commission, TID-25190, November $(1.970)$. Sections 5,6 and 8 .

A.12 G. A. Meerson and G. V. Samsonov, "Deternination of Free Carbon in Boron Carbide," Zavodikaya Lab, 16, 1423 (1950). Section 7.

A.13 R. H. Powell and O. Menis, "Separation of Fluoride from Inorganic Compounds by Pyrolysis," Ana1. Chem., 30, 1546 (1958). Sections 9 and 10 .

A. 14 G. A. Rechnitz, "Ion-Selective Electrodes," Chem. Eng. News, 45, 153, June 12 (1.967). Section 9.

A. 15 J. E. Rein and R. M. Abernathey, "Rapid Mass-Spectrometric Determination of Boron Isotoplc Distribution in Boron Carbide, Talanta, 19, 857 (1972). Section 6 .

A.16 John Roboz, Introduction to Mass Spectrometry, Instrumentation and Techniques, Interscience Publishers, New York, N. Y., 1968. Section 6 .

A.17 C. J. Rodden, Analysis of Essential Nuclear Reactor Materials, U. S. Atomic Energy Comnission, Washington, D. C., Government Frinting office (1964). Sections 5 and 8 .

A.18 E. J. Spitzer and J. R. S1tes, Isotopic Mass Spectrometry of the Elements, ORNL-3528, December (1963). Section 6 .

A.19 J. E. Warf, W. D. Cline, and R. D. Tevebaugh, "Pyrohydrolysis in the Determination of Fluoride and Other Halides," Anal. Chem., 26, 342 (1954). Sections 9 and 10.

A.20 F. A. White, Mass Spectrometry in Science and Technology, John Wiley and Sons, Inc., New York, N. Y. 1968. Section 6

A.21 James E. Rein et al, "Methods of Chemical Analysis for FBR Uranium - Plutonium Oxide Fuel and Source Materials", LA-4622, February 1971. 